\title{
A delphi study to identify teaching competencies of teacher education faculty in 2015
}

\author{
Sonhwa $\mathrm{Na}$ \\ West Virginia University
}

Follow this and additional works at: https://researchrepository.wvu.edu/etd

\section{Recommended Citation}

$\mathrm{Na}$, Sonhwa, "A delphi study to identify teaching competencies of teacher education faculty in 2015" (2006). Graduate Theses, Dissertations, and Problem Reports. 3448.

https://researchrepository.wvu.edu/etd/3448

This Dissertation is protected by copyright and/or related rights. It has been brought to you by the The Research Repository @ WVU with permission from the rights-holder(s). You are free to use this Dissertation in any way that is permitted by the copyright and related rights legislation that applies to your use. For other uses you must obtain permission from the rights-holder(s) directly, unless additional rights are indicated by a Creative Commons license in the record and/ or on the work itself. This Dissertation has been accepted for inclusion in WVU Graduate Theses, Dissertations, and Problem Reports collection by an authorized administrator of The Research Repository @ WVU.

For more information, please contact researchrepository@mail.wvu.edu. 


\title{
A DELPHI STUDY TO IDENTIFY TEACHING COMPETENCIES OF TEACHER EDUCATION FACULTY IN 2015
}

\author{
Sonhwa $\mathrm{Na}$ \\ Dissertation submitted to the \\ College of Human Resources and Education \\ at West Virginia University \\ in partial fulfillment of the requirements \\ for the degree of \\ Doctor of Education \\ in \\ Technology Education \\ John G. Wells, Ph.D., Chair \\ Virginia Polytechnic Institute \\ Stacy A. Gartin, Ph.D. \\ David L. McCrory, Ph.D. \\ Neal Shambaugh, Ph.D. \\ Floyd L. Stead, Ed.D. \\ Department of Advanced Educational Studies \\ Morgantown, West Virginia \\ 2006
}

Keywords: Teaching Competencies, Course Delivery Modes, Teacher Education, Delphi Copyright 2006 Sonhwa Na 


\title{
ABSTRACT \\ A DELPHI STUDY TO IDENTIFY TEACHING COMPETENCIES OF TEACHER EDUCATION FACULTY IN 2015
}

\author{
By Sonhwa Na
}

The purpose of this study was to reach consensus on future course delivery modes and recommended teaching competencies that would be required for teacher education faculty in future course delivery environments. A three-round, online modified Delphi study was used to answer the following research questions (RQs): (a) RQ1: What course delivery modes will teacher education faculty of traditional colleges and universities be using in 2015?, and (b) RQ2: What competencies will teacher education faculty of traditional colleges and universities need to teach using these delivery modes? Course delivery modes and general teaching competencies were determined as a result of consensus reached by a panel of 17 educational experts drawn from institutions within the National Council for Accreditation of Teacher Education (NCATE) and other educational organizations. The first round used an open-ended questionnaire format. The responses generated by the first round contributed to the development of the Round II instrument. In the second round, panelists were asked to rate the items identified in round one on a 7 point Likert-scale. The Round III questionnaire was designed using Round II results. Ratings by individual panel members were shown relative to the group response (median, mode, and IQR), followed by a request for the panelist to re-rate or confirm their original rating from Round II. Based on an analysis of data collected in Rounds I, II, and III, the following conclusions were drawn for each research question. Data collected to answer RQ1 found that teacher education faculty of traditional colleges and universities in 2015 will integrate more online technologies into their face-to-face classroom-based teaching environment. Blended course delivery modes integrating online components was strongly supported by the panel experts who participated in the study. Among the various future online approaches identified through this study, the asynchronous, or combination asynchronous and synchronous, mode will be preferred over the synchronous mode alone. Data analyzed to address RQ2 found that there will be a total of 77 general teaching competencies needed by higher education faculty in the coming decade. These competencies were logically grouped into the following five categories: planning and designing learning environment; teaching and learning; technology; assessment and evaluation; and cultural and ethical issues. 


\section{ACKNOWLEDGMENTS}

The successful completion of this dissertation would not have been possible without the support and cooperation of many people. I would like to sincerely thank each of those individuals for all of their encouragement throughout this journey.

First and foremost, I would like to express my deepest appreciation to my committee members, Dr. John G. Wells, Chair, Dr. Stacy A. Gartin, Dr. David L. McCrory, Dr. Neal Shambaugh, and Dr. Floyd L. Stead, for their professional insight and remote guidance throughout this process. I am truly grateful to have the most supportive committee that any student could have. I am particularly grateful to Dr. Wells for serving as my committee chair even after his departure from West Virginia University. He had more faith than I did in my ability to complete this study. I would also like to thank the individual panelists in this study for their time, expertise, and continued participation.

The support and compassion of my family throughout the doctoral program has been immeasurable. I want to express gratitude to my parents, Yun $\mathrm{Su} \mathrm{Na}$ and Ju Rae Yun who instilled in me the values of hard work, respect for knowledge and perseverance needed to accomplish my goal. I am indebted to my husband, Songnam Yi, who has continually offered his love, support, and guidance throughout my doctoral study. I would like to thank my children, Nayoung and Ghoon, who are always my inspiration. Lastly, I would like to thank other family members, friends and colleagues for their support and encouragement. Without them, I would have not been able to achieve this goal. 


\section{TABLE OF CONTENTS}

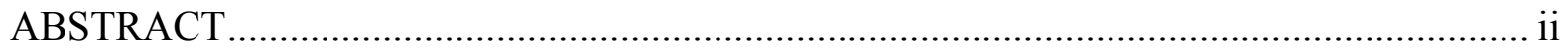

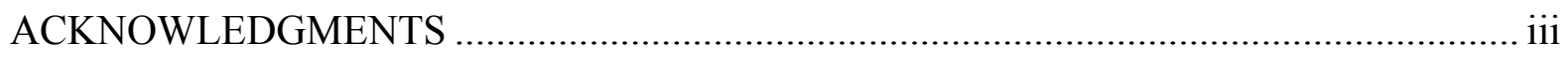

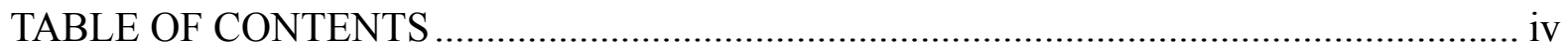

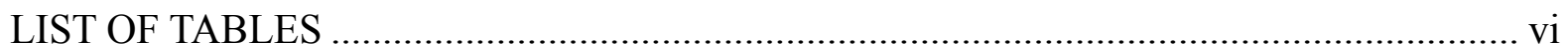

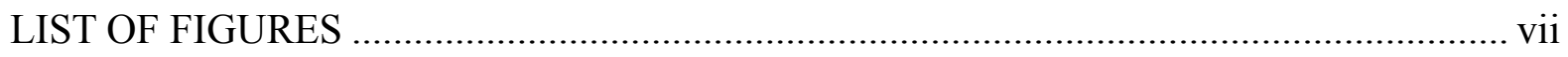

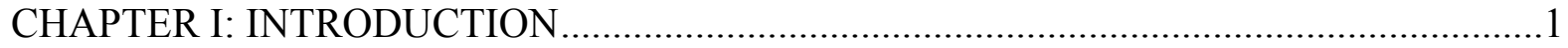

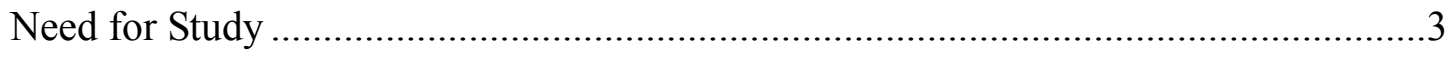

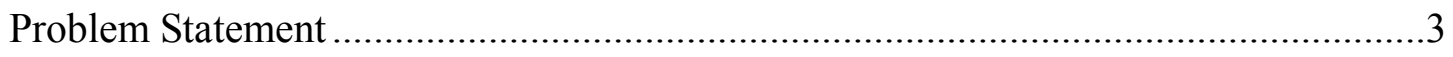

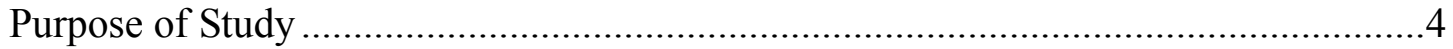

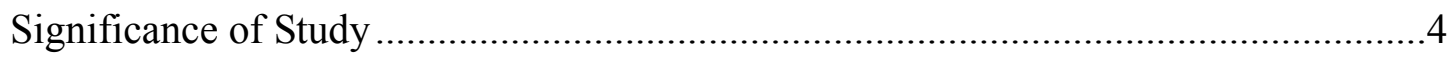

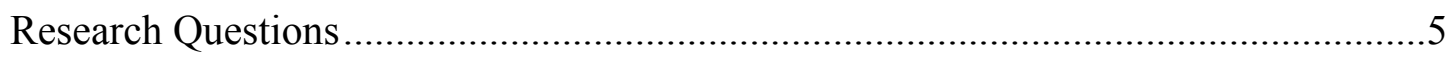

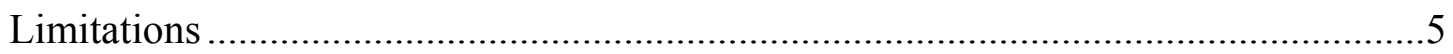

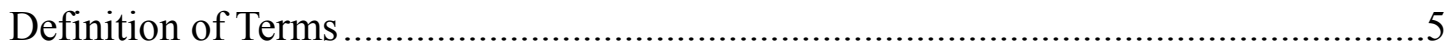

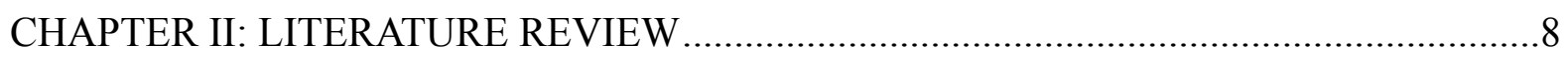

Emerging Trends in Higher Education ...............................................................

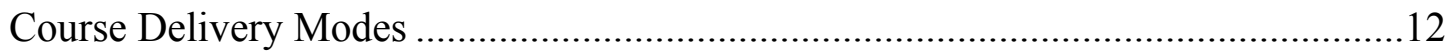

Faculty Roles in Higher Education ......................................................................

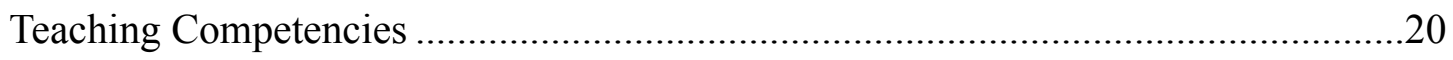

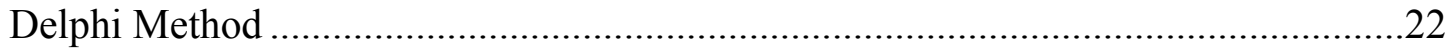

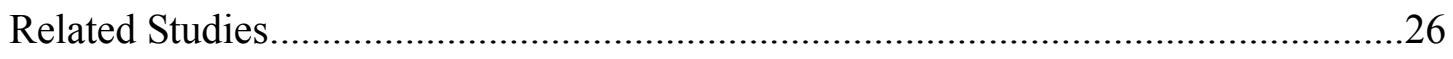

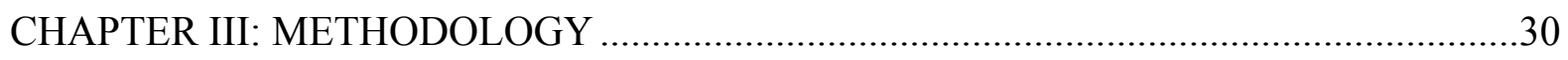

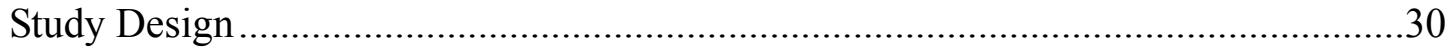

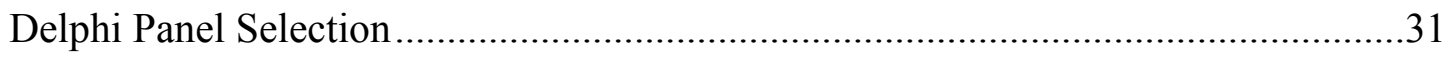

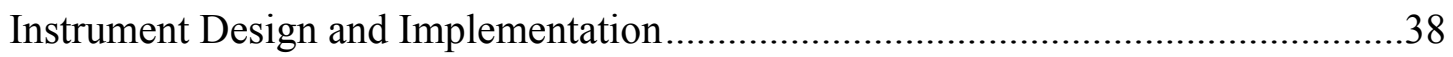

Method of Data Analysis ...........................................................................................43

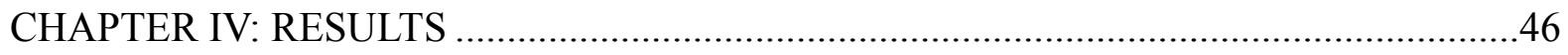

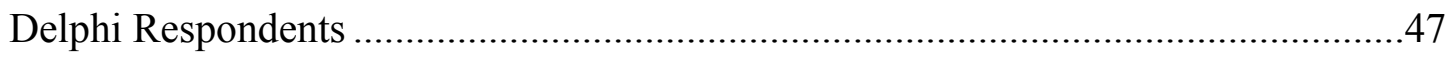

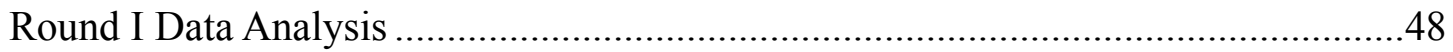

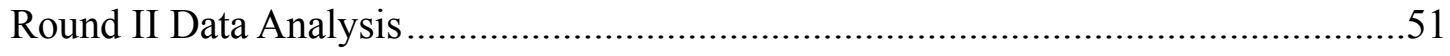




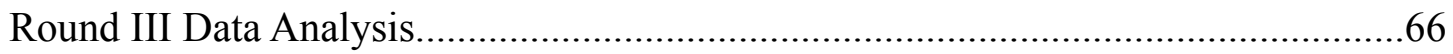

Shifting of Panel Responses from Round II to Round III............................................70

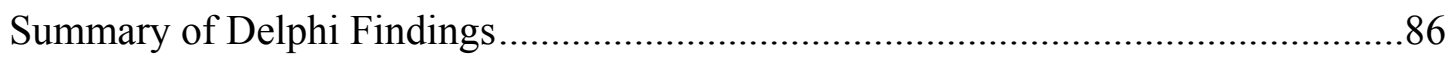

CHAPTER V: CONCLUSIONS, IMPLICATIONS, AND SUGGESTIONS …………..........97

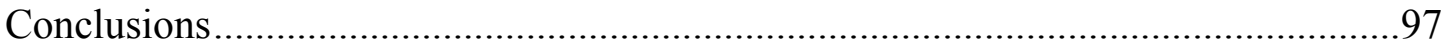

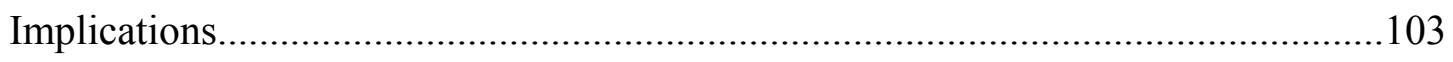

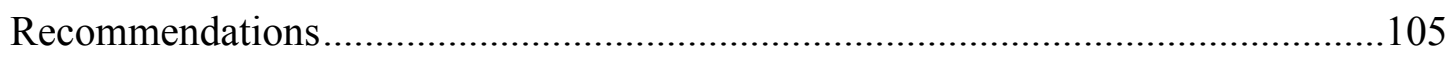

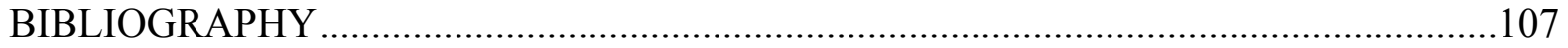

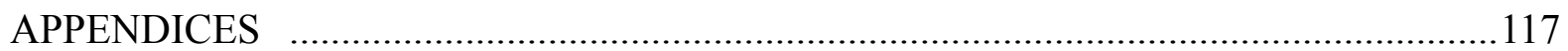

Appendix A: List of the Source Organizations ......................................................118

Appendix B: Delphi Round I Invitation Letter ........................................................120

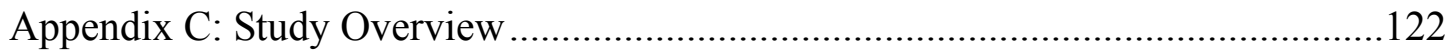

Appendix D: Study Participation Agreement.........................................................124

Appendix E: Round I Instructions and Questionnaire ……………….....................126

Appendix F: Round I Data Color Coding Scheme …………….............................131

Appendix G: Round II Invitation Letter and Questionnaire ......................................137

Appendix H: Round III Invitation Letter and Questionnaire.....................................151 


\section{LIST OF TABLES}

Table 1. Western Governors University Technology-enhanced Class Delivery Modes ...........16

Table 2. Roles and Role Specific Competencies That Were Considered Very Important .......28

Table 3. Number of Initial Participants by Organization ...........................................................36

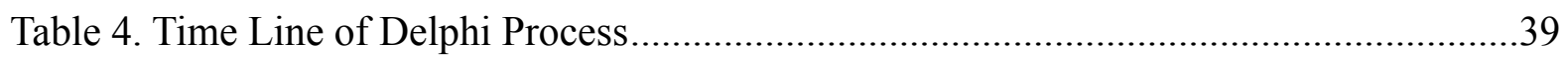

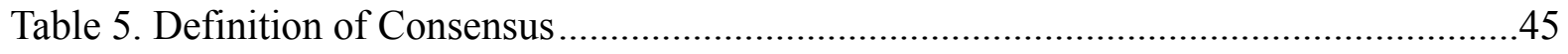

Table 6. Number of Delphi Respondents by Organizations for Each Round ..........................47

Table 7. Delivery Mode and Instructional Options Matrix Generated from Round I...............50

Table 8. Summary of Panel Ratings on Delivery Modes from Round II.................................53

Table 9. Delivery Modes Reached Consensus in Round II .................................................55

Table 10. Summary of Panel Member Comments on Delivery Mode from Round II..............57

Table 11. Summary of Panel Ratings on Competency Category 1 from Round II ...................60

Table 12. Summary of Panel Ratings on Competency Category 2 from Round II..................61

Table 13. Summary of Panel Ratings on Competency Category 3 from Round II..................63

Table 14. Summary of Panel Ratings on Competency Category 4 from Round II...................64

Table 15. Summary of Panel Ratings on Competency Category 5 from Round II..................64

Table 16. Summary of Panel Comments on Teaching Competencies from Round II ..............65

Table 17. Additional Delivery Modes Reaching Consensus after Round III............................67

Table 18. Additional Teaching Competencies Reaching Consensus after Round III ...............68

Table 19. Summary of Panel Member Comments from Round III...........................................69

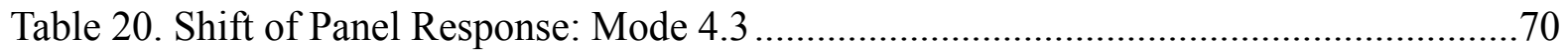

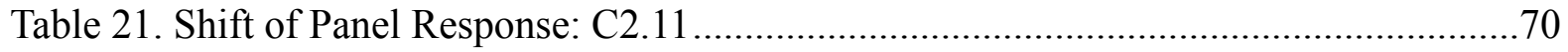

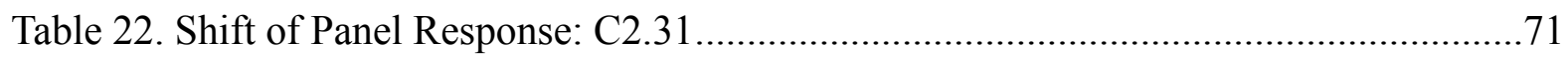

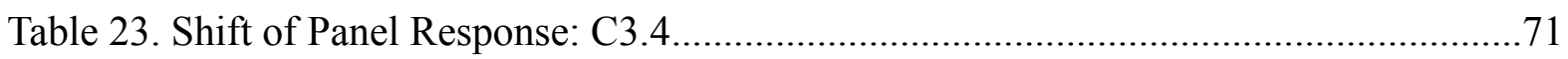

Table 24. Shift of Panel Response: C3.9......................................................................

Table 25. Summary of Final Delphi Findings on Delivery Modes ...........................................86

Table 26. Movement towards Consensus on Delivery Modes..................................................87

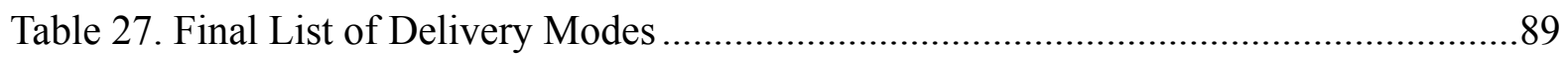

Table 28. Summary of Final Delphi Findings on Teaching Competencies .............................91

Table 29. Movement towards Consensus on Teaching Competencies .....................................91

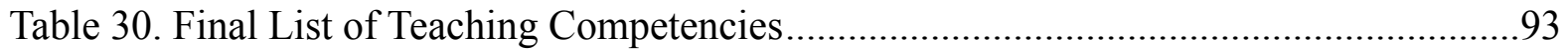




\section{LIST OF FIGURES}

Figure 1. Frequency distribution for Mode 2, Face-to-Face + Satellite Combo.....................72

Figure 2. Frequency distribution for Mode 3.6, F2F + Web-Synchronous Audio ..................73

Figure 3. Frequency distribution for Mode 6.2, Web-Asynchronous/Synchronous Audio .....73

Figure 4. Frequency distribution for Mode 3.3, F2F + Web-Asynchronous Video ................74

Figure 5. Frequency distribution for Mode 3.10 ....................................................... 74

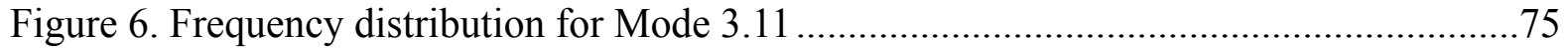

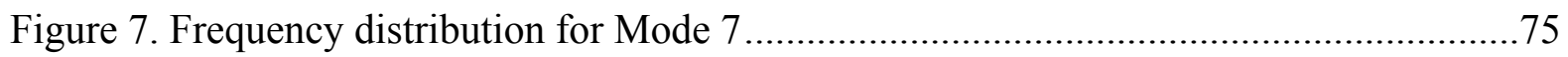

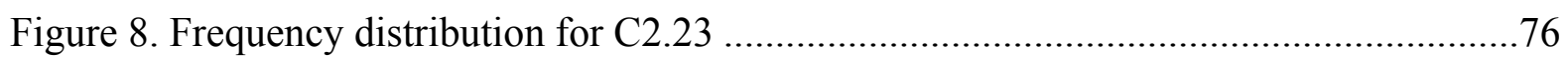

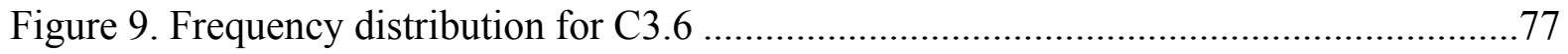

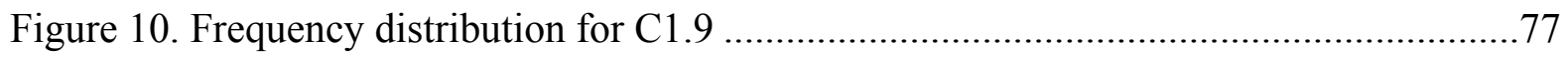

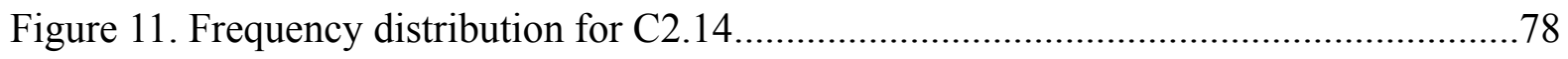

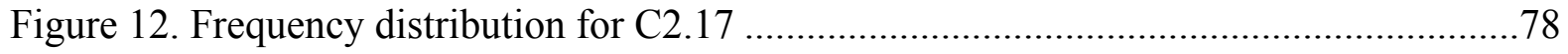

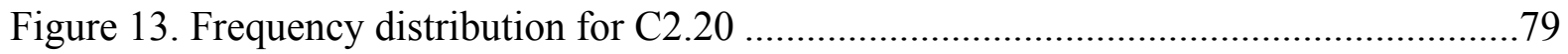

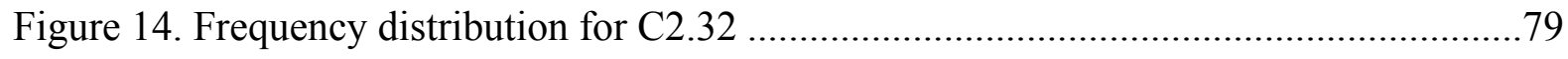

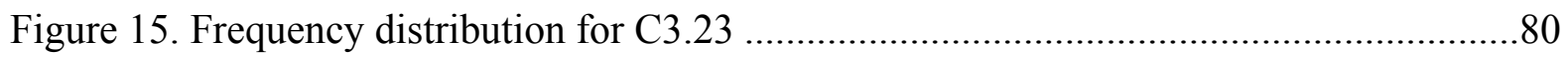

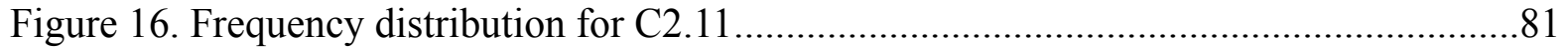

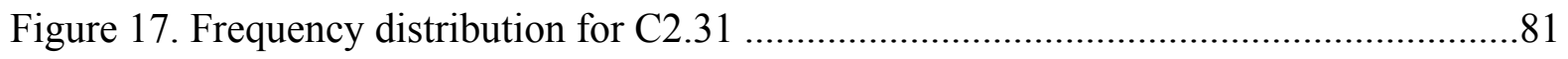

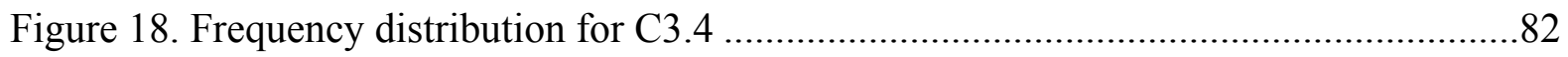

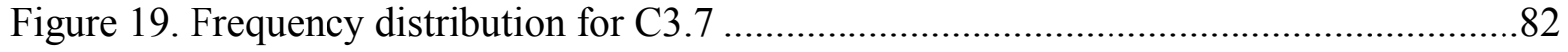

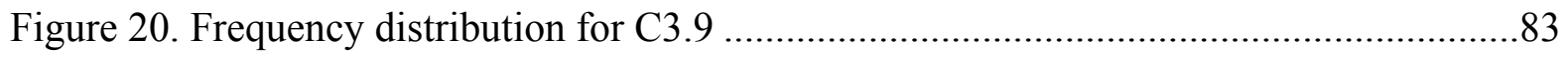

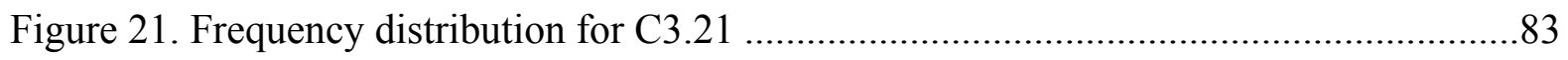

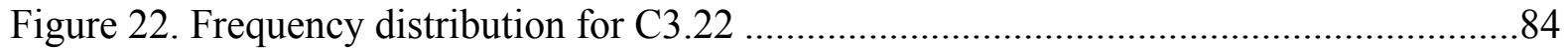

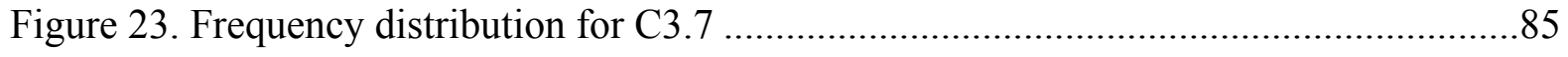

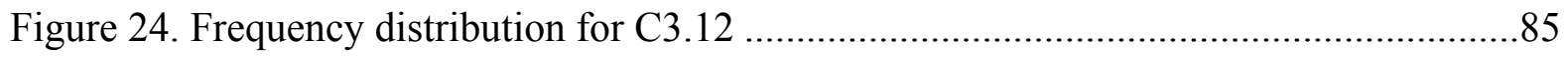




\section{CHAPTER I: INTRODUCTION}

Internet technology has advanced rapidly over the last few years. New forms of knowledge accumulation are evolving; written text, dynamic images, voices, and instructions on how to create new sensory environments can be packaged in dynamic modes of communication (Harley, 2001). The applications of such new knowledge forms challenge the creativity and intent of authors, teachers, and students (Lightfoot \& Ihrig, 2002). Technology such as computers, networks, high-definition television, ubiquitous computing, and other technologies may invalidate most of the current assumptions and thoughts about the future nature of the university (Duderstadt, 2001).

As networking and computers in general have become pervasive features of college campuses, it is inevitable that they would influence the emergence of course content delivery methods (Armitage \& Rodrigues, 2002). More electronic capabilities continue to be integrated into the classroom and the rest of the learning environment, thus, creating new opportunities for teaching in different modes (Sherer \& Shea, 2002). When teaching context is changing, teaching competencies must be viewed in the light of the various contexts in which teaching takes place. It is important for curriculum planners to have timely information about the future competencies needed by teachers. In order to identify the competencies, it is essential to predict the conditions of teaching. The delivery environment, such as classroom-based, online-based, and hybrid environment, is a particularly relevant condition in which to identify teaching competencies.

The importance of good strategic planning for faculty development, support, and training is recognized throughout higher education. One of the well-known strategic planning methods is forecasting. Forecasting was developed around 1970. Since then there has been a trend in forecasting that moves beyond the maximum horizon of ten years (Coates, 1999). Lang (1998) 
has described the Delphi method as the best known qualitative, structured, and indirect interaction research method to study the future. A consensus among future-minded professionals is more appropriate than techniques that simply analyze current trends in the field of educational technology and teacher education. Therefore, the Delphi-method seems to be a useful method. In the Delphi procedure, a panel expert rates statements through different rounds until consensus or stability in panel member's responses are reached (Williams \& Webb, 1994).

"In the foreseeable future, teachers and learners will not be anchored to classrooms as they make appropriate use of various forms of computer enhanced learning" (Conhaim, 2003, p. 38). The traditional mode of teaching will become just one of several modes that learners and teachers will switch between depending upon their particular needs. Life-long learning for future teachers will require using appropriate technologies available. Teachers in the future will make more use of information technology for professional activities including lesson planning, preparation of teaching materials, recording student assessment, administrative tasks, and their own professional development and continuing education (Rossman, 2002). Materials for lessons will be placed on public websites and will incorporate many links to other relevant web sites (Johnstone, 2002).

Online education has become more than an alternative form of delivery. According to the July 2003 U.S. Department of Education report, more than 3 million people were enrolled in online classes in 2001, and 6 million are projected for 2006. The current developments in flexible modes of course delivery are making increased use of the World Wide Web (Sherer \& Shea, 2002). As Williams (2000) indicates, teaching competencies will vary depending on the instruction delivery mode. For example, web-based course delivery demands other teaching competencies. However, many educators criticize that the current framework of teaching 
competencies does not consider changing pedagogy and emerging technologies. These critics of the existing frameworks have implications for designing a new framework. Although some descriptive literature is available, few studies have been conducted to identify teaching competencies predicted to be required in the future.

Need for Study

Since the early 1990s, the use of computers in education has led to an explosion of material and delivery modes for teaching, learning, and assessment tasks. Redesigning the current teacher-training model is necessary to accommodate the emerging course delivery modes (Trotter \& Zehr, 2000). Therefore, it is essential to identify a framework of adequate competencies to teach using the emerging delivery modes. Since teaching competencies will vary depending on the instructional delivery mode, it is necessary to know the future course delivery modes in order to identify teaching competencies. Moreover, it is important to validate a framework for teaching competencies through involvement of educational experts. Educational experts, who have knowledge of important aspects of teaching from their theoretical and practical experience, are a useful source of information to develop and validate the framework.

\section{Problem Statement}

Traditional methods of curriculum development do not take into consideration the changes that may happen before the curriculum is in place. As a result, there is a four-to-sevenyear lag in the process from origination to achievement of curriculum revision (Iverson, 1993). In terms of information technology and its applications, this time period will encompass an enormous amount of change. Considering the amount of time that the curriculum development process takes, the higher education institution's strategic plan uses a 10-year horizon. Such a period involves an assessment of current strengths and weaknesses, the gradual redeployment or 
retraining of staff, and the identification and recruitment of new staff in the face of competition from other institutions.

\section{Purpose of Study}

The purpose of the study is to determine consensus on future course delivery modes and recommended teaching competencies that would be required for teacher education faculty in the future course delivery environment. Teaching competencies are reflective of instructional delivery modes and environments. Therefore, the study will identify the emerging course delivery modes and the competencies needed by teacher education faculty for the identified teaching environment in the year 2015.

\section{Significance of Study}

The study data are essential to making informed decisions about how to structure teacher education. It is expected that the competencies determined by the study would be beneficial to teacher educators planning the curriculum for training future teachers being prepared to work in the changing environment of teaching. The study will provide information to college and university policy makers and curriculum planners working to prepare future course delivery modes. Educators who are involved in teacher preparation programs may use the results to design a curriculum in order to address competencies that would be required to teach in future teaching environment. Existing in-service and pre-service training programs for college professionals can be updated based on the competencies identified in this study. This framework can be used as a starting point for pre-service and in-service teacher evaluation in higher education. 


\section{Research Questions}

The study is directed by two main research questions:

1. What course delivery modes will teacher education faculty of traditional colleges and universities be using in 2015 ?

2. What competencies will teacher education faculty of traditional colleges and universities need to teach using these delivery modes?

\section{Limitations}

1. The potential limitations of this study are biases introduced by the methods used to select participants, design questionnaires, and process results (Lang, 1998).

2. The information this study generated about the future is fundamentally linked to panel members' personal values, concepts, ideas, experience, and quality of opinions (Woudenberg, 1991).

3. For this study, the Web-based Delphi method was selected for collecting information and achieving consensus. Due to the nature of the Web-based Delphi method, participation was limited to individuals who have Internet access.

\section{Definition of Terms}

Teaching Competencies: Teaching competencies are defined as an integrated set of personal characteristics, knowledge, skills and attitudes that are needed for effective performance in various teaching contexts (Smith \& Simpson, 1995).

Delphi: Delphi is a forecast technique based on subjective information that can be defined as a various stages procedure that allows the researcher to collect separately the opinion of several experts on one specific topic, avoiding face-to-face discussion (Weaver, 1971). 
E-learning: E-learning is defined as a type of learning that is aided by information and communications technology tools. In particular, e-learning can be referred to as the effective learning process created by combining digitally-delivered content with learning support and services. These services may include the Internet, intranets, computer-based technology, or interactive television (Churchill \& Munro, 2002).

Face-to-Face (F2F): Face-to-Face is used to describe personal interaction in real life as opposed to via some digital or electronic communications medium. F2F course delivery is defined as traditional classroom teaching environment referring to meeting students in person.

Forecasting: Forecasting is defined as a probabilistic and reasonably definite statement about the future based upon an evaluation of alternative possibilities (Amara \& Salanik, 1972).

Hybrid Instruction: Hybrid Instruction, also known as blended instruction, means any format of instruction combining face-to-face classroom instruction with computer-based learning in a way that moves a significant part of the course online (Park, 2000).

Interquartile Range (IQR): The IQR is defined as the absolute value of the difference between the 25 th and the 75 th quartiles, with smaller values indicating higher degrees of consensus.

Modified Delphi Method: A modified Delphi method is a variation of the Delphi method developed by Dalkey and Helmer at Rand. It utilizes rounds of a survey, with questions dropping off, new questions added, and participants being able to see anonymous responses from the other participants. Unlike the original Delphi, a modified Delphi method provides panelists with opportunity to provide their comments between the rounds (Murray \& Hammons, 1995). Panelists are able to view the comments anonymously and consider it while making their choices. The Modified Delphi method described here uses electronic mail to gather information, provide feedback, and report conclusions. 
Web-Based Delphi: Web-Based Delphi, a kind of Technology-Enhanced Delphi (Andrews

\&Allen, 2002), is defined as an electronic form of Delphi using the Internet and the World Wide Web as a primary data collection. 


\section{CHAPTER II: LITERATURE REVIEW}

Over the past several decades, computers have evolved into powerful information systems with high-speed connectivity to other systems throughout the world (Murphy, 2002). Public and private networks permit voice, image, and data to be made instantaneously available across the world to wide audiences at low costs. The creation of virtual environments where human senses are exposed to artificially created sights, sounds, and feelings liberates us from restrictions set by the physical nature of the world. Computer-based learning systems are being developed, opening the doors to new modes of instruction and learning.

\section{Emerging Trends in Higher Education}

Traditional colleges and universities are in transition. Internet technology has advanced very rapidly over the last few years and a new trend in educational development for learning and teaching has emerged. A number of current trends to education and learning technologies are summarized by Wilson (2001): (a) student learning, (b) advances in information technologies, (c) e-learning and virtual learning environment, and (d) collaboration approach in course delivery. Each of the trends will play a role in future developments of education and teacher training.

\section{Student Learning}

Market shifts across the nation and abroad are accompanied by increased student diversity in age, socioeconomic status, racial and ethnic background, and life experience. These changes have generated new demands for skills and knowledge that have prompted America's colleges and universities to re-examine their academic programs and the processes and outcomes of student learning (Wilson, 2001). 


\section{Advances in Information Technologies}

For the most part, U.S. colleges and universities are well connected with high- speed access to the Internet (Groves \& Zemel, 2000). Schools are beginning to use wireless technology for computers, especially wireless local area networks (WLAN) that enable connection to remote servers without the constraint of cables. Newer laptop computers with more efficient batteries will enable WLAN technology to operate almost anywhere on the school campus. Eventually laptop computers will be replaced by something even more portable and flexible, perhaps handheld technology (Sherer \& Shea, 2002). Some researchers have started to investigate teaching and learning with handheld devices. With the advent of wireless technology, collaboration technologies are becoming more sophisticated. Some university researchers are experimenting with real-time, person-to-person collaboration software for wireless networks. Some colleges, meanwhile, are opting for commercial software suites -integrated programs that bring together different types of communications software. Using collaboration suites from companies such as IBM, Microsoft, Oracle, and Sun, faculty and staff members can make phone calls, exchange instant messages, concurrently view and revise papers for publication, share instrument data, and hold videoconferences.

\section{E-Learning}

The convergence of web technology, wireless networks, and portable client devices provides new design opportunities for computer communications systems (Churchill \& Munro, 2002). E-learning is online training that is delivered in a synchronous (real-time, instructor-led) or asynchronous (self-paced) format (KnowledgeNet, 2002). It is also called virtual learning or digital learning and it aims to exploit web-based technology to improve learning for students. Improvement is seen as a consequence of enhancing traditional face-to-face classroom based 
learning through the use of technology that employs different modes of delivery and can cater to thousands of students in geographically different locations, learning at different times, while allowing for inexpensive and on-going updating of content. Most of the traditional universities are in the process of restructuring by introducing Virtual Learning Environment (VLE) (Black, 2001). Participants are experiencing new ways of learning and communicating with peers and teachers by organizing the learning environment in a different way, based on several technological configurations.

Virtual learning communities are learning communities that are computer-mediated by interconnected computers (Luppicini, 2003). Communication characteristics of virtual learning communities include: asynchronous and synchronous communication, high interactivity, and multi-way communication. Often virtual learning communities of practice are apprenticeshipbased. For instance, Gold (2001) investigated a two-week faculty development pedagogical training course aimed at preparing teachers to operate effectively within an online educational environment. Collaborative exercises employed included virtual field trips, online evaluations, interactive essays, and group projects.

Many educational organizations are currently involved in future initiatives. Educause and Siemens Enterprise Networks' research identify three major trends on the state, national, and international educational institutions. The first trend is the growing level of e-learning activity in colleges and universities. The PT3 Vision Quest Project is one of the examples that anticipate dynamic e-learning environment in higher education. The project investigates the characteristics of networked environments and their implication on the future of higher education (McCombs \& $\mathrm{McNabb}, 2003)$. The second trend is that educational institutions are beginning to restructure many campus services, academic as well as nonacademic, by using web tools. Most of the 
universities have implemented a wide variety of web-enabled student services as well as administrative services to provide $24 / 7$ access to information, reduce the costs, and support issues of face-to-face contact (Harley, 2001). The final trend is the growing interest in sharing online academic materials with increasing numbers of colleges and universities that are cutting budgets. Over the last five years, there has been an explosion in the number of institutions that are working together to share resources in e-learning.

\section{Collaboration Approach in Course Delivery}

More and more colleges and universities are beginning to participate in course-sharing activities (Johnstone, 2002). One example of this movement is the formation of consortia. Some state and multi-state consortia create a common web site that lists all the courses available electronically from the colleges and universities that participate. Another good example of the collaboration effort is Massachusetts Institute of Technology (MIT)'s OpenCourseWare (OCW) project. Through OCW, MIT will post more than two thousand courses on the web over the next ten years (Vest, 2004). It will make course materials available to anybody, anywhere in the world, at no cost.

To cope with these pressures and demands, the majority of universities are turning to the use of the Internet and intranets to deliver courses at distance as well as to enhance campus educational programs. Information technology (IT) has the potential to solve many of the problems associated with these societal pressures and concurrent changes in the higher education sector. IT can change the roles of students and teachers, and facilitate more student-centered learning (Horgan, 1998).

For higher education, open standards and open-source software will be used in the future. Four universities are now working together to build a course-management system using only 
open-source software and nonproprietary, publicly available standards for developing the software. Indiana University, Massachusetts Institute of Technology, University of Michigan, and Stanford University are each contributing roughly five full-time staff members to the effort (Vest, 2004). These universities expect to have a complete course-management system that they can begin using on a trial basis in 2004. They plan to have tens of thousands of students using the system in all of their campuses in 2005 . Other colleges will be free to download and use the software and contribute to the information system.

\section{Course Delivery Modes}

Delivery mode refers to the means whereby teaching methods are implemented, focusing on the forms of communication used (Park, 2000). In addition to the traditional delivery modes of lectures and seminars, delivery modes available through technology include audiovisual media (e.g., audio tape, video tape), computer-based media (e.g., hypertext, interactive multimedia and the internet) and teleconferencing media (e.g., audio-teleconferencing, audio-graphics).

Sherer and Shea (2002) predict that teaching will occur outside of a traditional, brick and mortar classroom, typically in a virtual classroom facilitated by the use of the Internet. Three existing modes of course delivery were identified from the literature: 1) traditional, 2) blended or hybrid, and 3) online. The current literature on the course delivery mode focuses on online instruction and the changing technology that supports the new culture of asynchronous teaching and learning. Recent developments in hybrid instruction, a flexible mode of course delivery, are increasing the use of the World Wide Web. Universities and colleges need to move toward a more effective use of innovative networking and telecommunications technology for distancedeveloped instruction. Universities started launching online instruction to respond to the needs of changing and culturally diverse student demography (Trotter \& Zehr, 2000). The recent 
explosion in distance-education enrollments is likely to continue over the next 10 years, forcing many institutions to seek outside help to manage rising student populations and demands for the latest technology (Olsen et al, 2004).

\section{Traditional Mode}

Traditional classroom teaching focuses on a number of elements including lecture, case studies, team projects, and so forth. Learning is conducted in a synchronous environment, meaning that the students must be in the same place at the same time in order to learn. The traditional classroom has the major advantage of face-to-face interaction between the student and the educator as well as between the students themselves. Students derive motivation from the teacher as well as from the other students. In this environment, learning is enhanced when it is more like a team effort than a solo race. Working with others increases involvement in learning. Sharing one's own ideas and responding to others' reactions improve thinking and deepen understanding (Chickering \& Gamson, 1987). Particularly in small classes, the educator has the opportunity to know and motivate each student on an individual basis. It is this belief in the human contact element of teaching that leads many skeptics to discount the possibility that online learning can be as effective as the traditional method of information delivery (Black, 2001).

\section{Hybrid Mode}

Hybrid Mode, also known as blended mode of education and training, is a new and emerging content delivery mode. Blended or hybrid delivery is defined as an asynchronous, internet technology combined with instructor-led, live classroom instruction (Murphy, 2002). Some institutions blend both synchronous and asynchronous technologies to deliver content. However, most experts agree that blended delivery is the combination of the traditional 
classroom model with Internet technology. The combination of instructor-led (synchronous) and online (asynchronous) course delivery (blended delivery) has great promise in terms of delivering effective education and training to working adults in learning organizations. The hybrid classroom incorporates characteristics of both the traditional and online classroom settings. In hybrid courses, it is up to the teacher to determine what aspects of the course are best suited to presentation via the various delivery modes. Ideally, hybrid courses offer educators the best of both worlds. Online material is viewed as an extension of the classroom and traditional lectures may be linked with virtual tours of organizations being studied. Students receive the benefit of face-to-face interaction with faculty and students while at the same time being exposed to web-based learning paradigms such as virtual real-time information, maps, pictures, streaming video and audio clips. Hybrid approaches may also extend to providing students with both "real" office hours and "virtual" office hours working in both face-to-face teams and virtual teams. The key to successful hybrid classrooms is to analyze course material, determine how well existing material will translate online, creating new approaches to communicating with students, and evaluating and rebuilding the course as problems arise (Black, 2001).

\section{Online Mode}

Online learning environments occur in an asynchronous mode, meaning that students have the opportunity to learn independently from anywhere at any time. From a learning perspective, one advantage of this mode of educational information delivery is that students can set learning to their own paces. In addition, online modes of course delivery offer the student access to the World Wide Web. In this environment, students can take virtual tours of organizations being studied, view streaming video clips, hear audio tapes of Chief Executive Officers, and interact with people from all over the world. Furthermore, online environments 
transcend the need for a "real" classroom, allowing the student to operate in a virtual reality. This opens up the chance for students, who would be otherwise unable to attend a university, to gain a higher education by facilitating the busy schedule of many individual in society. It also reduces university constraints due to limited classroom space and limited funding. Although not all educators see virtual classrooms as a viable option (Noble, 1998), many believe the benefits outweigh the drawbacks.

According to the July 2003 U.S. Department of Education report, more than 3 million people were enrolled in online classes in 2001, and 6 million are projected for 2006 (Waits \& Lewis, 2003). The Sloan Survey of Online Learning found that $81 \%$ of all higher education institutions offer at least one fully online or blended course, and $34 \%$ offer one or more complete online degree programs. More public higher education institutions than private ones offer online courses. More importantly, three quarters of academic leaders believe that the learning outcomes for online education are equal to or superior to those of face-to-face instruction in three years, and less than one quarter (23\%) of the respondents at all schools surveyed expect online learning to be inferior to face-to-face learning in three years (Allen \& Seaman, 2004).

Some institutions have started taking advantage of online course. The University of Maryland had more than 110,000 registrations in 540 Web-based courses in 2003. It already offers 80 certificates and degrees completely online (Conhaim, 2003). E-learning programs have helped the for-profit University of Phoenix become the world's largest private college. Western Governors University, a nationally accredited online university in Utah, set up its course catalog with specified delivery modes to allow students to find and select courses based on which delivery modes are suitable for their learning preferences. The course catalog provides the most exhaustive list of technology-enhanced course delivery modes (Table 1). 
Table 1

Western Governors University Technology-enhanced Class Delivery Modes

\begin{tabular}{|c|c|c|}
\hline \multicolumn{2}{|c|}{ Types of Delivery Modes } & Description \\
\hline $\begin{array}{l}\text { Audio } \\
\text { Technologies }\end{array}$ & Audio Tape & $\begin{array}{l}\text { This delivery mode uses either analog or digital } \\
\text { audiocassettes to deliver instruction to a student. }\end{array}$ \\
\hline & Broadcast Radio & $\begin{array}{l}\text { Courses delivered via radio can be tuned in on a regular } \\
\text { home, office, car or portable radio. Courses may be } \\
\text { broadcast on either AM or FM. }\end{array}$ \\
\hline & Compact Disc & $\begin{array}{l}\text { This delivery mode uses the same format as consumer } \\
\text { music CD's. A compact disc for a course will play on } \\
\text { any typical CD player. }\end{array}$ \\
\hline & $\begin{array}{l}\text { Telephone } \\
\text { Conferencing }\end{array}$ & $\begin{array}{l}\text { For courses that use phone conferencing for } \\
\text { communication between an instructor and a group of } \\
\text { students, students can participate using any normal } \\
\text { telephone. }\end{array}$ \\
\hline \multirow[t]{4}{*}{$\begin{array}{l}\text { Video } \\
\text { Technologies }\end{array}$} & Video Tape & $\begin{array}{l}\text { Courses that employ this delivery mode typically require } \\
\text { a student to view course lectures or material by watching } \\
\text { a videotape that is mailed to the student. }\end{array}$ \\
\hline & Broadcast Television & $\begin{array}{l}\text { Courses delivered via this mode will come through a } \\
\text { standard television set. Your instructor will tell you } \\
\text { which channel and at what time to tune in for a } \\
\text { particular course. }\end{array}$ \\
\hline & Cable Television & $\begin{array}{l}\text { Courses delivered through this mode are similar to those } \\
\text { delivered via broadcast television. The difference is that } \\
\text { you must be a subscriber to your local cable service in } \\
\text { order to receive the channels that carry these courses. }\end{array}$ \\
\hline & Home Satellite & $\begin{array}{l}\text { Courses delivered via home satellite can be received by } \\
\text { anyone with a small dish (about } 12 \text { " to } 18 \text { " in diameter), } \\
\text { which is pointed permanently at one satellite and will } \\
\text { receive } 50 \text { to } 100+\text { channels of entertainment, music, } \\
\text { and other information services. There is usually a } \\
\text { monthly fee for home satellite service (similar to cable } \\
\text { television). A small fixed dish is common on homes in } \\
\text { the city (even where cable is available) and is common } \\
\text { in rural areas because of their distance from transmission } \\
\text { towers and cable systems. }\end{array}$ \\
\hline \multirow[t]{3}{*}{$\begin{array}{l}\text { Computer } \\
\text { Technologies }\end{array}$} & Real-Time Chat & $\begin{array}{l}\text { Courses that employ text chat rooms will require you to } \\
\text { communicate with an instructor or other students in "real } \\
\text { time" by typing comments on the computer keyboard. }\end{array}$ \\
\hline & Audiographics & $\begin{array}{l}\text { Using this mode, you and your instructor can exchange } \\
\text { still pictures, diagrams and printed messages, and you } \\
\text { can talk to each other. }\end{array}$ \\
\hline & Desktop Video & $\begin{array}{l}\text { Using this mode of delivery, students and instructors can } \\
\text { see and talk to each other using computers with attached } \\
\text { audio and video equipment using Internet connections. }\end{array}$ \\
\hline
\end{tabular}


Table 1 (continued)

\begin{tabular}{|c|c|c|}
\hline \multicolumn{2}{|c|}{ Types of Delivery Modes } & Description \\
\hline & Desktop Video & $\begin{array}{l}\text { Using this mode of delivery, students and instructors } \\
\text { can see and talk to each other using computers with } \\
\text { attached audio and video equipment using Internet } \\
\text { connections. }\end{array}$ \\
\hline & Instructional Software & $\begin{array}{l}\text { The media used in this delivery mode will come in } \\
\text { many formats. An example of instructional software is } \\
\text { a } 3.5 \text { " or } 5.25 \text { " computer disk that contains course } \\
\text { material. You will load the course materials from this } \\
\text { disk into a computer and view and work with the } \\
\text { material from there. }\end{array}$ \\
\hline & CD-ROM & $\begin{array}{l}\text { In courses using this mode, course materials are } \\
\text { placed on a CD-ROM disk, which is capable of storing } \\
\text { large amounts of text, graphics, and some audio and } \\
\text { video segments. }\end{array}$ \\
\hline & Computer Conferencing & $\begin{array}{l}\text { In this delivery mode, the instructor and a number of } \\
\text { students solve problems, ask questions, and conduct } \\
\text { other activities using a common discussion site. This is } \\
\text { often called a list-serve. You may connect to a bulletin } \\
\text { board or Internet address that allows you to type a } \\
\text { message and read another person's response; over } \\
\text { time, the communication poses questions and allows } \\
\text { responses which are usually viewed and reacted to by } \\
\text { all participants. }\end{array}$ \\
\hline & E-Mail & $\begin{array}{l}\text { If your course uses this delivery mode, you can expect } \\
\text { to be asked to use the World Wide Web to send } \\
\text { electronic letters to your instructor and, possibly, other } \\
\text { students }\end{array}$ \\
\hline & World Wide Web & $\begin{array}{l}\text { Courses that use the Web as a delivery mode rely, at } \\
\text { least in part, on the Internet. }\end{array}$ \\
\hline $\begin{array}{l}\text { Print/Correspond } \\
\text { ence Delivery }\end{array}$ & Postal Correspondence & $\begin{array}{l}\text { This mode describes the traditional correspondence } \\
\text { courses that colleges and universities have offered for } \\
\text { decades. This format usually involves the purchase of } \\
\text { books and other course materials which are the basis } \\
\text { of questions and projects for several lessons which are } \\
\text { written, mailed to, and graded by the instructor. }\end{array}$ \\
\hline & FAX & $\begin{array}{l}\text { Courses using fax delivery of course materials rely on } \\
\text { paper documents which are sent using special } \\
\text { telephone equipment. }\end{array}$ \\
\hline $\begin{array}{l}\text { Specially- } \\
\text { Equipped Site } \\
\text { Delivery }\end{array}$ & $\begin{array}{l}\text { Satellite } \\
\text { Terrestrial (Land) } \\
\text { Network }\end{array}$ & $\begin{array}{l}\text { Specially-equipped site delivery modes are those that } \\
\text { require that students travel to previously designated } \\
\text { locations to participate in classes via one- or two-way } \\
\text { video and audio connections. }\end{array}$ \\
\hline
\end{tabular}


Table 1 (continued)

\begin{tabular}{|c|c|c|}
\hline \multicolumn{2}{|c|}{ Types of Delivery Modes } & Description \\
\hline \multirow[t]{5}{*}{ Other } & DVD Disks & $\begin{array}{l}\text { These are digital video disks that have a new format } \\
\text { with far greater information-storage capacity than CD- } \\
\text { ROM disks. This format is capable of storing huge } \\
\text { amounts of high-quality audio and video material. }\end{array}$ \\
\hline & Virtual Reality & $\begin{array}{l}\text { Virtual Reality is a computer-generated three- } \\
\text { dimensional environment in which the participant can be } \\
\text { actively involved. The user must wear some type of } \\
\text { headgear which contains the projection and audio } \\
\text { devices. Interactivity is gained through a joystick or } \\
\text { electronic glove which the user manipulates. This allows } \\
\text { the user to feel and react as if in the perceived } \\
\text { environment. Virtual Reality is a very sophisticated new } \\
\text { technology requiring an elaborate setup. Although not } \\
\text { commonly available for educational use, it has potential } \\
\text { in the educational setting as a means of providing } \\
\text { "concrete" experiences for the user. }\end{array}$ \\
\hline & $\begin{array}{l}\text { Compact-Disc } \\
\text { Interactive }\end{array}$ & $\begin{array}{l}\text { CDI technology incorporates text, audio, graphics and } \\
\text { animation in the compact-disc programming. It requires } \\
\text { a very sophisticated player which connects to a } \\
\text { television set. The user interacts with the program } \\
\text { through a special remote control which also has a } \\
\text { joystick and activation buttons. This technology is easy } \\
\text { to use and has high-quality sound and video. Players are } \\
\text { not much more expensive than a VCR but may be } \\
\text { difficult to find. }\end{array}$ \\
\hline & $\begin{array}{l}\text { Digital Video } \\
\text { Interactive }\end{array}$ & $\begin{array}{l}\text { DVI, which uses a computer, has full-motion video and } \\
\text { high-quality sound and video. It is compatible with both } \\
\text { Macintosh and IBM platforms. Digital Video Interactive } \\
\text { (DVI) requires a DVI board installed in your computer } \\
\text { (this board may cost as much as a computer). A DVI } \\
\text { disc plays in a standard CD-ROM player and } \\
\text { incorporates text, audio, graphics and animation into the } \\
\text { programs. }\end{array}$ \\
\hline & Videodiscs (laser discs) & $\begin{array}{l}\text { Laser discs are similar to LP's in size but store digital } \\
\text { information which can be searched and controlled via } \\
\text { computer. }\end{array}$ \\
\hline
\end{tabular}

Note. It is a list of delivery modes that Western Governors University (WGU) uses in providing students with courses and programs. 
Faculty Roles in Higher Education

Shifts in technology, markets, the social charter, and student preparedness are challenging traditional thinking about how faculty time should be distributed among their expected roles. In addition, conditions of heightened accountability, fiscal uncertainty, and new academic management practices are transforming criteria for evaluating faculty work (Duderstadt, 2001).

Professional associations have established various initiatives to address changing faculty work. The American Association for Higher Education (AAHE) Faculty Roles and Rewards project is one of the new initiatives. New faculty roles will emerge from the dynamic e-learning cultures when the course delivery mode changes (Conhaim, 2003; McCombs \& McNabb, 2003). Rossman (2002) and Morrison, Ericson, and Kohler (2003) discuss future technologies such as how the digital textbook can empower future e-learning. Marie Eaton (2002), in summing up how the new higher education models could change faculty role, writes: "In the new university, faculty will relinquish some of their responsibility for delivery of instruction to become designers of learning environments." Teaching competencies will vary depending on the instructional delivery mode. The future instructional environment will require new teaching competencies such as more advanced technical competencies and engineering skills (Williams, 2000).

With the great demand for online courses, there is an urgent necessity to reflect upon the roles and competencies of teachers who plan to deliver courses via Internet. This reflection is important due to the fact that some teachers believe that it is possible to simply transfer curricular content to the Web material that is traditionally used in the classroom without any adjustment to the media. Each medium requires different approaches to be implemented. The teachers should be trained to teach online so they can achieve their pedagogical goals in a more 
effective, creative and innovative way when using a Virtual Learning Environment (VLE) (Gold, 2001).

\section{Teaching Competencies}

According to the International Board of Standards for Training, Performance and Instruction (IBSTPI), a competency involves a related set of knowledge, skills and attitudes that enable a person to effectively perform the activities of a given occupation or function in such a way that meets or exceeds the standards expected in a particular profession or work setting (Richey, Fields, \& Foxon, 2001). Competencies are dynamic in nature and they depend on the relevant social context (Spector, 2001). For example, to facilitate a common understanding of competencies in the context of online and distributed learning some specifications have been elaborated (IMS, 2001). The constant transformation of information technology makes the development of competencies for online teachers a continuous process and demands continuing professional preparation and training for online teachers.

The use of IT in teaching calls for additional competencies adapted to new roles and circumstances. The current literature discusses teaching competencies that are unique to online environments. Much of what has already been published with regard to online teaching has focused on technical skills and requirements of successfully moderating and facilitating online discussions and chat sessions (Rosenberg, 2001; Williams, 2000). Queiroz (2003) specifically identifies these competencies: to be able to use technology; to have skills to design and implement courses depending on the applications to be used; to moderate, organize and archive asynchronous discussions; to establish ground rules, guide and animate synchronous discussions; to integrate different teaching and learning styles to the course; to interact actively with students and give them constant feedback; to make students aware of cultural differences among members 
of a group, of Internet ethics and netiquettes, among others.

\section{Competency Development Initiatives}

International Society for Technology in Education (ISTE) (2002) created the National Educational Technology Standards (NETS) project to develop national standards for educational uses of technology that facilitate school improvement in the United States. While the NETS project is concerned with PreK - 12 educations, the broader and more long-range implications affect all phases of education, continuing through postsecondary to the adult and lifelong learner.

The Certification in Teaching of College Science and Mathematics of Michigan State University (MSU) set core competencies to provide graduate students a comprehensive preparation for teaching at the college level (Michigan State University, 2001). These competencies are identified in the five core domains: creating learning environments, teaching strategies in science and mathematics, assessment of learning, use of technology in the classroom, and understanding the academy. These core competencies are being used in in-service teacher training programs as well as teaching assistant training programs.

National Board for Professional Teaching Standards (NBPTS) plays an important role in National Board standards-based teacher preparation and development programs funded by the U.S. Department of Education and the National Science Foundation. NBPTS is a nonprofit and non-governmental organization. Its mission is to advance the quality of teaching and learning by: maintaining high standards for what accomplished teachers should know and be able to do, providing a national voluntary system certifying teachers who meet these standards, and advocating related education reforms to integrate National Board Certification in American education and to capitalize on the expertise of National Board Certified Teachers (National Board for Professional Teaching Standards, 2001). 
National Board Certification was created in 1994 and since then, 16,030 teachers have achieved National Board Certification, with over 16,000 participating in 2001-2002. Over the last several years, many institutions of higher education have reported their work in aligning programs and teacher education curriculum with the NBPTS standards for accomplished teaching. According to a NBPTS research, as of January 2003, 561 institutions of higher education engage in a variety of NBPTS related activities, ranging from National Board Certification candidate support to implementing advanced degree programs aligned with the National Board's standards.

Institutions of higher education are challenged to meet all the emerging trends such as virtual learning environment, changing course delivery modes, and therefore changing faculty roles. Higher education institutions are faced with the need to implement training programs for their faculties to be able to teach in the future context. The initial step in creating a successful professional development program is to identify the competencies needed to deliver the course in the future. Some educational organizations are currently involved in competency development initiatives and standards-based teacher preparation and development programs. In these organizations, educational experts who are experienced in developing curriculum are useful sources of information to identify teaching competencies.

\section{Delphi Method}

The Delphi method is based on a structured process for collecting and distilling knowledge from a group of experts by means of a series of questionnaires interspersed with controlled opinion feedback (Clayton, 1997). The Delphi technique uses panel experts to examine a particular subject. The panel is brought together by written communication only. There are no face-to-face meetings, and no panel member knows the identities of other panel 
members. The technique was introduced in 1958 through Project DELPHI directed by the Rand Corporation to predict alternate national defense futures. It is a procedure to "obtain the most reliable consensus of opinion of a group of experts ... by a series of intensive questionnaires interspersed with controlled opinion feedback" (Dalkey \& Helmer, 1963, p. 458). Studies comparing the Delphi's results with other methods confirmed the effectiveness of the method related to generating ideas and the use of participants' time (Ulschak, 1983). Lang (1998) described the Delphi method as the best known qualitative, structured, and indirect interaction research method to study the future.

The Delphi technique has several advantages that make it useful. First, it is an efficient method to obtain information from educational experts and to reach consensus, for after each round, the panelists are confronted with their own ratings in comparison with the mean score and standard deviation on each item (Martino, 1993). Furthermore, the bias of dominant views within group discussions are avoided (Lang, 1998); members can individually consider what teaching competencies they find important. And finally, Delphi has the advantage that opinions and ideas are crystallized and not only based on critical tasks in which only important conspicuous elements of teaching can be taken into account (Clayton, 1997; Murray \& Hammons, 1995; Williams \& Webb, 1994).

Literature mixes both advantages and criticisms of using the Delphi method in forecasting. The common criticisms are uncertainty about the future, subjective judgment of experts, and required multidisciplinary perspectives (Stillwell, 1999). Sackman (1975) argued that the conventional Delphi method neglects major areas of professional standards for questionnaire design, administration, application, and validation. Despite this imperfection, many researchers agree that the Delphi method is a valuable tool for educational forecasting and 
planning (Lang; Martino; Ulschak; Welty, 1973).

\section{Computer-based Delphi}

According to Turoff and Hiltz (Turner \& Turner, 1999), the computer-based Delphi study has a number of advantages over paper-and-pencil Delphi:

1. Asynchronous interaction used in Delphi procedures is more easily accomplished.

2. Continuous access to the emerging database by contributors without prior summarization and possible introduction of bias by the investigators.

3. Participants can frequently update themselves about the discussion before contributing, enabling a more informed contribution and with less duplication of responses.

4. Responses can be screened more easily prior to distribution; record keeping, data processing, and statistical analyses are facilitated.

5. Communication among participants is faster and less costly; participants who are geographically distanced can be included.

6. Provision of a structure for the dynamic contribution of knowledge over time (p. 127).

\section{Web-based Delphi}

Traditional methods of survey distribution and collection that utilize the postal system are slow and provide low rates of return. Internet technology provides a medium to drastically decrease the amount of time and provides easy follow-up using electronic mail (Turner \& Turner 1999). Many existing research studies in the area of information technology are utilizing the Internet and the World Wide Web as a media to collect consensus data (Nesbary, 2000). The World Wide Web spans the globe, and geographical boundaries are becoming less of an issue in communication. Because of advanced online capability, the cost of survey administration for educational research is becoming cheaper, and the amount of work required in survey 
distribution, collection and analysis is greatly reduced. Although studies remain to be done, the validity of web-based survey research is likely to be strongest for researchers who target specific population samples (Watt, 1999). Early methods of Internet-based data collection typically embedded the instrument directly in the body of an e-mail message and requested the response to be replied to as an attachment or modification of the original message. However, researchers are increasingly directing participants to complete instruments that have been published as web pages (White \& Dailey, 2001).

Linstone and Turoff (1975) established a criteria to determine the appropriateness of using the Delphi technique:

1. When the problem does not lend itself to precise analytical techniques but can benefit from subjective judgements on a collective basis.

2. When the individuals who need to contribute to the examination represent diverse backgrounds with respect to experience or expertise.

3. When more individuals are needed than can effectively interact in a face-to-face exchange.

4. When the time and cost make group meetings infeasible.

5. When disagreements are so severe or politically unpleasant that the communication process must be refereed and/or anonymity assured.

6. When the heterogeneity of the participants must be preserved to assure validity of the results and to avoid domination by the strength of certain personalities.

7. When a supplemental group communication process can help the efficiency of faceto-face meetings (p. 59). 
This study meets most of these criteria. Item 5, regarding severe disagreement, is not applicable. Because all the other criteria were met, the Delphi technique was used to conduct this study.

\section{Related Studies}

The Delphi method has been used in predicting future educational trends and identifying the competencies (Benjamin et al, 2000; Iwu, 1988; McCoy, 2001; Rickman, 1987; Williams, 2000). A research study funded by the Texas Higher Education Coordinating Board employed the Delphi method to determine future issues for Texas higher education. It presents the results of analyses of how well the higher education system in Texas will meet these challenges if current trends and patterns continue. It identifies the kinds of changes needed to realign higher education in Texas with these demands. The time frame of the study is 10 years (Benjamin et al).

The Association of American Medical Colleges (AAMC) conducted a study, Better Health 2010 Delphi Study (2001), to identify changes in organization, operations, roles, and function that will occur as a result of information technology and the Internet. This web-based, three-round, Delphi study used a 7-point scale to rate the likelihood of 75 statements about how information technology might change medical education over the next 10 years. The study was conducted fully via the Internet and involved 268 participants.

Rickman (1987) used the Delphi technique to identify the emerging competencies needed by information processing employees for the automated office environment in the year 2000. Rickman expected that the competencies determined by the study would be beneficial to business educators planning the curriculum for training future employees to be prepared to work in the changing environment. The study used panel experts to identify competencies needed by 
information processing specialists and to determine the degree of importance attributed to these competencies.

Iwu (1988) conducted a study to examine the importance of computer competencies needed for the certification of secondary school business teachers in the United States. The purpose of the study was to: (a) identify important computer competencies, (b) determine the degree of importance of the competencies, and (c) rank the categories of competencies. Iwu recommended using a national panel of business education professors to determine the needs of educators for future training and to periodically reassess these determinations to eliminate business practices that become obsolete.

Williams (2000) compared his research results with those of a previous competency study done in 1994 by Liz Thach. Based on the comparison, three competencies related to the Internet emerged in the study as well as two competencies related to pedagogy, underscoring on the one hand the need for basic technology competencies across all roles and on the other hand the need for sound pedagogical practice in distance education initiatives. A dual trend emerged related to technology skills. First, the more advanced technical competency, engineering skills, was not as highly rated as before. Secondly, basic technology skills are indispensable across all roles, having become part of the entry-level skill set needed by any staff member. In addition to the general competencies, each role requires other competencies that are role-specific. Table 2 includes the role specific competencies on which the panel reached a level of consensus as being very important due to either frequency or criticality.

McCoy (2001) identified the computer competencies needed for business education teachers in the $21^{\text {st }}$ century. The study consisted of three rounds of a Delphi instrument using electronic mail as the primary means of communication. Twenty-three experts nominated by the 
National Association for Business Teacher Education (NABTE) served on the Delphi panel. The

responses generated by the first round contributed to the development of an instrument; the second round involved rating the importance of each competency using a 5-point Likert scale;

and the third round determined the consensus on items.

Table 2

Roles and Role Specific Competencies That Were Considered Very Important

Role Competencies

\begin{tabular}{|c|c|}
\hline Administrative Manager & Managerial Skills, Budgeting Skills, Marketing Skills, Strategic Planning Skills \\
\hline Instructor/ Facilitator & $\begin{array}{l}\text { Content Knowledge, Teaching Strategies/Models, General Education Theory, Skill } \\
\text { with Internet Tools for Instruction, Instructional Design for Interactive } \\
\text { Technologies, Library Research Skills, Modeling of Behavior/Skills }\end{array}$ \\
\hline Instructional Designer & $\begin{array}{l}\text { Instructional Design Skills, Instructional Design for Interactive Technologies; } \\
\text { Media Attributes Knowledge; General Education Theory; Text Layout Skills; Skill } \\
\text { with Internet Tools for Instruction; Teaching Strategies/ Models, Web Related } \\
\text { Programming skills; Learning Style and Theory; HTML Authoring Skills }\end{array}$ \\
\hline Technology Expert & $\begin{array}{l}\text { Computer Hardware Skills; Technology Operation/Repair Skills; Skill with } \\
\text { Internet Tools for Instruction }\end{array}$ \\
\hline Support Staff & Advising/Counseling Skills \\
\hline Librarian & Library Research Skills \\
\hline Technician & $\begin{array}{l}\text { Technology Operation/Repair Skills; Computer Hardware Skills; Computer } \\
\text { Networking Skills }\end{array}$ \\
\hline Evaluation Specialist & General Education Theory \\
\hline Graphic Designer & $\begin{array}{l}\text { Graphic Design Skills; Text Layout Skills; Media Attributes Knowledge; Skill } \\
\text { with Internet Tools for Instruction }\end{array}$ \\
\hline Trainer & $\begin{array}{l}\text { Training Skills; Modeling of Behavior/Skills; General Education Theory; Teaching } \\
\text { Strategies/Models; Skills with Internet Tools for Instruction; Advising/Counseling } \\
\text { Skills }\end{array}$ \\
\hline Media Publisher/ Editor & $\begin{array}{l}\text { Skills with Internet Tools for Instruction; Graphic Design Skills; Media Attributes } \\
\text { Knowledge Leader/Change Agent }\end{array}$ \\
\hline Leader/Change Agent & $\begin{array}{l}\text { Modeling of Behavior/Skills; Managerial Skills; Strategic Planning Skills; Policy- } \\
\text { Making Skills; General Education Theory }\end{array}$ \\
\hline
\end{tabular}


From the study, 95 competencies with consensus were grouped in five categories: computer hardware, software, computer programming, computer integration, and general computer knowledge. The findings presented nine very important general knowledge items that should be included in business teacher education. The panel believed that the two most important competencies about general computer knowledge for business teachers are to be able to readily assess the computer skills/knowledge of students, and to show competency in the fundamentals of computers and information processing. The methodology used in the McCoy study helped guide this study.

Literature review indicates that the Delphi method has been used in many studies to identify competencies. Furthermore, with the advanced online capability Delphi method became a very popular educational research method by saving time and cost to do research. The Delphi method was selected to draw group consensus from a panel of educational experts. 


\section{CHAPTER III: METHODS AND PROCEDURES}

This chapter describes the procedures that the investigator undertook to conduct the Delphi study. The purpose of the study was to reach consensus on recommended teaching competencies needed by teacher education faculty for teaching environments in the year 2015 . The study was directed by two main research questions: (a) what course delivery modes will teacher education faculty of traditional colleges and universities be using in the year 2015? and (b) what competencies would teacher education faculty of traditional colleges and universities need to teach using these delivery modes?

\section{Study Design}

The study followed the pattern of previous competency studies (McCoy, 2001; Williams, 2000) by using a panel of experts to determine the future course delivery modes and teaching competencies. Limited time and financial resources for travel along with geographically dispersed experts necessitated the use of a method that would allow the chosen experts to participate from their respective locations (Ludwig, 1997). The approach used in this study to achieve its purposes was the online modified Delphi methodology. This study involved three rounds to achieve consensus among a group of experienced teacher education faculty in higher education. Individuals were either nominated or selected from various educational organizations to serve on the panel of experts. All data were gathered via e-mail and the World Wide Web as a primary mode of communication using Web-based instruments that resided on the Web Services server of West Virginia University. This study followed the rules for conducting a Delphi study as Martino (1993) indicated: iteration with controlled feedback, anonymity, and statistical representations of group response. 


\section{Delphi Panel Selection}

Panel selection is critical in using the Delphi technique (Lang, 1998). The success of a Delphi study rests upon selecting appropriate experts qualified in the subject area. The effective selection of the panel not only maximizes the quality of responses but also gives the results of the study credibility. According to Lang, random selection of the participants is not acceptable. Instead, characteristics and qualifications of desirable respondents should be identified to select participants. For this study, the Delphi Panel members were purposefully selected. The selection of experts was done via e-mail communication. The two primary advantages of e-mail panel selection over traditional recruitment approaches are time and cost (Andrews \& Allen, 2002). Simultaneous e-mail messages can be sent to all potential panelists, as opposed to individual mailings. Response time to e-mail inquiries is also faster than the time generally observed with mailed solicitations. Cost saving is a major plus since the cost of an individual e-mail message is negligible and the cost of postage is eliminated.

\section{Sources for Potential Panelist}

To create the necessary panel of experts for this study, four sources for experts in or related to, the field of teacher education were determined. The sources agreed upon were (a) teacher education organizations; (b) subject-specific teacher organizations; (c) educational technology organizations; (d) policymaker organizations, and (e) other educational organizations. A list of the source organizations selected for this study is provided in Appendix A. Selection of source organizations was to seek appropriate participants who are capable of forecasting the competencies of teacher education faculty in 2015. A list of possible organizations was selected to include nationally recognized teacher educators, curriculum planners, educational technology experts, and educational policy makers representing different disciplines and institutions. The 
study needed panel experts who had ideas on what teaching competencies would be required in higher education from different perspectives.

Nineteen organizations were selected: 2 teacher education organizations, 10 subjectspecific teacher organizations, 5 educational technology organizations, and 2 policymaker organizations. Fifteen out of 19 organizations were selected from the National Council for Accreditation of Teacher Education $\left(\mathrm{NCATE}^{1}\right)$ member organizations, four organizations selected were leading organizations of educational technology such as Asynchronous Learning Network (ALN), The Sloan Consortium, and Center for Digital Education, and Department of Education.

Two teacher education organizations were selected: The Association of Teacher Educators (ATE) and The American Association of Colleges for Teacher Education (AACTE). The ATE is national organization devoted solely to the improvement of teacher education for both school and campus-based teacher educators. The AACTE is the leader for innovation in teacher education. It fosters development of a global perspective in teaching and teacher education and promotes the use of this perspective in decision-making within the Association and member institutions. The AACTE is a national voluntary organization of colleges and universities that prepare the nation's teachers and other educational personnel.

To seek panel experts who are responsible for preparing future teachers in specific disciplines, ten subject-specific teacher organizations from NCATE member organizations were selected: American Council on the Teaching of Foreign Languages (ACTFL), American Alliance for Health, Physical Education, Recreation and Dance (AAHPERD), International Reading Association (IRA), International Technology Education Association (ITEA), National Council

\footnotetext{
${ }^{1}$ NCATE is the professional organization for teacher preparation in the United States. It is a coalition of over 30 organizations representing teachers, teacher educators, content specialist, and policymakers. NCATE currently accredits 588 colleges of education with over 100 more seeking NCATE accreditation.
} 
for the Social Studies (NCSS), National Council of Teachers of English (NCTE), National Council of Teachers of Mathematics (NCTM), National Science Teachers Association (NSTA), North American Association for Environmental Education (NAAEE), and Teachers of English to Speakers of Other Languages (TESOL).

To include organizations which inspire leadership for the integration of technology in education, five educational technology organizations were selected: Association for Education Communications and Technology (AECT), International Society for Technology in Education (ISTE), *Asynchronous Learning Network (ALN), *The Sloan Consortium (Sloan-C), and *Center for Digital Education (CDE). They provide the most diverse opportunities for teacher educators to remain at the forefront of the education technology. AECT is to provide international leadership by promoting scholarship and best practices in the creation, use, and management of technologies for effective teaching and learning in a wide range of settings. It defines the disciplines and professional activities that comprise the field of educational communications and technology. ISTE is a nonprofit professional organization with a worldwide membership of leaders and potential leaders in educational technology. It is dedicated to providing leadership and service to improve teaching and learning by advancing the effective use of technology in K-12 education and teacher education. Asynchronous Learning Network (ALN) is a group of people who study asynchronous use of networks and some use of synchronous technology comparing face-to-face and online learning processes. They also study effectiveness of learning outcomes for students, and positive or negative impacts on faculty. The Sloan Consortium includes 267 organizations and 157 colleges as a member and cover a broad spectrum of the discipline areas such as agriculture-related, business and management, computers, education, engineering, environmental-related, health care and nutrition, humanities, 
language, law, liberal arts, math, medicine, social sciences and telecommunications. Collectively this is a consortium of institutions and organizations committed to quality online education. The Center for Digital Education is a leader in education technology and its mission is to provide its members with the best resources, opportunities and information, so they can make sound and successful decisions in 21 st century education.

Two Organizations which are responsible for decision making and policy making were included: Department of Education (DOE) and National Association of State Boards of Education (NASBE). The Department of Education establishes policies on education, and collects data on America's schools and disseminating research. It promotes improvements in the quality and usefulness of education through federally supported research, evaluation, and sharing of information. The National Association of State Boards of Education (NASBE) is the only national organization giving voice and adding value to the nation's State Boards of Education. A non-profit organization founded in 1958, NASBE works to strengthen state leadership in educational policymaking, promote excellence in the education of all students, advocate equality of access to educational opportunity, and assure continued citizen support for public education.

\section{Panel Member Selection Procedures}

To identify potential participants for the study, an email was sent to the president of each selected educational organization. In the email, the purpose of the study was described, and the presidents were asked to nominate up to three teacher educators including themselves in their organizations. To be considered as a panelist in the study, participants must have met 4 out of 5 of the following criteria.

1. Current involvement in teacher education with research and service as higher education professional with minimum of five years teaching experience in higher education. 
2. Provides leadership in developing, implementing, and evaluating programs for educating teachers that embrace diversity, and are rigorous, relevant, and grounded in best practice.

3. Record of publication or presentation in the field of alternative course delivery modes, e-learning, curriculum design, teacher training, and educational technology.

4. Models professional teaching practices which demonstrate knowledge, skills and attitudes reflecting best practice.

5. Collaborates regularly with school, university, state education department, professional associations, and community representatives to improve teaching, learning and teacher education.

The $1^{\text {st }}$ group nominated. During the month of March, 2005, the researcher contacted the presidents of 19 selected organizations to nominate those teacher education experts who meet the selection criteria. Thirteen presidents out of 19 organizations replied with 12 nominating a total of 36 potential participants from their organization.

The $2^{\text {nd }}$ group selected. The researcher found that some of the more prominent educational leaders and researchers in the field were not nominated through the organizational contact. Therefore the researcher identified an additional group of twenty-three potential panelists based on their prominence in the field of educational technology.

The potential participants identified. After two iterations of the selection process, the potential participants to serve on the expert panel were identified ( $N=59)$. These experts were either nominated or selected because they met the selection criteria. During the month of April 2005, all those 59 individuals nominated for inclusion in the initial group of possible panel members were contacted first by e-mail with 3 attachments: (a) Invitation Letter (see Appendix 
B), (b) Study Overview (see Appendix C), and (c) Study Participation Agreement (see Appendix D) to be part of the study.

Final panel group. From the first group nominated, 15 out of the 36 (42\%) educational experts agreed to participate in the study. The 15 people were from the following organizations: AAHPERD, AECT, ATE, ACTFL, ISTE, NCTM, and TESOL. From the second group selected by the researcher, eleven people replied, and six out of the $23(19 \%)$ selected educational experts agreed to participate in the study. The 6 people were from the following organizations: AACE, AACTE, AAHE, APA, and DOE. A total of 21 potential panel members agreed to participate in the study. Table 3 summarizes the number of initial participants by organization.

Table 3

Number of Initial Participants by Organization

\begin{tabular}{ccc}
\hline Organizations & No. participants \\
\hline Teacher Education Organizations & \multicolumn{1}{c}{4} \\
AACTE & 1 & \\
ATE & 3 & 7 \\
Subject Specific-Organizations & & \\
ACTFL & 1 & \\
AAHPERD & 1 & \\
NCTM & 3 & 5 \\
TESOL & 2 & \\
AECT & 3 & \\
ISTE & 2 & 4 \\
*DOE & 1 & \\
Policymaker Organizations & \\
Other Educational Organizations & & \\
*APA & 1 & \\
*AACE & 2 & \\
*AAHE & 1 & \\
\hline Note. N=21. Organizations with * are non-NCATE member organizations.
\end{tabular}


The resultant 21 member panel of educational experts was 13 females and eight males from 12 different educational organizations. Panel experts identified for potential participation were curriculum planners, educational policy makers, teacher educators, technology coordinators, and distance education experts from various educational organizations.

Panel Size

The size of the panel can vary depending on the problem that is being examined.

However, there needs to be a sufficient number to ensure that the results of the study do represent a true cross-section of experts and have a significant degree of reliability. Delbecq, Van de Ven \& Gustafson (1975) suggested using the minimally sufficient number of respondents which is between 15 - 20 because large numbers of respondents generate many items and ideas making the summarizing process difficult. Dalkey, Rourke, Lewis \& Snyder (1972) reported that there was a definite and monolithic increase in the reliability of group responses with increasing group size.

Linstone and Turoff (1975) suggests a panel size of anywhere from ten to fifty participants. Reliability with a correlation coefficient approaching .9 was found with a group size of 13 . It has also been reported that the validity and reliability of the Delphi technique does not significantly improve with more than 30 participants. According to Dalkey and Helmer (1963), although reliability increases as a panel gets larger, the increase is only slight once 30 participants is surpassed. Delbecq, Van deVen, and Gustafson (1975) found that error decreased rapidly as the group size increased from one to about thirteen; further small decreases in error continued to a size of about 25 people, at which point the error rate stabilized. Based on these findings, they continued their experiments using groups of fifteen to twenty people. The panel size of twenty one fits within the guidelines recommended for Delphi studies. 


\section{Instrument Design and Implementation}

This study involved three rounds: Round I, Round II, and Round III. Questionnaires were constructed for each round of the Delphi study. The number of rounds depended upon reaching consensus among panel members. Most Delphi studies find that more than three or four rounds do not add significant value (Clayton, 1997). This study used three instruments that are identifiable as Round I Questionnaire, Round II Questionnaire, and Round III Questionnaire. This Delphi method went through three rounds of electronic questionnaires and controlled feedback in order to achieve consensus from the panel experts. Participants remained anonymous to each other, avoiding influences of reputation, authority or affiliation, and it enabled panel members to change their opinions without losing face (Martino, 1993). Each round took approximately one month.

All panel experts were invited to participate in three rounds of communication utilizing e-mail and the World Wide Web. The identities of the panel members were kept confidential throughout the study, and each panel member was assigned a unique identity that kept the panel expert anonymous to the other participating panel members. Table 4 outlines the three-round Delphi procedure that was followed in this study: 
Table 4

Time Line of Delphi Process

\begin{tabular}{|c|c|c|c|}
\hline & Round I & Round II & Round III \\
\hline Start Date & May 1, 2005 & November 15, 2005 & February 13, 2006 \\
\hline End Date & June 1, 2005 & December 30, 2005 & March 6, 2006 \\
\hline Instrument & Questionnaire I & Questionnaire II & Questionnaire III \\
\hline Response Rate & $17 / 21(81 \%)$ & 17/17 (100\%) & $15 / 17(88 \%)$ \\
\hline Data Collected & $\begin{array}{l}42 \text { course delivery } \\
\text { modes and } 167 \\
\text { teaching competencies }\end{array}$ & $\begin{array}{l}\text { Level of agreement (on a } \\
\text { seven point scale) for each } \\
\text { identified delivery mode } \\
\text { and competence. }\end{array}$ & $\begin{array}{l}\text { Revised level of } \\
\text { agreement (on a seven } \\
\text { point scale) for items } \\
\text { included in Round III. }\end{array}$ \\
\hline Data Analysis & $\begin{array}{l}\text { Compile list of delivery } \\
\text { modes and teaching } \\
\text { competencies. } \\
\text { Prepare Questionnaire } \\
\text { II using compiled list. }\end{array}$ & $\begin{array}{l}\text { Compute mean, median, } \\
\text { mode, IQR, frequency, and } \\
\text { level of agreement for each } \\
\text { item. } \\
\text { Prepare Questionnaire III } \\
\text { using only items that didn't } \\
\text { reach consensus. }\end{array}$ & $\begin{array}{l}\text { Compute mean, } \\
\text { median, mode, IQR, } \\
\text { frequency, and level of } \\
\text { agreement for each } \\
\text { item. }\end{array}$ \\
\hline
\end{tabular}

Development of Delphi Round I Questionnaire

Helmer (1983) suggests that it may be necessary to begin a Delphi study with an openended question designed to help define and identify potential subject matter to be included in subsequent questionnaires. The first round questionnaire for this study consisted of one open ended question asking panelists to provide possible delivery modes that might be developed over the next ten years and teaching competencies required for the modes. The open-ended question was:

Reflecting on the anticipated future advancement of information technology, what course delivery modes will the teacher education faculty use in 2015? Please list all possible delivery modes that might be developed over the next ten years. Give the specific description of each mode and list teaching competencies required for the mode. Please feel free to expand the text box, if necessary. 
A sample answer was provided to clearly guide panel members in answering the question. Five text boxes were given and in each text box were three items to answer: (a) Name of Delivery Mode; (b) Description; and (c) Teaching Competencies (see Appendix E for a copy of the Delphi I instrument). The instrument was reviewed for content and face validity by a 3-member panel with expertise from the WVU Technology Education Department. Revisions concerning clarity of directions and layout of the Delphi I instrument were made as a result of the review.

\section{Administration of Delphi Round I}

The Delphi Round I packet was developed that contained the following items: (a) Delphi Round I invitation letter (Appendix B), (b) study overview to explain the purpose of the study (Appendix C), (c) study participation agreement form (Appendix D), and (d) Round I Questionnaire, including instructions (Appendix E). This initial document was submitted to the committee chair for review. Revisions were made as a result of the review. This Round I packet was sent out to the panel members as e-mail attachments. They were asked to return the questionnaire along with the signed study participation agreement form by e-mail within two weeks. Reminder e-mails were sent out to those panel members two weeks after the initial e-mail who had not yet responded.

\section{Development of Round II Questionnaire}

The Round II questionnaire was developed based on the open-ended responses participants provided in the first round. Two sets of information were generated: one for course delivery modes and their description, and the other for teaching competencies. Responses from the panel experts indicated 42 delivery modes and 167 competencies. The raw data collected from Round I were coded and analyzed, resulting in seven delivery modes and five competency categories. The Round II questionnaire condensed these responses from the first round into 
scalable statements. Combining similar statements resulted in seven delivery mode categories with 29 sub-modes and five competency categories with a total of 89 sub-competencies. The five competency categories grouped capabilities according to the type of instructional activity involved.

A web-based questionnaire consisting of two questions was designed by SimpleForms (https://webadmin.wvu.edu/SimpleForms) provided by the Web Admin of West Virginia University. The Round II Questionnaire was divided into two parts, presenting Delivery Modes first, followed by Competencies. For those two questions, panel members were asked to use a 7point Likert scale to rate their level of agreement on each statement, where 7 was highest agreement and 1 was the lowest. Radio buttons were used so that panel members could click a button representing the scale number that they selected. Comment fields (text boxes) were provided for members to type a justification for their rating. Each delivery mode, except Mode $\# 1$ and \#2, had sub-modes to differentiate instructional options. A brief explanation was added for each mode/sub-mode unless a mode was clearly self explanatory, as in the case of Mode \#3. These panelist responses were used to create the Round II questionnaire, which consisted of two structured questions: (a) Delivery Modes and (b) Teaching Competencies (see Appendix G for the MS Word version of the online (html) Round II Questionnaire). Panel members were asked to review all items identified by the first round, and to rate their agreement with them using a 7 point Likert-scale. Spaces were provided following each part so that respondents could add additional delivery modes and competencies. The first round was completed in four weeks.

\section{Administration of Delphi Round II}

The second round questionnaire was posted on a web page hosted by the Web Services of West Virginia University. The Delphi Round II packet contained the following items: 
(a) Delphi Round II invitation e-mail (see Appendix G for a copy of e-mail invitation) and (b) a link to the web site where the Round II Questionnaire was posted. Panel members were notified through e-mail regarding the second round questionnaire and given a unique password enabling them to access and respond to the instrument on the web. When a participant completed the questionnaire, the researcher received a notification e-mail listing all the responses from the Web Services server. The second round was completed in six weeks following the initial e-mail. Development of Round III Questionnaire

The purpose of Round III was to develop consensus among panel members. To measure consensus, interquartile range (IQR) and frequency were used. The median was used to determine the level of agreement and disagreement. Those statements that received high median and low IQR (Median $\geq 5 ; \mathrm{IQR} \leq 1.5$ ) were kept for the final list. In the Round III questionnaire, only the delivery modes and competencies that did not reach consensus in Round II were included. The third round questionnaire was developed in PDF format using Adobe Acrobat Professional 7.0. This version of Acrobat was necessary in order to provide a questionnaire that would afford the panelists electronic commenting and could present the result of Round II in the fewest number of pages. The PDF format was the easiest method for the panel members to respond electronically directly on the instrument. The instrument indicated the ratings of the individual panel member to each item in Round II. In this format each panelist was able to see how others rated each item on the scale and was reminded of his or her own rating relative to the group. Panel members were asked to re-rate or confirm their original rating of each item. In addition, participants were provided with the statistical analysis results for Round II: (a) median, mode and the frequency of response on each item, (b) individual panel ratings for each item from Round II, and (c) comments made by each participant. This passive persuasive feedback process 
made the Delphi panelists aware of the range of opinions and the reasons underlying those opinions. This also enabled participants to see where their response stands in relation to that of the group.

\section{Administration of Delphi Round III}

Panel members were sent e-mails with the individually customized PDF instrument attached and asked to re-rate each statement retained from the second round using a 7-point Likert scale. As the instrument required using Adobe Acrobat commenting tools, a few challenges were expected for the participants. Therefore, instructions for completing the questionnaire were provided on the first page of the PDF document (see Appendix $\mathrm{H}$ for a copy of Round III Questionnaire). Also provided in the Round III invitation e-mail was a link to download Adobe Reader 7 for the participants who did not have the version installed on their computer. The third round was completed in three weeks.

\section{Method of Data Analysis}

In a Delphi study, panelists are confronted with the results after each round, until consensus or stability of results is reached. Before starting the Delphi study, stability was defined as occurring when there was minimal or no further shifting of panel responses from round to round. As a criterion of stability for median scores, a shift of 15 percent or less (a shift of one on a scale of one to seven) after successive rounds was chosen. Data Analysis for this Delphi study had two purposes: (a) to provide feedback between rounds for respondents and (b) to identify when consensus or stability had been reached. Data collected using Likert-type scales were treated as interval data calculating the median and the IQR due to its widespread use in group response studies (Murphy, 2002). Nominal data were reported using frequencies and percentages. Central tendencies (the frequency, mean, median, and mode) and level of dispersion (standard 
deviation and the IQR) were calculated. The IQR is defined as the absolute value of the difference between the 25th and the 75th quartiles, with smaller values indicating higher degrees of consensus. The IQR was understood as a representation of the amount of disagreement within the panel. If the IQR is low, then the panel is in agreement and the converse is also true. If the IQR is high, the panel is in disagreement. Due to the small group size of this study, the median was chosen to identify the central tendency of the responses for each item. In other words, the median indicated the level of agreement at which half of the responses fell above and half fell below. The median was understood to represent group opinion.

The approach to measuring consensus is the least-developed component of the Delphi method (Crisp, Pelletier, Duffield, Adams, \& Nagy, 1997), and it varies from study to study. Frequency distributions are often used to assess agreement (McKenna, 1994), and the criterion of at least $51 \%$ responding to any given response category is used to determine consensus (McKenna, 1989). In one study using yes-no response categories, the criterion for agreement was $67 \%$ of participants giving the same response (Alexandrov, Pullicino, Meslin, \& Norris, 1996). Others (Williams, 2000) use IQR to determine consensus. Wells (1992) used Q-values (same as IQR) to determine consensus and the $25^{\text {th }}$ percentile to determine the cut-off point of acceptance. Consensus used in his study, is defined as those items, rated on an eleven point scale, having Qvalues larger than 4.00. Raskin (1994) identified an IQR of 1.00 or less as an indicator of consensus. However, the potential range of IQR values depends on the number of response choices, with larger IQRs expected as the number of response choices increases (Hahn \& Rayens, 2000). Thus, the use of a particular IQR as a cutoff for consensus requires consideration of the number of response choices, with larger IQRs expected as the number of response choices increase. 
For this study, the IQR and frequency were used to determine consensus, and the median was used to determine the central tendency, the level of agreement and disagreement. Specifically, the first criterion used in the process was an IQR $\leq 1.5$ to indicate consensus among panel responses to each statement. The second criterion used to establish consensus was a frequency of $70 \%$. Because the IQR criterion lacked sensitivity in distinguishing degree of agreement for items with $\mathrm{IQR} \leq 2.5$, this additional criterion for determining consensus for such items was developed. See Table 5 for a summary of dual criteria used in determining consensus and the level of agreement and disagreement.

Table 5

Definition of Consensus

\begin{tabular}{|c|c|}
\hline Consensus & Definition \\
\hline \multirow[t]{2}{*}{ Agree (A) } & If the median $\geq 5$, and $\mathrm{IQR} \leq 1.5$ \\
\hline & If the median $\geq 5, \mathrm{IQR} \leq 2.5$, and frequency, $5-7 \geq 70 \%$ \\
\hline \multirow[t]{2}{*}{ Disagree (D) } & If the median $\leq 3$, and $\mathrm{IQR} \leq 1.5$ \\
\hline & If the median $\leq 3$, and IQR $\leq 2.5$, and frequency, $1-3 \geq 70 \%$ \\
\hline Neutral (N) & If the median $=4, \mathrm{IQR} \leq 2.5$ \\
\hline
\end{tabular}

For example, items with IQR $\leq 1.5$ and a median rating of 5, 6, or 7 were considered to be in consensus for agreement. Items with IQR $\leq 1.5$ and a median rating of 1,2 , or 3 were considered to be in consensus for disagreement. Items with IQR $\leq 2.5$ and with more than $70 \%$ of respondents rating 5, 6 or 7 were considered to be in consensus for agreement. Items with IQR $\leq$ 2.5 and with more than $70 \%$ of respondents rating 1,2 , or 3 were considered to be in consensus for disagreement. Items with the median of 4 and $\mathrm{IQR} \leq 2.5$ was considered to be in consensus for neutral. This analysis strategy is similar to that developed by Alexandrov et al. (1996), who used a cutoff of $67 \%$ in one of two categories (e.g., yes-no) to designate consensus. 


\section{CHAPTER IV: RESULTS}

This chapter presents the results of Delphi Round I, Round II, and Round III. Statistical data are provided in order to identify the possible course delivery methods and teaching competencies needed by teacher education faculty for teaching environments in the year 2015 .

\section{Delphi Respondents}

The total percentage of questionnaires returned during the first round was $81 \%$, during the second $100 \%$, and during the third $88 \%$. Out of the 21 individuals who expressed their willingness to participate in the study, 17 responded to the first round by signing the study participation agreement form and also completing Round I Questionnaire. After the panelist received the first round instrument, four members ( 2 from ATE and 2 from TESOL) withdrew from the study due to time constraints. The resultant 17 member panel of educational experts was comprised of 12 females and 5 males from 11 different organizations. Of these 17 panelists who completed Round I Questionnaire, 17 completed the second round (100\% response rate). Of these 17 panelists, 15 completed the third round of this study resulting in a response rate of $88 \%$. It was noted that participants from educational technology organizations $(100 \%)$ showed strong participation rate than general teacher education organizations (25\%) throughout the study. Table 6 summarizes the number of participants by organization for each round. 
Table 6

Number of Delphi Respondents by Organizations for Each Round

\begin{tabular}{|c|c|c|c|c|}
\hline \multirow{2}{*}{ Organizations } & \multicolumn{4}{|c|}{ Number of Respondents } \\
\hline & $\begin{array}{c}\text { Initial } \\
(n=21)\end{array}$ & $\begin{array}{l}\text { Round I } \\
(n=17)\end{array}$ & $\begin{array}{c}\text { Round II } \\
(n=17)\end{array}$ & $\begin{array}{c}\text { Round III } \\
(n=15)\end{array}$ \\
\hline Teacher Education Organizations & 4 & 2 & 2 & 1 \\
\hline AACTE & 1 & 1 & 1 & 1 \\
\hline ATE & 3 & 1 & 1 & \\
\hline Subject Specific-Organizations & 7 & 5 & 5 & 4 \\
\hline ACTFL & 1 & 1 & 1 & 1 \\
\hline AAHPERD & 1 & 1 & 1 & 1 \\
\hline NCTM & 3 & 3 & 3 & 2 \\
\hline TESOL & 2 & & & \\
\hline Educational Technology Organizations & 5 & 5 & 5 & 5 \\
\hline AECT & 3 & 3 & 3 & 3 \\
\hline ISTE & 2 & 2 & 2 & 2 \\
\hline Policymaker Organizations & 1 & 1 & 1 & 1 \\
\hline$* \mathrm{DOE}$ & 1 & 1 & 1 & 1 \\
\hline Other Educational Organizations & 4 & 4 & 4 & 4 \\
\hline *APA & 1 & 1 & 1 & 1 \\
\hline *AACE & 2 & 2 & 2 & 2 \\
\hline *AAHE & 1 & 1 & 1 & 1 \\
\hline
\end{tabular}




\section{Round I Data Analysis}

Out of 21 individuals who expressed their willingness to participate in the study, 17 responded to the first round by signing the study participation agreement form and also completing Round I Questionnaire. After the panelists received the first round instrument, four members withdrew from the study due to the time constraints. The Round I response rate was $81 \%$ with 42 delivery modes and 167 competency statements collected from the 17 panel experts. Content analysis (Mayring, 2000) was used as the qualitative method to determine the categories from the Round I Delphi Questionnaire. All the statements collected from the first round were analyzed by coding and grouping of similar items. The process yielded a Round II survey containing 29 delivery modes grouped in seven categories and 89 teaching competencies grouped in five categories.

\section{Round I Delivery Modes}

The Round I raw data was collapsed and categorized through a color coding scheme (see Appendix F for color coding of delivery mode and its description). These descriptions and grouping systems needed to be verified to ensure that the data were fairly represented. To reach consensus about how the raw data could best be reduced to a set of manageable delivery modes and teaching competencies, the researcher crafted a table and had one co-rater respond to the proposed coding. The coding method was used by a similar qualitative analysis of open-ended questions in Mayring's study. From the co-rating, the researcher searched for commonalties, and consequently produced a Matrix where the 42 delivery modes were collapsed to 7, with instructional options (text, audio, video, etc) noted for each. To craft the Round II instrument, the Round I raw data were collapsed and reduced into a smaller set of logical categories. Common categories of delivery modes were recognized based on the "descriptions" and "competencies" 
provided by the participants for each mode. The delivery mode suggested by participants could be understood better by looking for key terms and/or phrases in the description and competencies given for each. For example, "Multi-media presentation" might have been categorized as "Standalone computer presentation." However, the terms in the Teaching Competencies alluded to "online, asynchronous" instruction. Therefore, this translated into a Web-Asynchronous category of course delivery. Some of the terms and phrases basically referred to the same thing and could, therefore, be placed into a single mode. For example, Online Methods Courses, Real time, Interactive Multimedia Learning Components and Individualized Computer-delivered courses spoke to the same delivery mode, Web-Synchronous. Sixteen delivery modes were identified from 42 participant responses:

1. Synch/Asynch Web-based Multi-Modal

2. DVI (one-to-one and one-to-many)

3. Satellite/F2F Combo

4. Asynch Web-based Multi-Modal

5. Synch Web/Text-Based

6. Traditional F2F

7. Avatar Based VR - unstructured/self-guided

8. Avatar Based VR - instructor led

9. Avatar Based VR - community led

10. Web-Based Multi-Modal: Course Management - Individual

11. Web-Based Multi-Modal: Course Management - Team Teach

12. Weblog - asynchronous

13. Video resource/database - asynchronous

14. Asynch/Synch Web-based Multi-Modal Team Teach

15. Synch Web-based Multiple Media (audio/text)

16. Asynch Web-based Multiple Media (audio/video/text)

Many spoke to similar or combinations of the same modes, and they could, therefore, be collapsed into seven delivery mode categories. Table 7 shows how the matrix was derived from this procedure. 
Table 7

Delivery Mode and Instructional Options Matrix Generated from Round I Delivery Mode Instructional Options

1) $\mathrm{F} 2 \mathrm{~F}$

2) F2F + Satellite Combo

3) F2F + Web Combo

4) Web - Asynchronous

5) Web - Synchronous

6) Web - Asynch/Synch Combo

7) Virtual Reality (Web and TV) $\underline{\text { Text }}$

Hypertext documents

Discussion boards

Weblogs

Listserv

$\underline{\text { Audio }}$

Recordings

Voice email

Sounds

Etc.

$\underline{\text { Video }}$

Clips

Etc.

Digital Text Interactive

Chat

Digital Audio Interactive

Web Phone

Etc.

Digital Video Interactive

Streaming (one-to-one and one-to-many)

Desktop (one-to-one and one-to-many)

Etc.

Digital Interactive Combos

Text

Audio

Video

Avatar Gaming

Self-Guided unstructured

Instructor Led

Community Led 


\section{Round I Teaching Competencies}

The number of statements for teaching competencies collected from the first round was 167. Some of them were repetitive and overlapped with each other. To reduce the raw data to a set of manageable teaching competencies, similar competency statements were put together into one statement resulting in a final list of 89 competencies. Then, key terms were color-coded in each competency statement. Five general competency areas surfaced from the key terms collected. The collapsed 89 statements were grouped into five categories based on the identified knowledge area: (a) Planning and Designing Learning Environment (12 competencies), (b) Teaching and Learning (36 competencies), (c) Technology (29 competencies), (d) Assessment and Evaluation (6 competencies), and (e) Cultural Ethical Issues (6 competencies). Thirty-six statements fell in the teaching and learning category, the largest category compared to all others.

\section{Round II Data Analysis}

The quantitative data were analyzed using the Statistical Package for the Social Sciences (SPSS) 11.0 for Windows. Previous studies have demonstrated a strong second round response rate for Delphi studies ranging from $80 \%$ to $95 \%$. In the current study, all 17 members of the panel who responded in Round I also responded to Round II (100\% response rate). Compared to other Delphi studies, the response rate of the Round II for this study was excellent. The second round questionnaire contained seven delivery mode categories with 29 sub-modes and five competency categories with a total of 89 sub-competencies. Participants were asked to rate each item on a scale of 1 to 7 for both delivery modes and competency statements. Responses from Round II were analyzed to determine if there was a consensus by looking at the median and an IQR for each item. The data were quantitatively analyzed using descriptive statistics such as medians and frequencies. 


\section{Round II Part 1: Delivery Modes}

The expert panel rated the delivery modes on a scale of 1 (strongly disagree) to 7

(strongly agree) based on how strongly they agree with each delivery mode and sub-mode. For calculating consensus, the score 1 was computed as "strongly disagree", 2 as "disagree", 3 as "somewhat disagree", 4 as "neutral", 5 as "somewhat agree", 6 as "agree", and 7 as "strongly agree". Using the data collected in Part I of the second round questionnaire (see Appendix G), the mean, median, and IQR for each of the delivery modes were computed. Results of the responses from round two are displayed in Table 8. Consensus was determined based on the median, IQR, and a 70\% frequency rate for a specific range within the 7-point scale (either 1-3 or 5-7). An IQR $\leq 1.5$ was used as the first criteria to determine consensus among panel responses to each delivery mode. Delivery modes with an $\mathrm{IQR} \leq 1.5$ and a median $\geq 5$ were considered a consensus reflecting agreement; i.e. is a delivery mode of the future. Delivery modes with an $\mathrm{IQR} \leq 1.5$ and a median $\leq 3$ were considered a consensus reflecting disagreement; i.e. not a delivery mode of the future.

Because the IQR method lacked sensitivity in distinguishing degree of agreement for items with $\mathrm{IQR} \leq 2.5$, an additional criterion for determining consensus for these items was developed. The additional criterion used to determine consensus was achieving a $70 \%$ frequency rate for a specific range within the 7-point scale (either 1-3 or 5-7). Items with an IQR $\leq 2.5$ and a frequency rate that was above $70 \%$ for respondents answering generally positive (a scale of of 5-7) or generally negative (a scale of 1-3) were considered to be in consensus. Items with an IQR $\leq 2.5$ and with a median of 4 were considered to be in consensus for neutral (uncertain).

Furthermore, items with an IQR of 2.0 or 2.5 and with more than $70 \%$ of respondents answering 5- 7 were also considered to have reached consensus on positive agreement. All items having 
reached consensus, positive or negative, were not included in the third round.

Table 8

Summary of Panel Ratings on Delivery Modes from Round II

\begin{tabular}{|c|c|c|c|c|c|c|c|c|c|c|c|c|c|c|c|c|}
\hline & \multicolumn{7}{|c|}{ Frequency } & \multirow{2}{*}{$M$} & \multirow{2}{*}{$M d n$} & \multirow{2}{*}{ Mode } & \multirow{2}{*}{$S D$} & \multirow{2}{*}{$I Q R$} & \multicolumn{3}{|c|}{ \% Frequency } & \multirow{2}{*}{ Consensus } \\
\hline & 1 & 2 & 3 & 4 & 5 & 6 & 7 & & & & & & $1-3$ & 4 & $5-7$ & \\
\hline M1 & & & & 1 & 2 & 7 & 7 & 6.18 & 6 & $7(a)$ & 0.883 & 1.0 & 0 & 5.9 & 94.1 & A \\
\hline M2 & & 6 & 2 & 3 & 2 & 2 & 2 & 3.88 & 4 & 2 & 1.833 & 3.5 & 47.1 & 17.6 & 35.3 & R3 \\
\hline M3.1 & & & 1 & 1 & 1 & 3 & 11 & 6.29 & 7 & 7 & 1.213 & 1.0 & 5.9 & 5.9 & 88.2 & A \\
\hline M3.2 & & 3 & 2 & 7 & 2 & 0 & 3 & 4.18 & 4 & 4 & 1.629 & 2.0 & 29.4 & 41.2 & 29.4 & R3 \\
\hline M3.3 & & & 5 & 1 & 8 & 0 & 3 & 4.71 & 5 & 5 & 1.404 & 2.0 & 29.4 & 5.9 & 64.7 & R3 \\
\hline M3.4 & & & 2 & 2 & 1 & 5 & 7 & 5.76 & 6 & 7 & 1.437 & 2.0 & 11.8 & 11.8 & 76.4 & A \\
\hline M3.5 & & 1 & 1 & 5 & 5 & 3 & 2 & 4.82 & 5 & $5(a)$ & 1.334 & 2.0 & 11.8 & 29.4 & 58.8 & R3 \\
\hline M3.6 & 2 & 0 & 6 & 1 & 4 & 2 & 2 & 4.12 & 4 & 3 & 1.833 & 2.5 & 47.1 & 5.9 & 47.0 & R3 \\
\hline M3.7 & 1 & 0 & 1 & 2 & 10 & 2 & 1 & 4.76 & 5 & 5 & 1.300 & 0.5 & 11.8 & 11.8 & 76.4 & A \\
\hline M3.8 & 1 & 0 & 1 & 0 & 5 & 5 & 5 & 5.53 & 6 & $7(a)$ & 1.586 & 2.0 & 11.8 & 0 & 88.2 & A \\
\hline M3.9 & 0 & 2 & 1 & 1 & 4 & 5 & 4 & 5.24 & 6 & 6 & 1.640 & 2.0 & 17.6 & 5.9 & 76.5 & A \\
\hline M3.10 & 0 & 2 & 1 & 4 & 5 & 2 & 3 & 4.76 & 5 & 5 & 1.562 & 2.0 & 17.6 & 23.5 & 58.9 & R3 \\
\hline M3.11 & 0 & 1 & 2 & 3 & 5 & 3 & 3 & 4.94 & 5 & 5 & 1.478 & 2.0 & 17.6 & 17.6 & 64.8 & R3 \\
\hline M3.12 & 0 & 1 & 1 & 1 & 2 & 4 & 8 & 5.82 & 6 & 7 & 1.551 & 2.0 & 11.8 & 5.9 & 82.3 & A \\
\hline M4.1 & 1 & 3 & 1 & 1 & 4 & 2 & 5 & 4.76 & 5 & 7 & 2.078 & 4.5 & 29.4 & 5.9 & 64.7 & R3 \\
\hline M4.2 & 4 & 6 & 4 & 1 & 0 & 1 & 1 & 2.59 & 2 & 2 & 1.583 & 1.5 & 82.4 & 5.9 & 11.7 & D \\
\hline M4.3 & 3 & 2 & 2 & 3 & 5 & 1 & 1 & 3.71 & 4 & 5 & 1.829 & 3.0 & 41.2 & 17.6 & 41.2 & R3 \\
\hline M4.4 & 1 & 1 & 1 & 0 & 2 & 6 & 6 & 5.53 & 6 & $7(a)$ & 1.841 & 2.0 & 17.6 & 0 & 82.4 & A \\
\hline M5.1 & 4 & 4 & 2 & 2 & 3 & 1 & 1 & 3.18 & 3 & $2(a)$ & 1.912 & 3.5 & 58.8 & 11.8 & 29.4 & R3 \\
\hline M5.2 & 6 & 4 & 4 & 0 & 1 & 1 & 1 & 2.59 & 2 & 1 & 1.839 & 2.0 & 82.4 & 0 & 17.6 & D \\
\hline M5.3 & 0 & 4 & 6 & 3 & 2 & 1 & 1 & 3.59 & 3 & 3 & 1.460 & 2.0 & 58.8 & 17.6 & 23.6 & D \\
\hline M5.4 & 0 & 3 & 0 & 1 & 6 & 4 & 3 & 5.00 & 5 & 5 & 1.658 & 1.5 & 17.6 & 5.9 & 76.5 & A \\
\hline M6.1 & 1 & 0 & 0 & 2 & 4 & 4 & 6 & 5.59 & 6 & 7 & 1.583 & 2.0 & 5.9 & 11.8 & 82.3 & A \\
\hline M6.2 & 4 & 2 & 5 & 2 & 2 & 0 & 2 & 3.24 & 3 & 3 & 1.921 & 3.0 & 64.7 & 11.8 & 23.5 & R3 \\
\hline M6.3 & 1 & 2 & 5 & 1 & 5 & 1 & 2 & 4.06 & 4 & $5(a)$ & 1.749 & 2.0 & 47.1 & 5.9 & 47.0 & R3 \\
\hline M6.4 & 1 & 0 & 1 & 0 & 2 & 4 & 9 & 5.94 & 7 & 7 & 1.676 & 1.5 & 11.8 & 0 & 88.2 & A \\
\hline M7.1 & 4 & 1 & 3 & 2 & 3 & 2 & 2 & 3.76 & 4 & 1 & 2.107 & 4.0 & 47.1 & 11.8 & 41.1 & \\
\hline M7.2 & 3 & 1 & 1 & 5 & 4 & 1 & 2 & 4.00 & 4 & 4 & 1.904 & 2.5 & 29.4 & 29.4 & 41.2 & R3 \\
\hline M7.3 & 3 & 1 & 1 & 5 & 4 & 2 & 1 & 3.94 & 4 & 4 & 1.819 & 2.5 & 29.4 & 29.4 & 41.2 & \\
\hline
\end{tabular}

Note. $N=17$. The higher IQR score, the wider range of panel ratings. *(a) When multiple modes exist, the greatest value is shown. A (Consensus for "Agree"), D (Consensus for "Disagree”), R3 (No consensus; Items for Round III). See Appendix G. Round II Questionnaire: Part I for the name of particular delivery mode. 
Out of the 29 delivery modes included in the second round, 13 (11 with positive agreement and 2 with negative agreement) demonstrated consensus using the dual criteria method previously outlined and were not included in the third round. As shown in Table 9, approximately $94 \%$ of the panel members agreed that traditional F2F would still be one of the course delivery methods in 10 years. F2F + Web-Asynchronous Text Supplement received the highest positive agreement out of all the delivery modes (median of 7; IQR of 1.0).

Some items with an IQR $\leq 2.5$ also were omitted from the Round III questionnaire because they achieved a $70 \%$ frequency rate for a specific range within the 7 -point scale (either 1-3 or 5-7). Other items with an IQR $\leq 2.5$ were included in the Round III questionnaire because there was considerable variability in the frequency distribution of responses among these items. For example, both Mode 3.3 and Mode 3.4 (see Appendix G for the name of particular delivery mode) did not make consensus from the IQR level (IQR $\leq 1.5)$. So the additional criteria, a $70 \%$ frequency rate for a specific range within the 7-point scale (either 1-3 or 5-7), was looked for those two delivery modes. When using the frequency criteria ( $\%$ Frequency, $5-7 \geq 70 \%$, Mode 3.4, F2F + Web-Asynchronous Text/Audio/Video Supplement (\% Frequency, 5-7 = 76.4\%) was considered to reflect consensus while Mode 3.3, F2F + Web-Asynchronous Video Supplement $(\%$ Frequency, $5-7=64.7 \%)$ was not. Therefore, Mode 3.3 was included in the Round III to further attempt to get consensus. 
Table 9

Delivery Modes Reached Consensus in Round II

\begin{tabular}{clcccc}
\hline \multicolumn{1}{c}{ Delivery Mode } & $M$ & $M d n$ & $I Q R$ & $\% f, 5-7$ \\
\hline Agreed & & & & & \\
M1 & Face-to-Face & 6.18 & 6 & 1.0 & 94.1 \\
M3.1 & F2F + Web-Asynchronous Text Supplement & 6.29 & 7 & 1.0 & 88.2 \\
M6.4 & Web-Asynchronous/Synchronous Text/Audio/Video & 5.94 & 7 & 1.5 & 88.2 \\
M3.8 & F2F + Web-Synchronous Text/Audio/Video Supplement & 5.53 & 6 & 2.0 & 88.2 \\
M4.4 & Web-Asynchronous Text/Audio/Video & 5.53 & 6 & 2.0 & 82.4 \\
M3.12 & F2F + Web-Asynch/Synch Text/Audio/Video Supplement & 5.82 & 6 & 2.0 & 82.3 \\
M6.1 & Web-Asynchronous/Synchronous Text & 5.59 & 6 & 2.0 & 82.3 \\
M3.9 & F2F + Web-Asynchronous/Synchronous Text Supplement & 5.24 & 6 & 2.0 & 76.5 \\
M5.4 & Web-Synchronous Text/Audio/Video & 5.00 & 5 & 1.5 & 76.5 \\
M3.4 & F2F + Web-Asynchronous Text/Audio/Video Supplement & 5.76 & 6 & 2.0 & 76.4 \\
M3.7 & F2F + Web-Synchronous Video Supplement & 4.76 & 5 & 0.5 & 76.4 \\
Disagreed & & & & & \\
M4.2 & Web-Asynchronous Audio & 2.59 & 2 & 1.5 & 11.7 \\
M5.2 & Web-Synchronous Audio & 2.59 & 2 & 2.0 & 17.6 \\
\hline
\end{tabular}

Note. $N=17$. The median cutoff used was 5 with the redefinition of Disagree $=1-3 ;$ Neutral $=4 ;$ Agree $=5-7$ (Strongly Disagree $=1$, Disagree $=2$, Somewhat Disagree $=3$, Neutral $=4$, Somewhat Agree $=5$, Agree $=6$, Strongly Agree $=7) . \% f, 5-7$ indicates the percentage of frequency for scores, 5-7.

Blended delivery mode (F2F + Web supplement) achieved consensus for positive agreement for most of its sub modes. A majority of the panelists did not agree Web-Synchronous Audio (median of 2; IQR 2.0) and Web-Asynchronous Audio (median of 2; IQR 1.5) being one of the course delivery methods used in higher education in 10 years. Approximately $80 \%$ of Round II respondents rated these two delivery modes within the 1-3 scale range. Neutral items (median of 4; IQR $\leq 1.5$ ) such as Virtual Reality mode were retained in the third round. The panel was uncertain about all three sub-modes (Self-Guided Virtual Reality, Instructor-Led Virtual Reality, and Community-Led Virtual Reality) of Virtual Reality being used by higher education faculty in 2015. More interestingly, those three sub-delivery modes all received the same median (4) and the frequency distribution looked almost identical. Therefore, they were merged into one (Mode 7 Virtual Reality) and included as such in the third round. 
As explained earlier, higher IQR scores indicate a large variation in panelist ratings.

High IQRs were noted in several delivery modes, including Web-Asynchronous Text (IQR 4.5), Self-Guided Virtual Reality (IQR 4.0), F2F + Satellite Combo (IQR 3.5), and Web-Synchronous Text (IQR 3.5), indicating a high degree of variance in agreement. These items also showed the greatest variance in frequency distribution. The higher IQR scores indicated the wider distribution of panel ratings. As a result, 14 delivery modes were retained for the third round:

- F2F + Satellite Combo

- F2F + Web-Asynchronous Audio

- F2F + Web-Asynchronous Video

- F2F + Web-Synchronous Text

- F2F + Web-Synchronous Audio

- F2F + Web-Asynchronous/Synchronous Audio

- F2F + Web-Asynchronous/Synchronous Video

- Web-Asynchronous Text

- Web-Asynchronous Video

- Web-Synchronous Text

- Web-Synchronous Video

- Web-Asynchronous/Synchronous Audio

- Web-Asynchronous/Synchronous Video

- Virtual Reality

Round II Panel Member Comments on Delivery Mode

An optional comment section was included in the Round II Questionnaire for panelists to provide a brief reason and/or justification of their rating for each major category of delivery modes. At the end of Part I of the questionnaire, panelists were asked to indicate any other delivery modes not listed that they felt should be. All the comments received from the panelists are compiled in Table 10. These comments were included in the third round instrument to bring out convergence of group opinion while seeking consensus. This passive persuasive feedback process made the Delphi panelists aware of the range of opinions and the reasons underlying those opinions. No additional delivery modes were suggested by the panelists in Round II. 
Table 10

Summary of Panel Member Comments on Delivery Mode from Round II

\begin{tabular}{|c|c|}
\hline Delivery Mode & Comment \\
\hline F2F & $\begin{array}{l}\text { Much of the social interaction of teacher training will likely still take } \\
\text { place F2F. } \\
\text { - I don't think this will go away entirely...rather it will be supplemented } \\
\text { by other things....and the face-to-face mode will still be present in } \\
\text { internships and field experiences, though that is not probably what you } \\
\text { meant. } \\
\text { - Although online learning will continue to grow, I think we will see a } \\
\text { more "blended model" that includes some face/face meetings. }\end{array}$ \\
\hline F2F + Satellite Combo & $\begin{array}{l}\text { - Satellite is older group technology. } \\
\text { - I think this one will turn out to be a dead end. } \\
\text { - Less expensive vehicles are available. }\end{array}$ \\
\hline F2F + Web Supplement & $\begin{array}{l}\text { - This had too many overlapping categories. They are non-discrete and } \\
\text { that causes response problems. } \\
\text { - I expect things to become increasingly asynchronous with the web...but } \\
\text { the web allows synchronous too so faculty will need to be familiar with } \\
\text { both environments. } \\
\text { - I'm not clear on whether these items are to be exclusive or if one is a } \\
\text { subset of the other...Also, I think these will vary greatly with the course } \\
\text { content - methods courses being very different than other courses. So, if } \\
\text { you are asking across a program if I think they will be used - yes. If you } \\
\text { want to know if I think all teacher education faculty will use these, then } \\
\text { no - I have rated based on how much I think they will get used across } \\
\text { the program. }\end{array}$ \\
\hline
\end{tabular}

Web-Asynchronous

- Asynchronous is appealing for freedom of schedule and will always have those willing to pay for that freedom.

- Asynchronous audio is as bad as a lecture except you can do it on your own...I expect text only will still have a strong presence, but the combination strategies will become more common.

- I make a distinction between synchronous, which might occur through iChat or through PolyCom or other interactive TV (and is therefore much easier to do) and asynchronous, in which the instructor has to go out of his/her way to create audio or video segments to put on the web. I do not see Ed. faculty doing the latter - it takes them out of their normal mode of operation.

- These categories as stated do not allow me to differentiate my reply because I foresee faculty using a variety or combination depending upon the purpose, time frame, and technology access. So in my opinion all have potential uses. It's more a matter of matching delivery modes to purpose and other access factors and learning outcomes. The survey appears limited to me in this regard as it is addressing delivery isolated from context and purpose. 
Table 10 (continued)

\begin{tabular}{|c|c|}
\hline Delivery Mode & Comment \\
\hline Web-Synchronous & $\begin{array}{l}\text { - There will likely always be demand for synchronous interactions. } \\
\text { - As above, but any solely synchronous approach is not taking advantage } \\
\text { of the web...there may be some of it, but I would not expect it to be } \\
\text { dominant. }\end{array}$ \\
\hline Web-Synch/Asynch & $\begin{array}{l}\text { - It is hard to imagine a future in which one needs to choose between } \\
\text { archiving text, audio, or video. Sideband transmissions should enable } \\
\text { simultaneous uses. } \\
\text { - There may well be some situations where some synchronicity would be } \\
\text { desirable within an overall asynchronous format...looking at a case study } \\
\text { at the same time. }\end{array}$ \\
\hline Virtual Reality & $\begin{array}{l}\text { - This stuff always sounds good. Maybe in } 10 \text { years. But right now the } \\
\text { problem is that there have to be "places" worth visiting and the visits } \\
\text { need to fit curricular demands. } \\
\text { - Yes, this is very attractive. } \\
\text { - This is definitely the mode of the future; just not sure we will be there in } \\
10 \text { years. May take longer. } \\
\text { - They'll never buy it. }\end{array}$ \\
\hline
\end{tabular}

\section{Round II Part 2: Teaching Competencies}

The expert panel rated the teaching competencies on a scale of 1 (not necessary) to 7

(essential) based on how strongly they perceived the need for each competency in the future delivery environment. Upon receipt of the completed Round II Delphi questionnaire, the mean, median, and IQR for each competency statement was computed. Scores of 1, 2 or 3 were interpreted as "Not Necessary," 4 as "Neutral," and scores of 5, 6 or 7 as "Essential." To reach consensus that a certain kind of competency would be required by college faculty in the next ten years, the competency had to receive a median rating of 5, 6 or 7 and an IQR of 1.5 or less. Furthermore, items with an IQR of 2.0 or 2.5 and with more than $70 \%$ of respondents answering 5,6 , or 7 were also considered to have reached consensus. Therefore, items meeting these consensus criteria were not included in the third round. Neutral items were retained in the third round to further attempt to get consensus for either positive or negative agreement. Out of 89 
competency items included in the second round, 66 demonstrated consensus $(74.2 \%$; 64 for agree; 2 for neutral).A total of 64 competencies that reached consensus for positive agreement were not included in the third round. A total of 25 competency statements that did not reach consensus, as well as those that were viewed as neutral were included in the Round III Questionnaire (see Appendix H).

Some competency categories had more items that reached consensus than other ones. For example, out of 12 competency statements in the Planning and Designing Learning Environment category (see Appendix G for the list of competency statements), 11 competencies reached consensus on being essential teaching competencies of teacher education faculty in 2015 . As shown in Table 11, all 17 panelists (100\%) agreed that competency 1.1, "Basic instructional design skills in planning teaching and learning materials/activities," competency 1.6, "Design of appropriate learning activities and instructional materials based on students' ability," and competency 1.10, "Selecting lessons and content matched to a delivery method" would be essential competencies for teacher education faculty in 2015. Competency 1.9, "Evaluation of computer software for educational purposes," was the only one that did not reach consensus as essential for the future. According to the comment made by one panelist, it was assumed that the ambiguity of the term, computer software caused a wide distribution of responses for this item. The panelist mentioned, "1.9 computer software may be ambiguous term here. I read it to mean CD-ROM based resource. Evaluation of web sites that provide software is essential." There were a few other similar comments to show some people would have understood computer software as CD-ROM and others as online application. 
Table 11

Summary of Panel Ratings on Competency Category 1: Planning and Designing Learning Environment from Round II

\begin{tabular}{|c|c|c|c|c|c|c|c|c|c|c|c|c|c|c|c|c|}
\hline & \multicolumn{7}{|c|}{ Frequency } & \multirow{2}{*}{$M$} & \multirow{2}{*}{$M d n$} & \multirow{2}{*}{ Mode } & \multirow{2}{*}{$S D$} & \multirow{2}{*}{$I Q R$} & \multicolumn{3}{|c|}{$\%$ Frequency } & \multirow{2}{*}{ Consensus } \\
\hline & 1 & 2 & 3 & 4 & 5 & 6 & 7 & & & & & & $1-3$ & 4 & $5-7$ & \\
\hline $\mathrm{C} 1.1$ & 0 & 0 & 0 & 0 & 1 & 1 & 15 & 6.82 & 7 & 7 & 0.561 & 0.5 & 0 & 0 & 100 & A \\
\hline $\mathrm{C} 1.2$ & 0 & 0 & 1 & 0 & 2 & 7 & 7 & 6.12 & 6 & $7(a)$ & 1.054 & 1.0 & 5.9 & 0 & 94.1 & A \\
\hline $\mathrm{C} 1.3$ & 0 & 0 & 1 & 0 & 5 & 5 & 6 & 5.88 & 6 & 7 & 1.111 & 2.0 & 5.9 & 0 & 94.1 & A \\
\hline $\mathrm{C} 1.4$ & & & 1 & 0 & 1 & 6 & 9 & 6.29 & 7 & 7 & 1.047 & 1.0 & 5.9 & 0 & 94.1 & A \\
\hline $\mathrm{C} 1.5$ & & & 3 & 0 & 2 & 8 & 4 & 5.59 & 6 & 6 & 1.372 & 1.5 & 17.6 & 0 & 82.4 & A \\
\hline C1.6 & & & & & 2 & 2 & 13 & 6.65 & 7 & 7 & 0.702 & 1.5 & 0 & 0 & 100 & A \\
\hline $\mathrm{C} 1.7$ & & & 1 & 0 & 0 & 2 & 14 & 6.65 & 7 & 7 & 0.996 & 0 & 5.9 & 0 & 94.1 & A \\
\hline C1.8 & & & & 1 & 4 & 2 & 10 & 6.24 & 7 & 7 & 1.033 & 2.0 & 0 & 5.9 & 94.1 & A \\
\hline C1.9 & & & 2 & 3 & 4 & 2 & 6 & 5.41 & 5 & 7 & 1.460 & 3.0 & 11.8 & 17.6 & 70.6 & R3 \\
\hline $\mathrm{C} 1.10$ & & & & & 2 & 0 & 15 & 6.76 & 7 & 7 & 0.664 & 0 & 0 & 0 & 100 & A \\
\hline C1.11 & & 1 & 1 & 0 & 4 & 4 & 7 & 5.76 & 6 & 7 & 1.480 & 2.0 & 11.8 & 0 & 88.2 & A \\
\hline $\mathrm{C} 1.12$ & & & & 1 & 1 & 2 & 13 & 6.59 & 7 & 7 & 0.870 & 0.5 & 0 & 5.9 & 94.1 & $\mathrm{~A}$ \\
\hline
\end{tabular}

Note. $N=17$. *(a) When multiple modes exist, the greatest value is shown. The median cutoff used was 5 with the redefinition of Disagree = 1-3; Neutral = 4; Agree = 5-7. A (Consensus for "Agree"), D (Consensus for "Disagree"), R3 (No consensus; Items for Round III). See Appendix G. Round II Questionnaire: Part II, Category 2 for competency statements.

Thirty-six statements were included in the Teaching and Learning category (See Appendix G, Part II, Category 2), the largest number compared to other categories. Consensus was reached for positive agreement on $27(76 \%)$ of these statements. The panel judged 14 items to be most essential (median rating of 7). Of the remaining 13 items, the panel considered eight essential (median rating of 6) and five as moderately essential (median rating of 5). Nine competency statements that did not reach consensus were included in the third round. Table 12 summarizes the analysis of data received on all 36 competency statements. Two items that showed the greatest frequencies were "Providing a different context to ensure that the learners apply the newly gained knowledge in Virtual Reality (median rating of 3; IQR of 4.0)" and "Monitoring and structuring student learning in virtual environment (median rating of 6; IQR of 4.0)." The higher IQR scores indicated the wider distribution of panel ratings. 
Table 12

Summary of Panel Ratings on Competency Category 2: Teaching and Learning from Round II

\begin{tabular}{|c|c|c|c|c|c|c|c|c|c|c|c|c|c|c|c|c|}
\hline & \multicolumn{7}{|c|}{ Frequency } & \multirow{2}{*}{$M$} & \multirow{2}{*}{$M d n$} & \multirow{2}{*}{ Mode } & \multirow{2}{*}{$S D$} & \multirow{2}{*}{$I Q R$} & \multicolumn{3}{|c|}{$\%$ Frequency } & \multirow{2}{*}{ Consensus } \\
\hline & 1 & 2 & 3 & 4 & 5 & 6 & 7 & & & & & & $1-3$ & 4 & $5-7$ & \\
\hline $\mathrm{C} 2.1$ & & & 1 & 1 & 3 & 2 & 10 & 6.12 & 7 & 7 & 1.269 & 2.0 & 5.9 & 11.8 & 82.3 & A \\
\hline $\mathrm{C} 2.2$ & & & & & 1 & 2 & 14 & 6.76 & 7 & 7 & 0.562 & 0 & 0 & 0 & 100 & A \\
\hline $\mathrm{C} 2.3$ & & 1 & 0 & 3 & 6 & 4 & 3 & 5.24 & 5 & 5 & 1.300 & 1.5 & 5.9 & 17.6 & 76.5 & A \\
\hline $\mathrm{C} 2.4$ & & & & 1 & 3 & 3 & 10 & 6.29 & 7 & 7 & 0.985 & 1.5 & 0 & 5.9 & 94.1 & A \\
\hline $\mathrm{C} 2.5$ & & & & & 2 & 2 & 13 & 6.65 & 7 & 7 & 0.702 & 0.5 & 0 & 0 & 100 & A \\
\hline $\mathrm{C} 2.6$ & 1 & 0 & 2 & 1 & 2 & 6 & 5 & 5.41 & 6 & 6 & 1.734 & 2.5 & 17.6 & 5.9 & 76.5 & A \\
\hline $\mathrm{C} 2.7$ & 1 & & & & 2 & 8 & 6 & 5.94 & 6 & 6 & 1.435 & 1.0 & 5.9 & 0 & 94.1 & A \\
\hline $\mathrm{C} 2.8$ & 1 & & 1 & & 2 & 5 & 8 & 5.88 & 6 & 7 & 1.654 & 1.5 & 11.8 & 0 & 88.2 & A \\
\hline C2.9 & & & 1 & & & 6 & 10 & 6.41 & 7 & 7 & 1.004 & 1.0 & 5.9 & 0 & 94.1 & A \\
\hline $\mathrm{C} 2.10$ & & 2 & 1 & 1 & 8 & 2 & 3 & 4.94 & 5 & 5 & 1.519 & 1.5 & 17.6 & 5.9 & 76.5 & A \\
\hline $\mathrm{C} 2.11$ & & & 2 & 5 & 3 & 3 & 4 & 5.12 & 5 & 4 & 1.409 & 2.5 & 11.8 & 29.4 & 58.8 & R3 \\
\hline $\mathrm{C} 2.12$ & & & & 2 & 6 & 3 & 6 & 5.76 & 6 & 7(a) & 1.091 & 2.0 & 0 & 11.8 & 88.2 & A \\
\hline $\mathrm{C} 2.13$ & & & & 1 & 7 & 4 & 5 & 5.76 & 6 & 5 & 0.970 & 2.0 & 0 & 5.9 & 94.1 & A \\
\hline $\mathrm{C} 2.14$ & & 2 & 1 & 4 & 2 & 6 & 2 & 4.88 & 5 & 6 & 1.576 & 2.0 & 17.6 & 23.5 & 58.9 & R3 \\
\hline $\mathrm{C} 2.15$ & & 2 & 3 & 4 & 2 & 3 & 3 & 4.59 & 4 & 4 & 1.698 & 3.0 & 29.4 & 23.5 & 47.1 & R3 \\
\hline $\mathrm{C} 2.16$ & & 1 & & 1 & 2 & 3 & 10 & 6.12 & 7 & 7 & 1.409 & 1.5 & 5.9 & 5.9 & 88.2 & A \\
\hline C2.17 & & 3 & 2 & 2 & 1 & 3 & 6 & 5.00 & 6 & 7 & 2.000 & 4.0 & 29.4 & 11.8 & 58.8 & $\mathrm{R} 3$ \\
\hline C2.18 & & & & 1 & & 2 & 14 & 6.71 & 7 & 7 & 0.772 & 0 & 0 & 5.9 & 94.1 & A \\
\hline C2.19 & & & 1 & 4 & 6 & 5 & 1 & 5.06 & 5 & 5 & 1.029 & 2.0 & 5.9 & 23.5 & 70.6 & A \\
\hline C2.20 & & 2 & 3 & 2 & 5 & 3 & 2 & 4.59 & 5 & 5 & 1.583 & 3.0 & 29.4 & 11.8 & 58.8 & $\mathrm{R} 3$ \\
\hline C2.21 & & & & 3 & 1 & 4 & 9 & 6.12 & 7 & 7 & 1.166 & 1.5 & 0 & 17.6 & 82.4 & A \\
\hline C2.22 & & & & & 4 & 4 & 9 & 6.29 & 7 & 7 & 0.849 & 1.5 & 0 & 0 & 100 & A \\
\hline $\mathrm{C} 2.23$ & 1 & 6 & 2 & 1 & 1 & 4 & 2 & 3.88 & 3 & 2 & 2.088 & 4.0 & 52.9 & 5.9 & 41.2 & $\mathrm{R} 3$ \\
\hline C2.24 & & & & & & 1 & 16 & 6.88 & 7 & 7 & 0.485 & 0 & 0 & 0 & 100 & A \\
\hline C2.25 & & & 1 & 3 & 7 & 4 & 2 & 5.18 & 5 & 5 & 1.074 & 1.5 & 5.9 & 17.6 & 76.5 & A \\
\hline C2.26 & 3 & & 1 & 1 & 4 & 5 & 3 & 4.76 & 5 & 6 & 2.078 & 2.5 & 23.5 & 5.9 & 70.6 & A \\
\hline C2.27 & 1 & 1 & & & 4 & 4 & 7 & 5.65 & 6 & 7 & 1.766 & 2.0 & 11.8 & 0 & 88.2 & A \\
\hline C2.28 & & & & & & 4 & 13 & 6.53 & 7 & 7 & 0.874 & 1.0 & 0 & 0 & 100 & A \\
\hline C2.29 & & & & & 2 & 2 & 13 & 6.65 & 7 & 7 & 0.702 & 0.5 & 0 & 0 & 100 & A \\
\hline C2.30 & 1 & & & 3 & 5 & 2 & 6 & 5.41 & 5 & 7 & 1.622 & 2.5 & 5.9 & 17.6 & 76.5 & A \\
\hline $\mathrm{C} 2.31$ & 2 & 3 & 2 & 1 & 6 & 2 & 1 & 3.94 & 5 & 5 & 1.853 & 3.0 & 41.2 & 5.9 & 52.9 & R3 \\
\hline $\mathrm{C} 2.32$ & 2 & 1 & 2 & 2 & 4 & 5 & 1 & 4.41 & 5 & 6 & 1.839 & 3.0 & 29.4 & 11.8 & 58.8 & $\mathrm{R} 3$ \\
\hline C2.33 & & 1 & & & 4 & 6 & 6 & 5.88 & 6 & 7(a) & 1.269 & 2.0 & 5.9 & 0 & 94.1 & A \\
\hline $\mathrm{C} 2.34$ & & 2 & 1 & 4 & 4 & 2 & 4 & 4.88 & 5 & 7(a) & 1.654 & 2.5 & 17.6 & 23.5 & 58.9 & R3 \\
\hline $\mathrm{C} 2.35$ & & & & & & 1 & 16 & 6.94 & 7 & 7 & 0.243 & 0 & 0 & 0 & 100 & A \\
\hline C2.36 & & & & & 1 & 4 & 12 & 6.65 & 7 & 7 & 0.606 & 1.0 & 0 & 0 & 100 & A \\
\hline
\end{tabular}

Note. $N=17$. The higher IQR score, the wider range of panel ratings. *(a) When multiple modes exist, the greatest value is shown. A (Consensus for "Agree"), D (Consensus for "Disagree"), R3 (No consensus; Items for Round III) 
The category with the fewest number of competency statements reaching consensus from the second round was "Category 3: Technology." Only 16 out of 29 competencies (55\%) reached consensus for positive agreement (See Table 13). The panel judged 6 items to be most essential (median rating of 7). Of the remaining 10 items, the panel considered 7 essential (median rating of 6) and 3 as moderately essential (median rating of 5). Two competency statements reached consensus with the median of 4, which was defined as "Neutral." These two items were included in Round III to further attempt to get consensus for either positive or negative agreement. As a result, a total of 13 (45\%) competency statements from this category were included in the third round. The competency statement receiving the smallest IQR and the highest median indicating the highest degree of consensus was "Using the Internet effectively" (median rating of 7; IQR of 0). The items with higher IQR indicating lower degrees of consensus were "Identifying and analyzing technical issues resulted from equipment malfunction or operator errors" (IQR 3.5) and "Using hypertext to navigate materials in a manner suited to the learner's own learning style" (IQR 3.5). The comments shown in Table 16 provide good explanation for why the competency statements related to technical skills were rated as not essential by most panel members. Some panelists rated these technology items low because they presumed heightened presence of technical support through instructional technology centers.

For "Category 4: Assessment and Evaluation," all six competency statements (100\%) reached consensus on their being essential for future teacher education faculty. See Table 14 for a summary of the statistical analysis. 
Table 13

Summary of Panel Ratings on Competency Category 3: Technology from Round II

\begin{tabular}{|c|c|c|c|c|c|c|c|c|c|c|c|c|c|c|c|c|}
\hline & \multicolumn{7}{|c|}{ Frequency } & \multirow{2}{*}{$M$} & \multirow{2}{*}{$M d n$} & \multirow{2}{*}{ Mode } & \multirow{2}{*}{$S D$} & \multirow{2}{*}{$I Q R$} & \multicolumn{3}{|c|}{ \% Frequency } & \multirow{2}{*}{ Consensus } \\
\hline & 1 & 2 & 3 & 4 & 5 & 6 & 7 & & & & & & $1-3$ & 4 & $5-7$ & \\
\hline C3.1 & & & & & 5 & 4 & 8 & 6.18 & 6 & 7 & 0.883 & 2.0 & 0 & 0 & 100 & A \\
\hline $\mathrm{C} 3.2$ & & & & 1 & 4 & 3 & 9 & 6.18 & 7 & 7 & 1.015 & 2.0 & 0 & 4.9 & 95.1 & A \\
\hline $\mathrm{C} 3.3$ & & 1 & 0 & 3 & 4 & 7 & 2 & 5.29 & 6 & 6 & 1.263 & 1.5 & 5.9 & 17.6 & 76.5 & A \\
\hline C 3.4 & & & 1 & 7 & 3 & 2 & 4 & 5.06 & 5 & 4 & 1.345 & 2.5 & 5.9 & 41.2 & 52.9 & R3 \\
\hline $\mathrm{C} 3.5$ & 1 & & 1 & 6 & 6 & 2 & 1 & 4.53 & 5 & $5(\mathrm{a})$ & 1.328 & 1.0 & 11.8 & 35.3 & 52.9 & A \\
\hline $\mathrm{C} 3.6$ & 3 & 4 & 2 & 4 & 2 & 1 & 1 & 3.29 & 3 & 4(a) & 1.795 & 2.5 & 52.9 & 23.5 & 23.6 & R3 \\
\hline $\mathrm{C} 3.7$ & 1 & 5 & 1 & 3 & 3 & 2 & 2 & 3.94 & 4 & 2 & 1.919 & 3.5 & 41.2 & 17.6 & 41.2 & R3 \\
\hline $\mathrm{C} 3.8$ & & & 2 & 2 & 3 & 2 & 8 & 5.71 & 6 & 7 & 1.490 & 2.5 & 11.8 & 11.8 & 76.4 & A \\
\hline C3.9 & & 1 & 2 & 6 & 3 & 2 & 3 & 4.71 & 4 & 4 & 1.490 & 2.0 & 17.6 & 35.3 & 47.1 & R3 \\
\hline C3.10 & & 1 & 1 & 4 & 5 & 3 & 3 & 5.00 & 5 & 5 & 1.414 & 2.0 & 11.8 & 23.5 & 64.7 & R3 \\
\hline C3.11 & & 1 & & 2 & 2 & 9 & 3 & 5.59 & 6 & 6 & 1.278 & 1.0 & 5.9 & 11.8 & 82.3 & A \\
\hline C3.12 & & 1 & 2 & 8 & 3 & 1 & 2 & 4.41 & 4 & 4 & 1.326 & 1.0 & 17.6 & 47.1 & 35.3 & *R3 (N) \\
\hline C3.13 & & 1 & 2 & 3 & 1 & 1 & 9 & 5.53 & 7 & 7 & 1.807 & 3.0 & 17.6 & 17.6 & 64.8 & R3 \\
\hline C3.14 & 1 & 1 & 2 & 3 & 4 & 3 & 3 & 4.71 & 5 & 5 & 1.759 & 2.5 & 23.5 & 17.6 & 58.9 & R3 \\
\hline C3.15 & 1 & 1 & 2 & 4 & 4 & 2 & 3 & 4.59 & 5 & $5(\mathrm{a})$ & 1.734 & 2.5 & 23.5 & 23.5 & 53.0 & R3 \\
\hline C3.16 & & & & 3 & 4 & 2 & 8 & 5.88 & 6 & 7 & 1.219 & 2.0 & 0 & 17.6 & 82.4 & A \\
\hline C3.17 & & & & & 2 & 1 & 14 & 6.59 & 7 & 7 & 1.004 & 0 & 0 & 11.8 & 88.2 & A \\
\hline C3.18 & 1 & & 1 & 6 & 6 & 2 & 1 & 4.53 & 5 & $5(\mathrm{a})$ & 1.328 & 1.0 & 11.8 & 35.3 & 52.9 & A \\
\hline C3.19 & 1 & 1 & 1 & 9 & 4 & 1 & 0 & 4.00 & 4 & 4 & 1.173 & 1.0 & 17.6 & 52.9 & 29.5 & *R3 (N) \\
\hline C 3.20 & & & 2 & 1 & & 4 & 10 & 6.12 & 7 & 7 & 1.409 & 1.0 & 11.8 & 5.9 & 82.3 & A \\
\hline C3.21 & & 3 & 1 & 3 & 3 & 5 & 2 & 4.71 & 5 & 6 & 1.687 & 2.5 & 23.5 & 17.6 & 58.9 & R3 \\
\hline C3.22 & 1 & 4 & & 3 & 5 & 2 & 2 & 4.24 & 5 & 5 & 1.855 & 3.5 & 29.4 & 17.6 & 53.0 & R3 \\
\hline C 3.23 & 1 & 2 & 2 & 3 & 3 & 3 & 3 & 4.53 & 5 & $7(\mathrm{a})$ & 1.875 & 3.0 & 29.4 & 17.6 & 53.0 & R3 \\
\hline C 3.24 & & & 1 & 3 & 2 & 6 & 5 & 5.65 & 6 & 6 & 1.272 & 2.5 & 5.9 & 17.6 & 76.5 & A \\
\hline C 3.25 & & 1 & 1 & 3 & 5 & 4 & 3 & 5.12 & 5 & 5 & 1.409 & 2.0 & 11.8 & 17.6 & 70.6 & A \\
\hline C3.26 & & 1 & 1 & & 4 & 2 & 9 & 5.88 & 7 & 7 & 1.536 & 2.0 & 11.8 & 0 & 88.2 & A \\
\hline C3.27 & & 1 & & 1 & 3 & 6 & 6 & 5.82 & 6 & $7(\mathrm{a})$ & 1.334 & 2.0 & 5.9 & 5.9 & 88.2 & A \\
\hline C 3.28 & & & & & & 3 & 14 & 6.82 & 7 & 7 & 0.393 & 0 & 0 & 0 & 100 & A \\
\hline C3.29 & & & & 2 & & 4 & 11 & 6.41 & 7 & 7 & 1.004 & 1.0 & 0 & 11.8 & 88.2 & A \\
\hline
\end{tabular}

Note. $N=17$. The higher IQR score, the wider range of panel ratings. *(a) When multiple modes exist, the greatest value is shown. A (Consensus for "Agree"), D (Consensus for "Disagree"), R3 (No consensus; Items for Round III). *R3 (N) indicates neutral items which therefore were included on Round III. See Appendix G. Round II Questionnaire: Part II, Category 3 for competency statements. 
Table 14

Summary of Panel Ratings on Competency Category 4: Assessment and Evaluation from Round II

\begin{tabular}{|c|c|c|c|c|c|c|c|c|c|c|c|c|c|c|c|c|}
\hline & \multicolumn{7}{|c|}{ Frequency } & \multirow{2}{*}{$M$} & \multirow{2}{*}{$M d n$} & \multirow{2}{*}{ Mode } & \multirow{2}{*}{$S D$} & \multirow{2}{*}{$I Q R$} & \multicolumn{3}{|c|}{$\%$ Frequency } & \multirow{2}{*}{ Consensus } \\
\hline & 1 & 2 & 3 & 4 & 5 & 6 & 7 & & & & & & $1-3$ & 4 & $5-7$ & \\
\hline $\mathrm{C} 4.1$ & & & 1 & 1 & & 1 & 14 & 6.53 & 7 & 7 & 1.179 & 0 & 5.9 & 5.9 & 88.2 & A \\
\hline $\mathrm{C} 4.2$ & & & & 2 & 3 & 5 & 7 & 6.00 & 6 & 7 & 1.061 & 2.0 & 0 & 11.8 & 88.2 & A \\
\hline $\mathrm{C} 4.3$ & & & & 1 & 1 & 1 & 14 & 6.65 & 7 & 7 & 0.862 & 0 & 0 & 5.9 & 94.1 & A \\
\hline C4.4 & & & & 1 & 1 & 4 & 11 & 6.47 & 7 & 7 & 0.874 & 1.0 & 0 & 5.9 & 94.1 & A \\
\hline $\mathrm{C} 4.5$ & & 2 & & 1 & & & 14 & 6.24 & 7 & 7 & 1.751 & 0 & 11.8 & 5.9 & 82.3 & A \\
\hline C4.6 & & & & 1 & & 2 & 14 & 6.71 & 7 & 7 & 0.772 & 0 & 0 & 5.9 & 94.1 & A \\
\hline
\end{tabular}

Note. $N=17$. The higher IQR score, the wider range of panel ratings. A (Consensus for "Agree"). See Appendix G. Round II Questionnaire: Part II, Category 4 for competency statements.

For "Category 5: Cultural Ethical Issues," four out of six competency statements (67\%) reached consensus on being essential teaching competencies of teacher education faculty in 2015 . The statements, "Reviewing demographic data on student" (C5.5 in Table 15) and "Setting up model searches online" (C5.6 in Table 15) did not reach consensus.

Table 15

Summary of Panel Ratings on Competency Category 5: Cultural Ethical Issues from Round II

\begin{tabular}{|c|c|c|c|c|c|c|c|c|c|c|c|c|c|c|c|c|}
\hline & \multicolumn{7}{|c|}{ Frequency } & \multirow{2}{*}{$M$} & \multirow{2}{*}{$M d n$} & \multirow{2}{*}{ Mode } & \multirow{2}{*}{$S D$} & \multirow{2}{*}{$I Q R$} & \multicolumn{3}{|c|}{ \% Frequency } & \multirow{2}{*}{ Consensus } \\
\hline & 1 & 2 & 3 & 4 & 5 & 6 & 7 & & & & & & $1-3$ & 4 & $5-7$ & \\
\hline $\mathrm{C} 5.1$ & & & & & 5 & 6 & 6 & 6.06 & 6 & $7(a)$ & 0.827 & 2.0 & 0 & 0 & 100 & A \\
\hline $\mathrm{C} 5.2$ & & & & & 1 & 5 & 11 & 6.59 & 7 & 7 & 0.618 & 1.0 & 0 & 0 & 100 & A \\
\hline $\mathrm{C} 5.3$ & & & 1 & 1 & 6 & 4 & 5 & 5.65 & 6 & 5 & 1.169 & 2.0 & 5.9 & 5.9 & 88.2 & A \\
\hline $\mathrm{C} 5.4$ & & & & & & 2 & 15 & 6.88 & 7 & 7 & 0.332 & 0 & 0 & 0 & 100 & A \\
\hline $\mathrm{C} 5.5$ & & & 2 & 5 & 4 & 2 & 4 & 5.06 & 5 & 4 & 1.391 & 2.5 & 11.8 & 41.0 & 47.0 & R3 \\
\hline C5.6 & & & 2 & 4 & 5 & 3 & 3 & 5.06 & 5 & 5 & 1.298 & 2.0 & 11.8 & 24.0 & 64.7 & R3 \\
\hline
\end{tabular}

Note. $N=17$. The higher IQR score, the wider range of panel ratings. *(a) When multiple modes exist, the greatest value is shown. A (Consensus for "Agree"), R3 (No consensus; Items for Round III). See Appendix G. Round II Questionnaire: Part II, Category 5 for competency statements. 
Round II Panel Member Comments on Teaching Competencies

In Delphi Round II, the panel members were asked to provide their comments on the ratings they felt require justification. Written comments by panelists play an important role in the process of bringing about convergence of group opinions while seeking consensus. Table 16 shows the summary of panel member comments on competencies for each category. The comments provided by panel members demonstrated why the technology category was the most controversial area.

Table 16

Summary of Panel Member Comments on Teaching Competencies from Round II Competencies Comment

Planning and Designing

Learning Environment
- I envision a future in which technical expertise will come second to ID expertise. This is the path of most natural evolutions of tech implementation. Hardware and software first, THEN good design. Unfortunately, the cycle then starts again and we are back to hardware and software with rotten ID.

- I have rated some of these lower not because the instructor should not be aware of them but I am assuming more and more support from instructional development centers in purely technical tasks will be available.

- 1.9 computer software may be ambiguous term here. I read it to mean CD-ROM based resource. Evaluation of web sites that provide software is essential.
Teaching and Learning
- I found many of these hard to argue with....my responses were based more on which of these environments I expect to prevail than on whether being able to do these things was desirable.

- I don't know what Q \# 2.26 means

- 2.32 terms Satellite sites is unclear. Earlier in the survey I thought you were referring to satellite supported communications; but does it mean learners at other physical locations?

- 2.7 Could be hard unless students are in a PDS situation.

- 2.26 I have no idea what this means so I marked it as a 1.
- Most of my answers here are again based on the presumed heightened presence of technical support through instructional technology centers...people will need to know how to "drive the car" but not necessarily how the car actually works or how to fix it.

- I believe that most people will have a tech expert to rely on and that's why some of my ratings are not essential. 
Table 16 (continued)

\begin{tabular}{lll}
\hline \multicolumn{1}{c}{ Competencies } & \multicolumn{1}{c}{ Comment } \\
\hline Technology & $\bullet \begin{array}{l}\text { Obviously I think faculty should need to know all of these things; } \\
\text { however because this is a huge demand on them, I do not think they } \\
\text { also should be responsible for technical maintenance and technical set } \\
\text { up. }\end{array}$ \\
& - $\begin{array}{l}3.17 \text { Assuming you mean email of today. I believe there will be better } \\
\text { online communication systems in 10 years. }\end{array}$ \\
\hline $\begin{array}{l}\text { Assessment and } \\
\text { Evaluation }\end{array}$ & $\bullet$ & Instructional Design matters. \\
& - & These are all basic to good teaching whatever the environment. \\
\hline $\begin{array}{l}\text { Cultural and Ethical } \\
\text { Issues }\end{array}$ & $\bullet$ & Some of what is here feels like "Miscellaneous" instead. \\
\hline
\end{tabular}

\section{Round III Data Analysis}

Fifteen panel members completed the third round questionnaire resulting in an $88 \%$ response rate. The literature reveals that a total response rate of $88 \%$ is within acceptable limits of third round response rates in Delphi studies. The Round III questionnaire consisted of 14 delivery modes and 25 competencies (See Appendix H) for which the panel had not reach consensus from Round II. The panel members were given the Round II median, mode, and the frequency of response for each item. Under the "Results of Delphi II" column, the original rating of each item was marked. If a panelist decided to change their previous rating on a given item, and their new rating was more than two points away from the mode, the panelist was asked to add comments to support their new position. There were far fewer comments were made in Round III than in Round II.

\section{Round III Part 1: Delivery Modes}

With the re-rating of some panel members in Round III, 13 out of 14 delivery modes reached consensus; six items for positive agreement (will be a mode in the future), five for negative agreement (will not be a mode in the future), and two for neutral (uncertain). These 
additional future delivery modes reaching consensus after Round III are summarized in Table 17.

Table 17

Additional Delivery Modes Reaching Consensus after Round III

\begin{tabular}{llccc}
\hline \multicolumn{1}{c}{ Delivery Modes } & Mdn & IQR & $\% f, 5-7$ \\
\hline Mode 3.3 & F2F + Web-Asynchronous Video Supplement & 5 & 1.0 & 94 \\
Mode 3.5 & F2F + Web-Synchronous Text Supplement & 5 & 2.0 & 73 \\
Mode 3.10 & F2F + Web-Asynchronous/Synchronous Audio Supplement & 5 & 0 & 73 \\
Mode 3.11 & F2F + Web-Asynchronous/Synchronous Video Supplement & 5 & 0 & 80 \\
Mode 4.1 & Web-Asynchronous Text & 6 & 2.0 & 82 \\
Mode 6.3 & Web-Asynchronous/Synchronous Video & 5 & 1.0 & 53
\end{tabular}

Note. $N=15$. The higher IQR score, the wider range of panel ratings. $\% f, 5-7$ indicates the percentage of frequency for scores, 5-7.

It was noted that the consensus reached for these additional modes was achieved only at the somewhat agreeable level (average median rating of 5). One delivery mode, WebAsynchronous Video (median rating of 4; IQR of 3.0), failed to reach consensus in Round III. The panel could not reach consensus regarding the following delivery modes being used by higher education faculty in 2015 :

- Face-to-Face + Satellite Combo (a median rating of 3)

- Face-to-Face + Web-Synchronous Audio Supplement (a median rating of 3)

- Web-Synchronous Text (a median rating of 3)

- Web-Synchronous Video (a median rating of 3)

- Web-Asynchronous/Synchronous Audio (a median rating of 3)

\section{Round III Part 2: Teaching Competencies}

Results of Round III found that 13 of 25 competencies reached consensus on their being essential for future teacher education faculty. Items that received a median rating of $\geq 5$, an IQR of $\leq 2.5$, and frequency rate $\geq 70 \%$ within the $5-7$ range, were considered to have reached consensus for agreement. Those 13 teaching competencies that reached consensus in the third round are summarized in Table 18. The panelist considered that "Detailed functional knowledge 
of how to use Telnet through the Web browser" (median of 3; IQR 1.0) and "Identifying and analyzing technical issues resulted from equipment malfunctions or operator errors" (median of 4; IQR 2.0) would not be very necessary for teacher educators. $67 \%$ of respondents considered that "Using FTP to share and retrieve course resources" (median of 5; IQR 2.0) would be needed by future teacher educators. "Preparation of graphics and art works" (median of 4; IQR 1.0) and “Troubleshooting technical problems" (median of 4; IQR 1.0) remained as "Neutral," which indicates that a majority of panelists could not decide whether they would be necessary or not for future teacher educators.

Table 18

\section{Additional Teaching Competencies Reaching Consensus after Round III}

\begin{tabular}{llccc}
\hline \multicolumn{1}{c}{ Teaching Competencies } & Mdn & IQR & $\% f, 5-7$ \\
\hline C1.9 & Evaluation of computer software for educational purposes & 7 & 1.0 & 100 \\
C2.14 & Managing non-verbal exchange in virtual environment & 6 & 1.0 & 87 \\
C2.17 & Monitoring and structuring student learning in virtual environment & 7 & 1.0 & 93 \\
C2.20 & Posting customized assignments in online environment & 5 & 1.0 & 80 \\
C2.32 & Stimulating individual/peer/group interaction at each of the Satellite & 6 & 1.0 & 80 \\
& sites & & & \\
C2.34 & Using appropriate vocal inflections and modulation to maintain learners & 5 & 1.0 & 73 \\
& attention and interest & 5 & 2.0 & 80 \\
C3.10 & Online file management & 6 & 2.0 & 80 \\
C3.13 & Preparation of lecture presentation using presentation software & 5 & 1.0 & 87 \\
C3.14 & Proficiency with all technical systems used in the course & 5 & 1.0 & 73 \\
C3.15 & Publishing multimedia such as audio, video and/or still images online & 5 & 2.0 & 80 \\
C3.23 & Using instructional video games and simulations in effective ways & 6 & 2.0 & 80 \\
C5.5 & Reviewing demographic data on student & 5 & 1.0 & 87 \\
C5.6 & Setting up model searches online & & 50
\end{tabular}

Note. $N=15$. The higher IQR score, the wider range of panel ratings. $\% f, 5-7$ indicates the percentage of frequency for scores, 5-7.

\section{Round III Panel Member Comments}

In the third round, panel members were asked to either re-rate or confirm their original rating for each item included. If the new response was more than 2 points away from the mode, they were required to add comments justifying the change. Table 19 summarizes panel member comments on both delivery modes and competencies. Fewer comments were made in the third 
round than in the second round. The comments provided by panel members indicate why some statements did not reach consensus in the third round.

Table 19

Summary of Panel Member Comments from Round III Delivery Modes Comment

\begin{tabular}{|c|c|}
\hline F2F + Web Supplement & $\begin{array}{l}\text { Mode 3.6. Thinking about F2F augmented with online audio chat with } \\
\text { off-site expert. } \\
\text { - Mode 3.10. Thinking about F2F augmented with online chat with off- } \\
\text { site expert. These could also be recorded for review later in the course. }\end{array}$ \\
\hline Web-Asynchronous & $\begin{array}{l}\text { - 4.1. Most teacher education courses will continue to include aspects of } \\
\text { modeling teaching practice. I do not see online text-only as an option } \\
\text { that will be widely used in } 10 \text { years. }\end{array}$ \\
\hline Web-Synchronous & $\begin{array}{l}\text { - 5.1. I think that "chatting" is a way of life for many students and will } \\
\text { prove to be an educational mode of communication. } \\
\text { - Use of the Internet for educational purposes is growing exponentially. } \\
\text { Access in poor or remote places is the barrier to not using it. } \\
\text { - Mode 5.1. This strategy more effective in combination with others, as } \\
\text { listed in combinations on this chart. }\end{array}$ \\
\hline Competencies & Comment \\
\hline $\begin{array}{l}\text { Planning and Designing } \\
\text { Learning Environment }\end{array}$ & $\begin{array}{l}\text { 1.19. In the previous round, I rated this low because software is more } \\
\text { and more web-based and computer software is becoming outdated. } \\
\text { Evaluation of courseware however remains essential. }\end{array}$ \\
\hline Teaching and Learning & $\begin{array}{l}\text {-2.23. Applying knowledge to new contexts is evidence of learning. I } \\
\text { consider this essential in any learning environment. However, not in } \\
\text { Virtual Reality. } \\
\text { - } 2.32 \text {. I cannot see myself using video games or simulations in my } \\
\text { undergraduate methods courses. } \\
\text { - 2.23. Goes with lower rating of Delivery Mode } 7 \text { (virtual reality). } \\
\text { - 2.31. Moved this higher since the group didn't seem to feel that virtual } \\
\text { reality would be functional within } 10 \text { years. }\end{array}$ \\
\hline Technology & $\begin{array}{l}\text { - 3.4. Even if colleges provide server space, I believe faculty will need to } \\
\text { track filenames and organize their own audio/video clips. } \\
\text { - 3.9. I assumed this meant online text messages within a course } \\
\text { management tool or web browser. } \\
\text { - 3.10. Required for faculty to build web pages. } \\
\text { - 3.23. I rarely lecture, so the preparation of lecture presentation using } \\
\text { presentation software is not important to me. } \\
\text { - It is unfortunate that even the "experts" rate PPT as the most essential. I } \\
\text { doubt some of the others are tech savvy. } \\
\text { - While I highly value the need for discussion, I do not see that } \\
\text { simulations are going to be the tool through which this occurs. }\end{array}$ \\
\hline
\end{tabular}




\section{Shifting of Panel Responses from Round II to Round III}

After Round III, for the items that did not reach consensus, stability of results was examined to determine if there was minimal or no further shifting of panel responses from Round II to Round III. In a Delphi study, panelists are confronted with the results after each round, until consensus or stability of results is reached. For this study, as defined in the data analysis section, the shifting of median scores was analyzed for one delivery mode and seven competency statements that did not reached consensus after Round III. The criterion of stability for median scores was defined as a shift of 15 percent or less (a shift of one on a scale of one to seven) after successive rounds. As shown in Tables 20, 21, 22, 23, and 24 the difference in median scores between Round II and Round III for those items is no more than 1. The frequency distributions also indicate that the panelists are stable in their position of opinion from round to round.

Table 20

Shift of Panel Response: Mode 4.3, Web-Asynchronous Video

\begin{tabular}{ccccccc}
\hline & \multirow{2}{*}{$N$} & Median & Mode & \multicolumn{3}{c}{$\%$ Frequency } \\
\cline { 5 - 7 } & 17 & 4 & 5 & 41.2 & 17.6 & 41.2 \\
Round II & 15 & 5 & 5 & 13.3 & 20 & 66.7 \\
\hline
\end{tabular}

Table 21

Shift of Panel Response: C2.l1, Incorporating visuals and interaction in meaningful ways, given the constraints of audio chat technology

\begin{tabular}{lcccccc}
\hline & \multirow{2}{*}{$n$} & Median & Mode & \multicolumn{3}{c}{$\%$ Frequency } \\
\cline { 5 - 7 } & 17 & 4 & 5 & 11.8 & 29.4 & 58.8 \\
\hline Round II & 15 & 5 & 5 & 0 & 33.3 & 66.7 \\
\hline
\end{tabular}


Table 22

Shift of Panel Response: C2.31, Stimulating appropriate individual and group discussions with the use of instructional video games and simulations

\begin{tabular}{lcccccc}
\hline & \multirow{2}{*}{$n$} & Median & Mode & \multicolumn{3}{c}{ \% Frequency } \\
\cline { 5 - 7 } & & 4 & 5 & 41.2 & 5.9 & 52.9 \\
\hline Round II & 17 & 5 & 5 & 40.0 & 13.3 & 46.7 \\
Round III & 15 & 5 & & & & \\
\hline
\end{tabular}

Table 23

Shift of Panel Response: C3.4, Archiving and organizing audio/video clips based on content areas

\begin{tabular}{lcccccc}
\hline & \multirow{2}{*}{$n$} & Median & Mode & \multicolumn{3}{c}{ \% Frequency } \\
\cline { 5 - 7 } & & 5 & 4 & 5.9 & 41.2 & 52.9 \\
\hline Round II & 17 & 5 & 4 & 0 & 46.7 & 53.3 \\
Round III & 15 & 5 & & & & \\
\hline
\end{tabular}

Table 24

Shift of Panel Response: C3.9, Knowledge of how online text messages may appear to the learners

\begin{tabular}{|c|c|c|c|c|c|c|}
\hline & \multirow[b]{2}{*}{$n$} & \multirow{2}{*}{ Median } & \multirow{2}{*}{ Mode } & \multicolumn{3}{|c|}{ \% Frequency } \\
\hline & & & & $1-3$ & 4 & $5-7$ \\
\hline Round II & 17 & 4 & 4 & 17.6 & 35.3 & 47.1 \\
\hline Round III & 15 & 4 & 4 & 13.3 & 46.7 & 40.0 \\
\hline
\end{tabular}

The results from Round III indicated stability with respect to panel consensus. The shift in median scores on those items which did not reach consensus by the third round was less than $15 \%$. All other items had reached consensus by Round III. Therefore, an additional fourth round was not deemed necessary. A comparison of the frequency distributions for all items was conducted to analyze the shifting of panel responses from Round II to Round III. Comparisons of 
a select number of items are presented as figures to visually demonstrate the shifting of opinions. These figures clearly illustrate that movement of the panel experts toward consensus was significant when comparing the frequency distribution between Round II and III.

\section{Delivery Modes}

The shifting of panel opinion was significant for the delivery modes that reached consensus either for positive or negative agreement in Round III. The following figures present a summary of the consensus-building process that happened between Round II and Round III. For example, as shown in Figures 1, 2, and 3, panel's central tendency was shifted to the lower ratings for Mode 2, Face-to-Face + Satellite Combo Mode 3.6, F2F + Web-Synchronous Audio Supplement delivery mode, and Mode 3.11, F2F + Web-Asynchronous/Synchronous Video Supplement. With this shift, the panel concluded that these delivery modes would not be course delivery modes in 2015 .
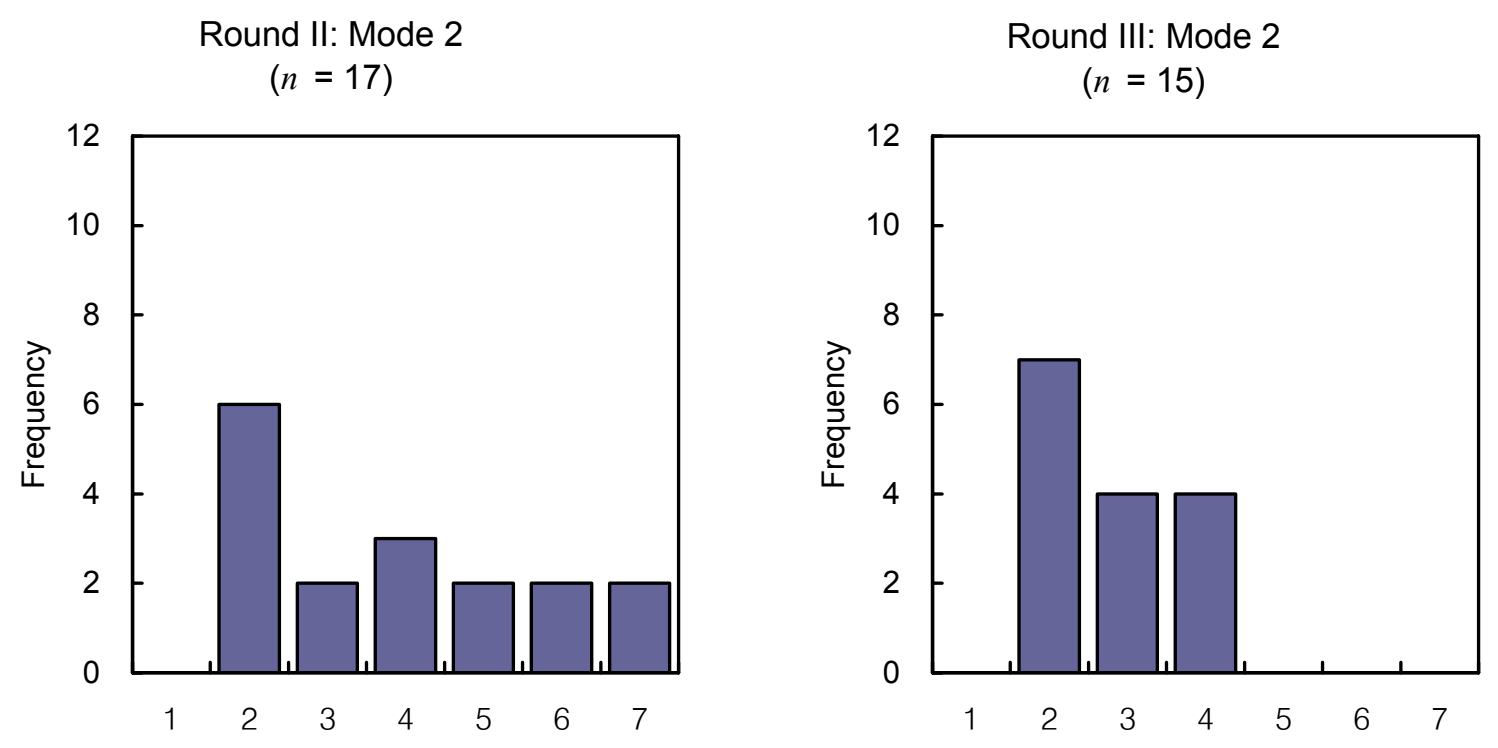

Figure 1. Frequency distribution for Mode 2, Face-to-Face + Satellite Combo. 
Round II: Mode 3.6

$$
(n=17)
$$

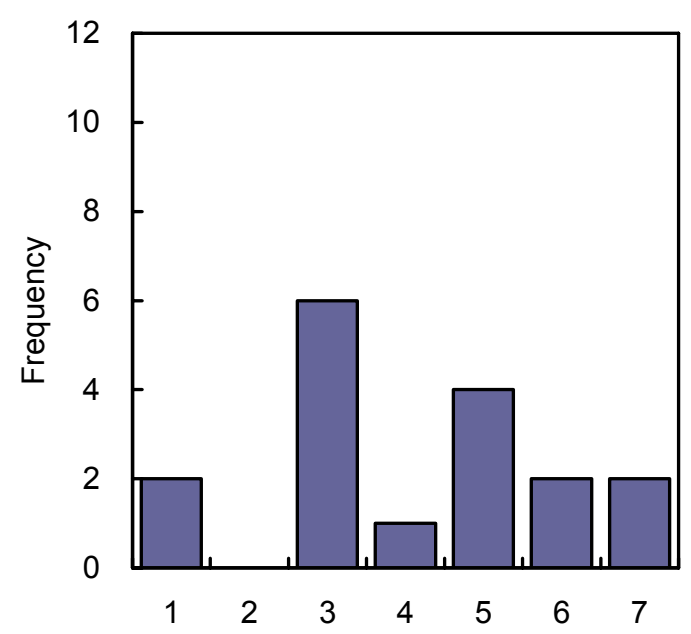

Round III: Mode 3.6

$(n=15)$

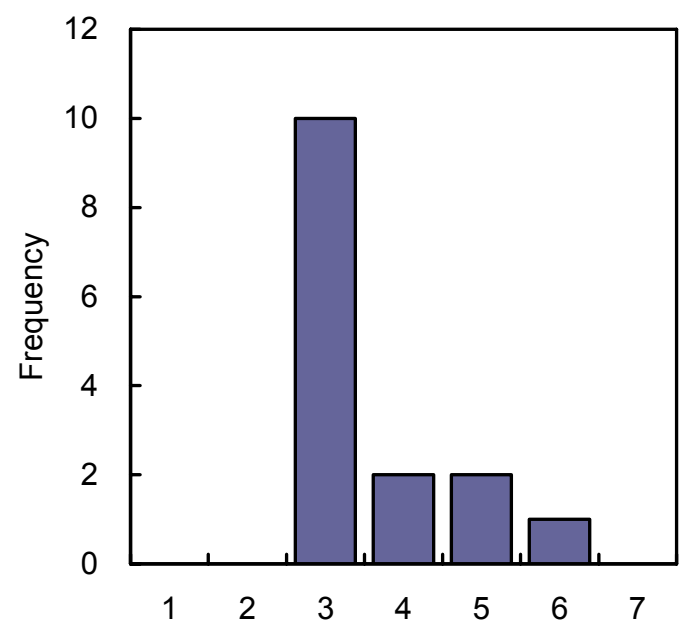

Figure 2. Frequency distribution for Mode 3.6, F2F + Web-Synchronous Audio Supplement.

Round II: Mode 6.2

$(n=17)$

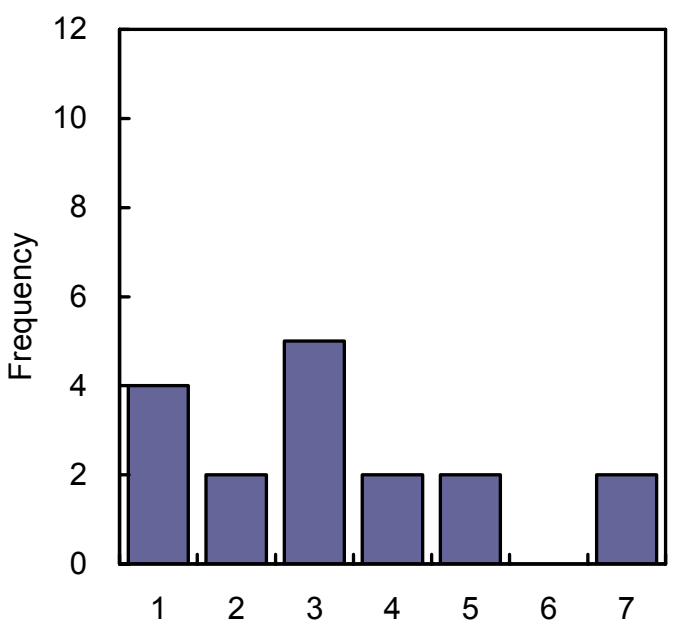

Round III: Mode 6.2

$(n=15)$

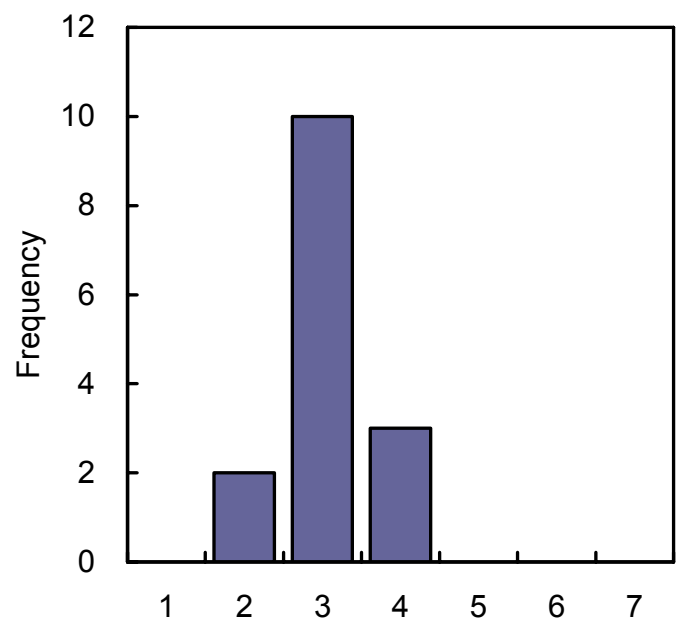

Figure 3. Frequency distribution for Mode 6.2, Web-Asynchronous/Synchronous Audio. 
Figures 4, 5, and 6 illustrate the similar shifting of panel opinion for those items that reached consensus for positive agreement after Round III.
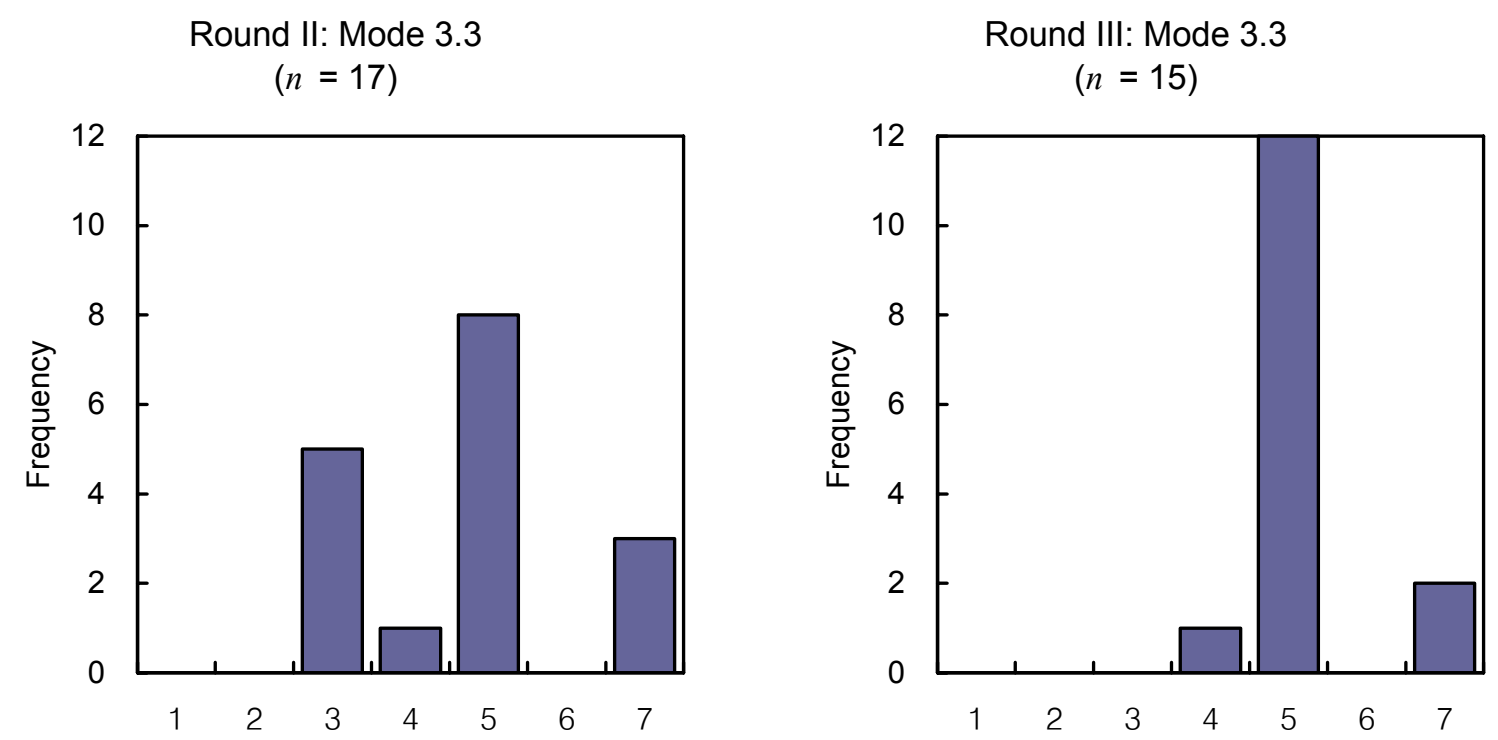

Figure 4. Frequency distribution for Mode 3.3, F2F + Web-Asynchronous Video Supplement.

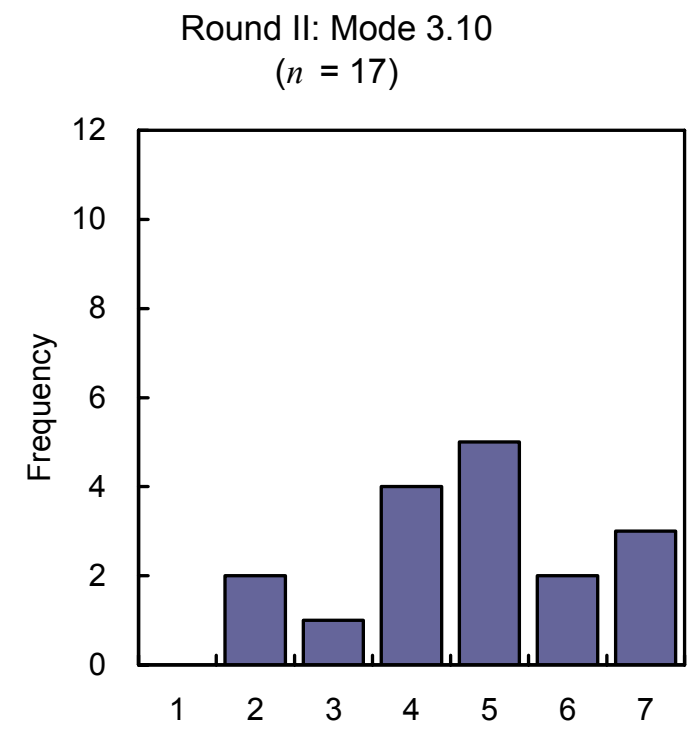

Round III: Mode 3.10

$$
(n=15)
$$

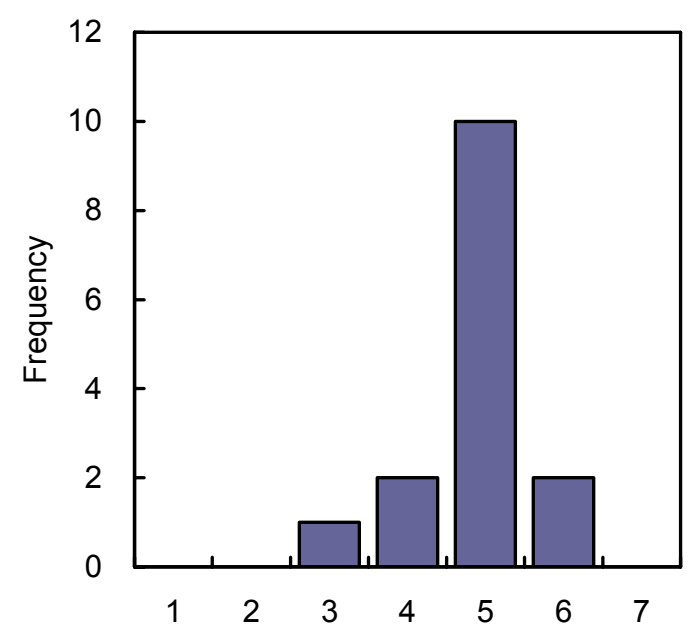

Figure 5. Frequency distribution for Mode 3.10, F2F + Web-Asynchronous/Synchronous Audio Supplement. 
Round II: Mode 3.11

$$
(n=17)
$$

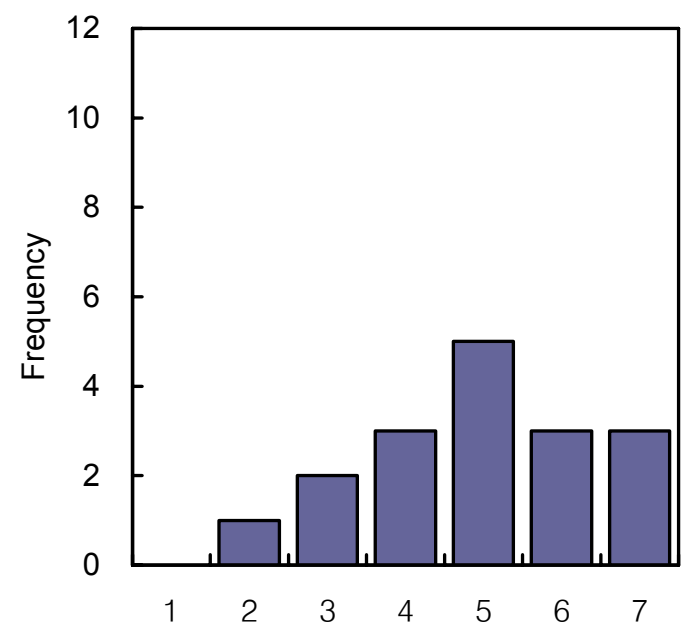

Round III: Mode 3.11

$(n=15)$

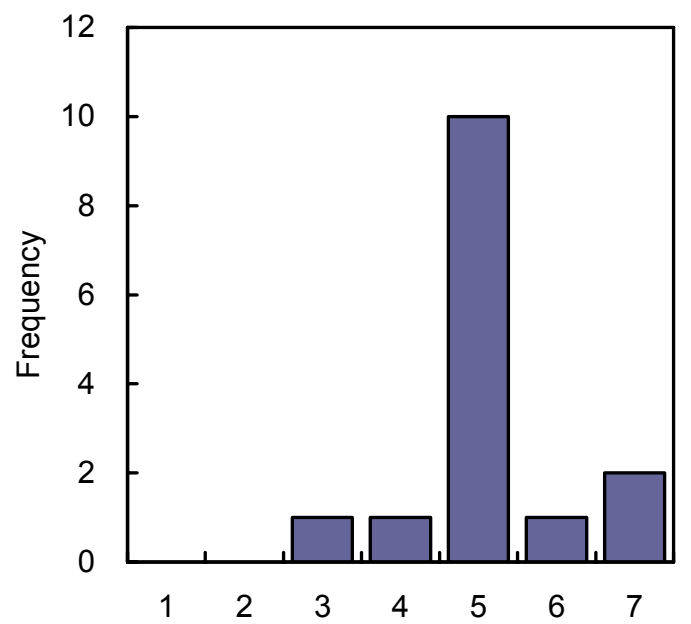

Figure 6. Frequency distribution for Mode 3.11, F2F + Web-Asynchronous/Synchronous Video Supplement.

Figure 7 illustrates the shifting of panel opinion for one delivery mode that reached consensus for neutral agreement after Round III.
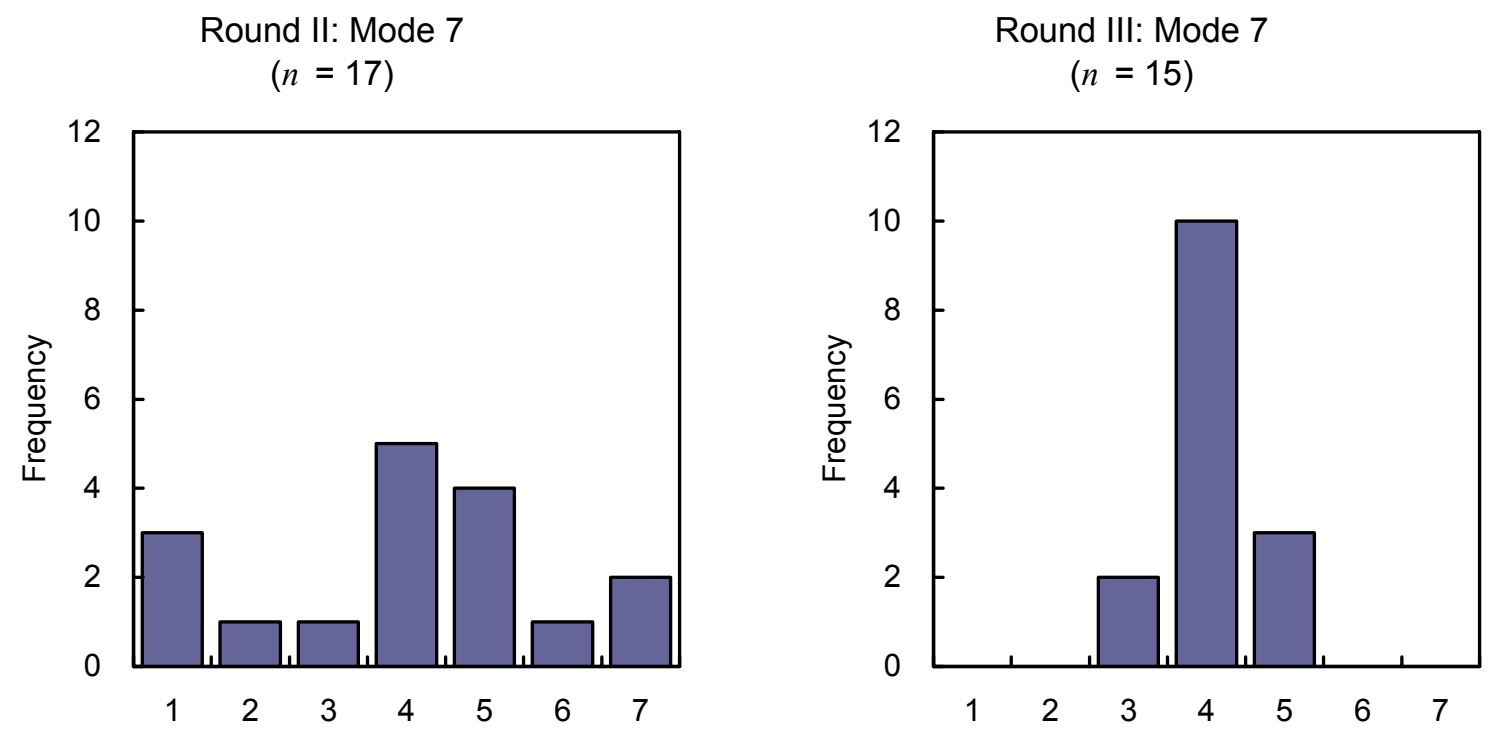

Figure 7. Frequency distribution for Mode 7, Virtual Reality. 


\section{Teaching Competencies}

Out of 25 teaching competencies included in Round III, 18 reached consensus (13 for agree; 3 for neutral; 2 for disagree). Figures 8 and 9 illustrate the shifting of panel opinion for the following two competency statements that reached consensus for disagree after Round III.

- C2.23, Providing a different context to ensure that the learners apply the newly gained knowledge in Virtual Reality

- C3.6, Detailed functional knowledge of how to use Telnet through the Web browser

Round II: C 2.23

$$
(n=17)
$$

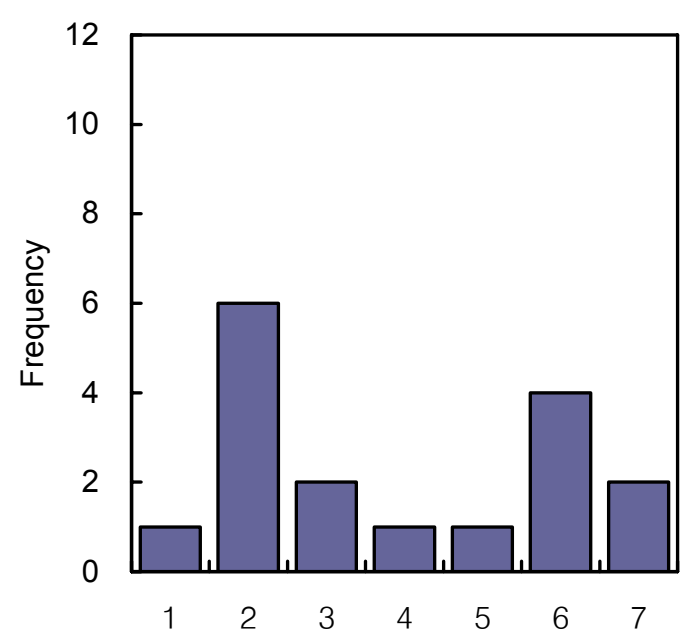

Round III: C 2.23

$(n=15)$

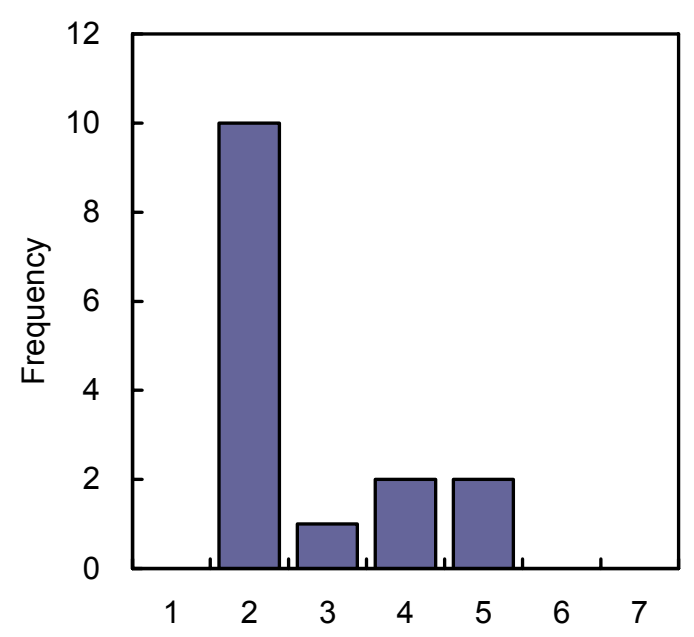

Figure 8. Frequency distribution for $\mathrm{C} 2.23$, Providing a different context to ensure that the learners apply the newly gained knowledge in Virtual Reality. 

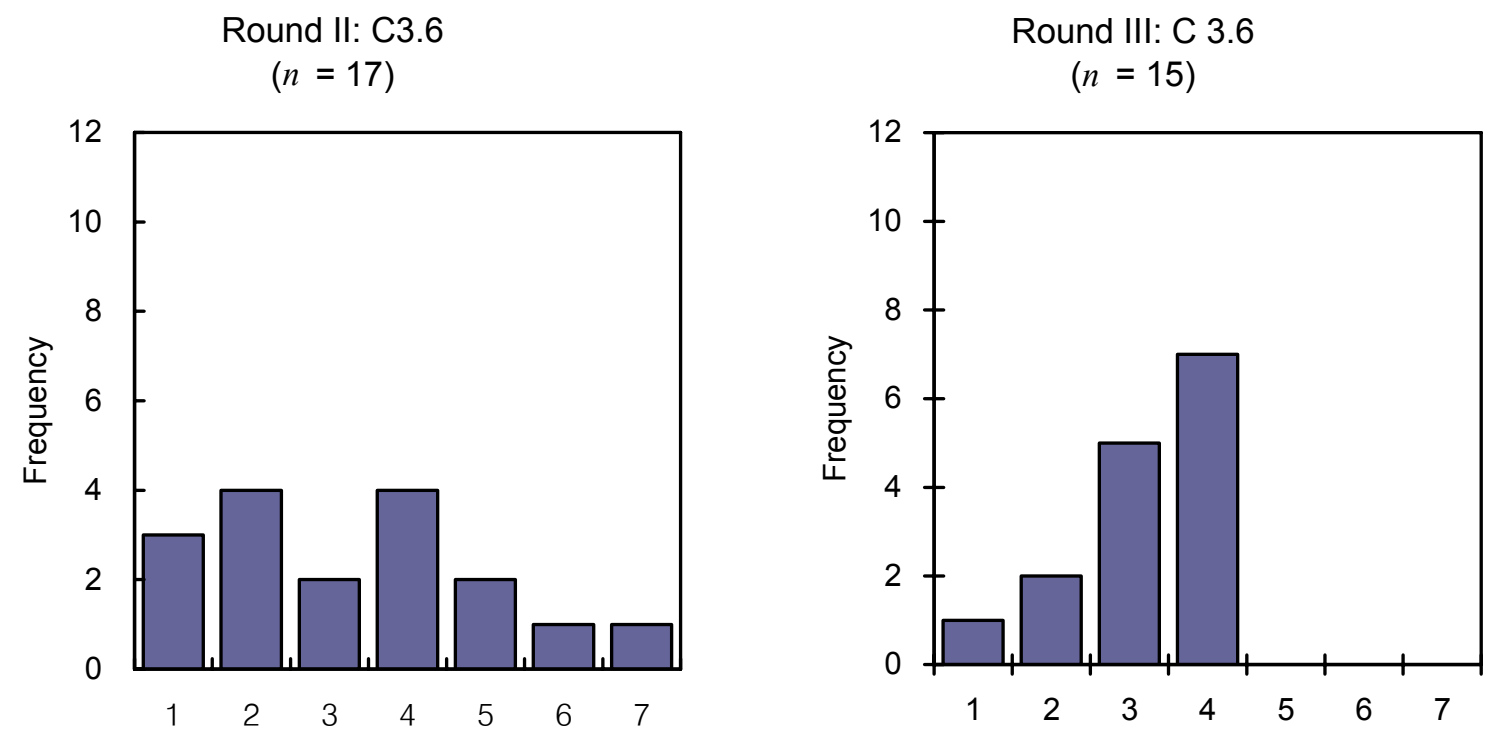

Figure 9. Frequency distribution for C3.6, Detailed functional knowledge of how to use Telnet through the Web browser.

Figures $10,11,12,13,14$, and 15 illustrate the shifting of panel opinion for the selected competency statements that reached consensus for positive agreement after Round III.
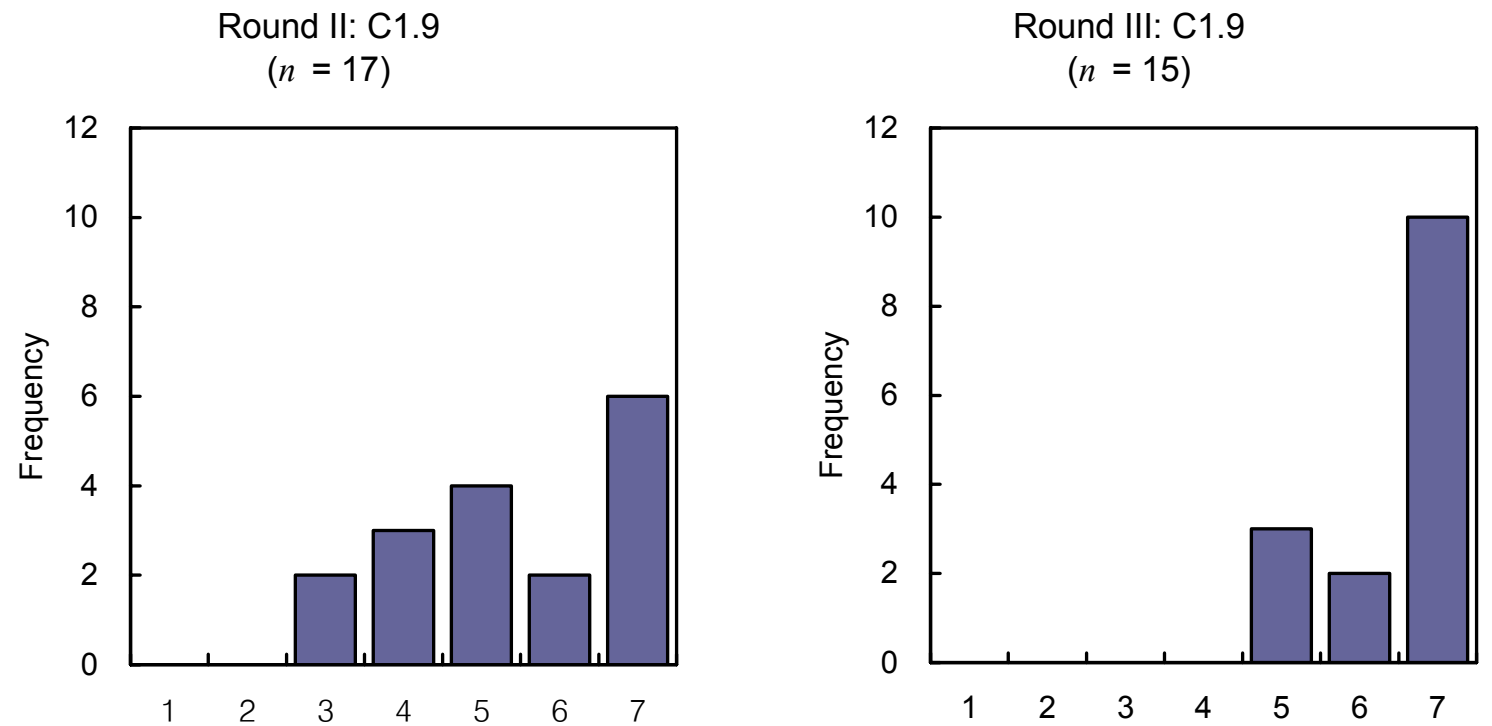

Figure 10. Frequency distribution for C1.9, Evaluation of computer software for educational purposes. 

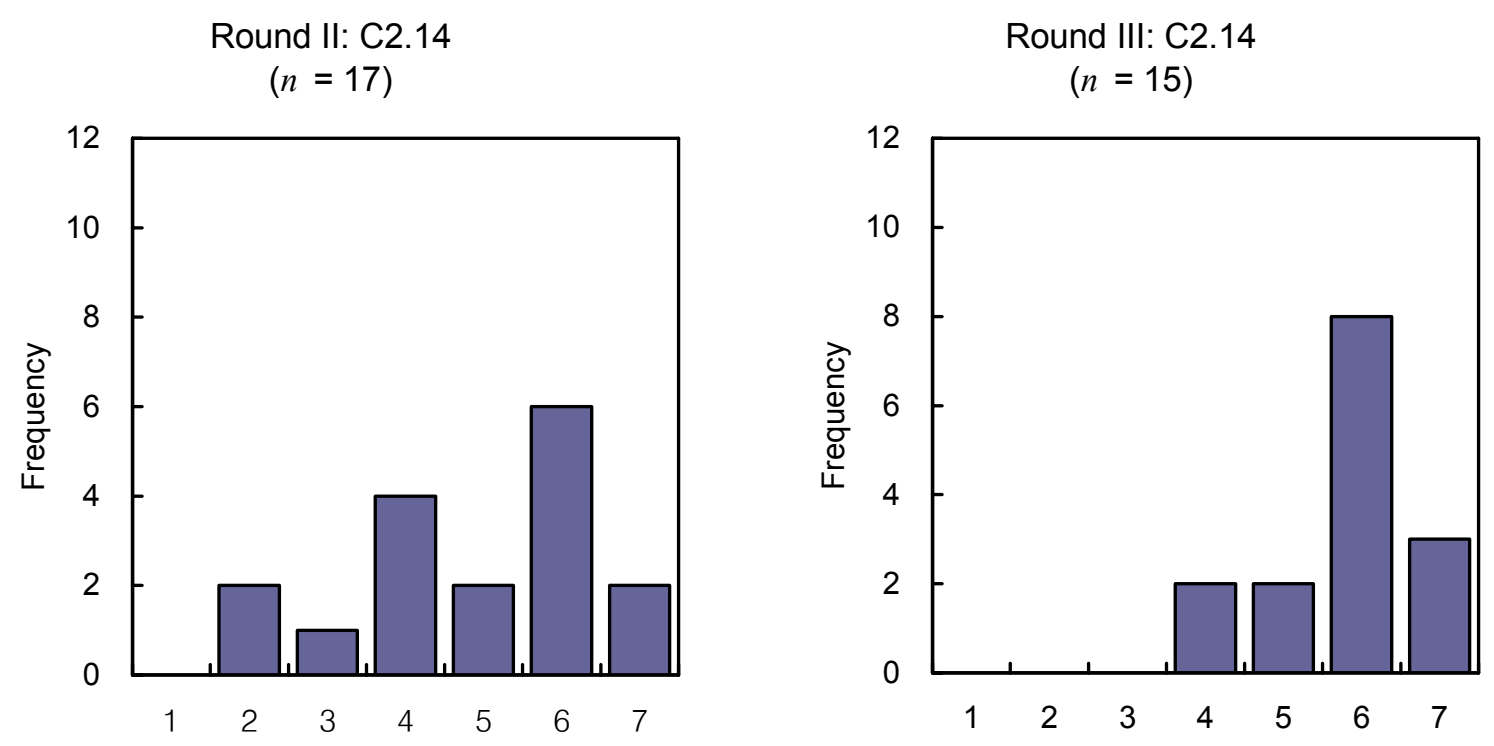

Figure 11. Frequency distribution for C2.14, Managing non-verbal exchange in virtual environment.
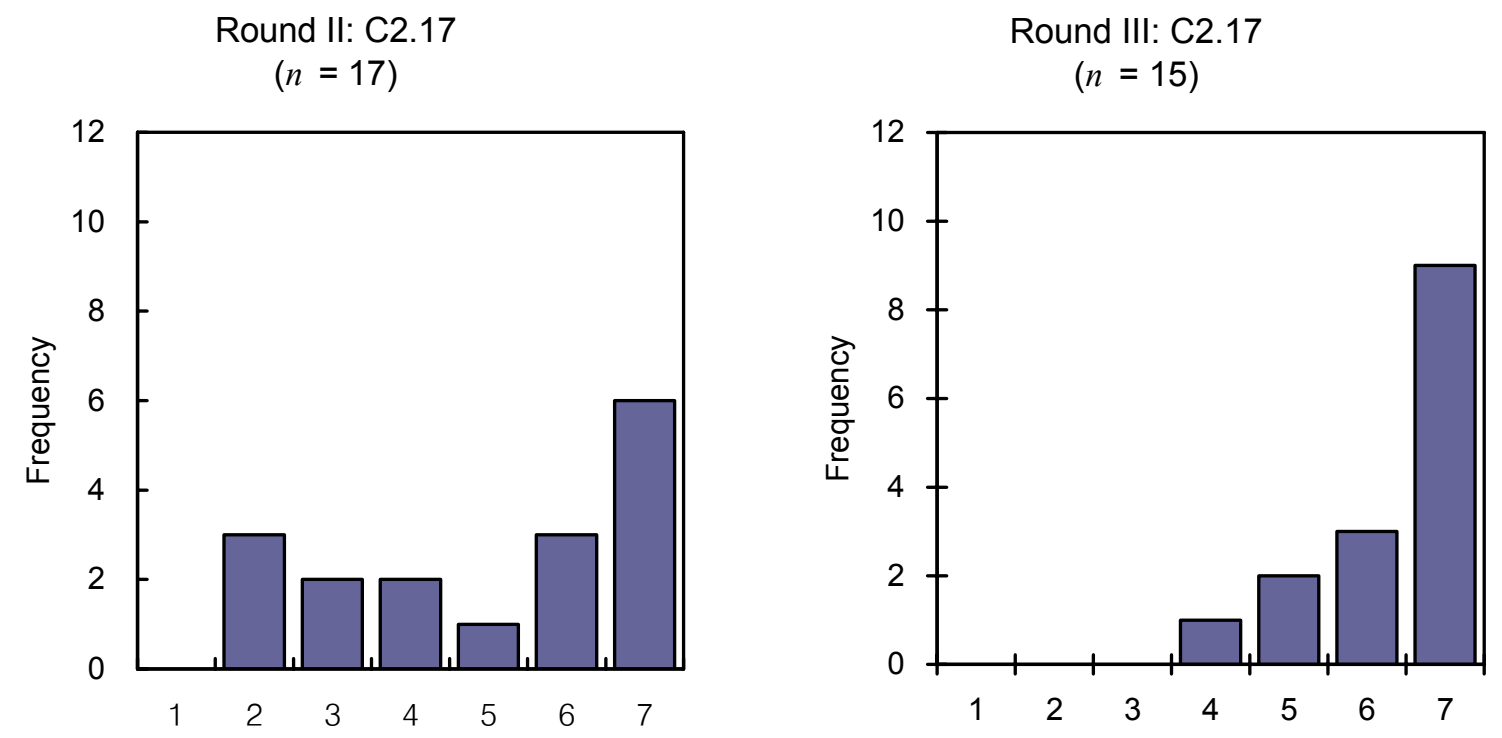

Figure 12. Frequency distribution for $\mathrm{C} 2.17$, Monitoring and structuring student learning in virtual environment. 

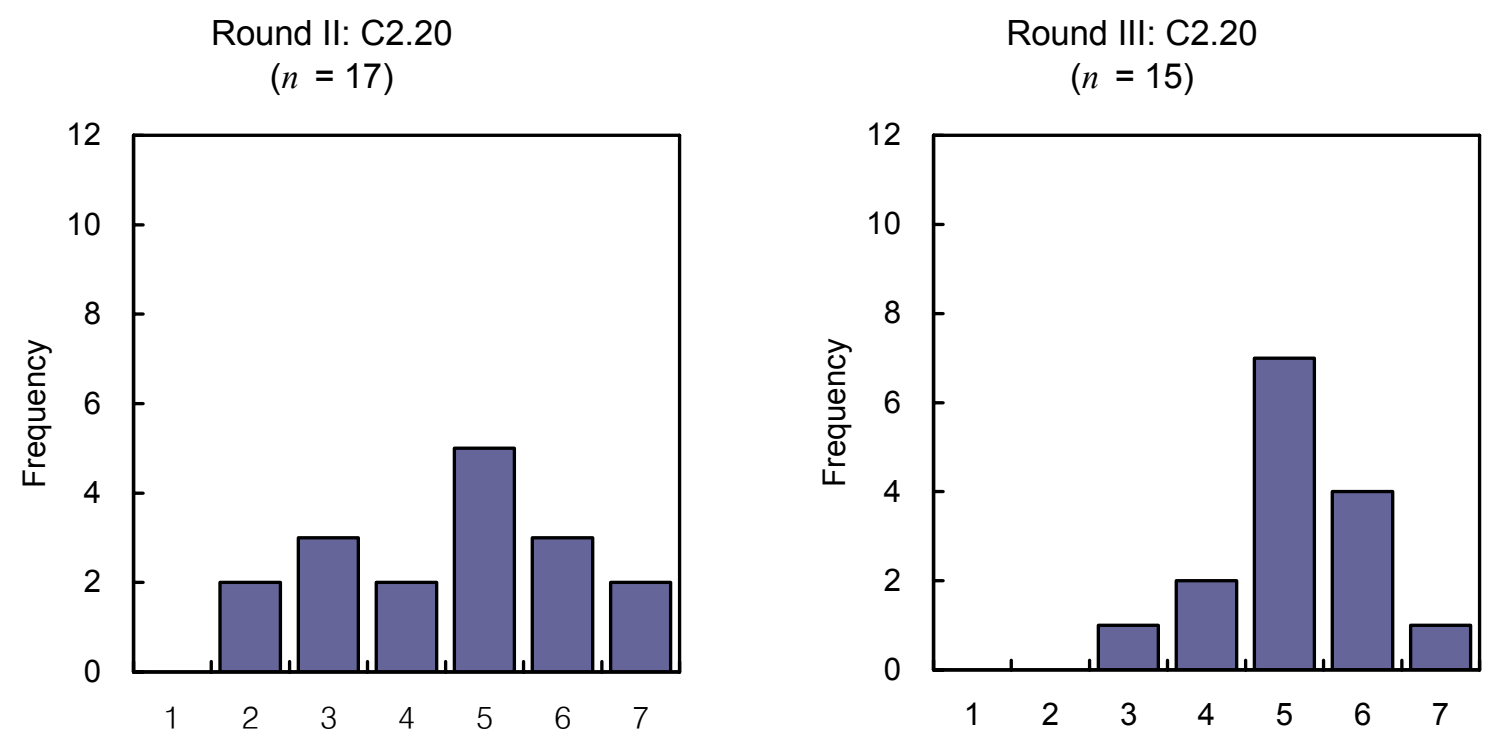

Figure 13. Frequency distribution for C2.20, Posting customized assignments in online environment.
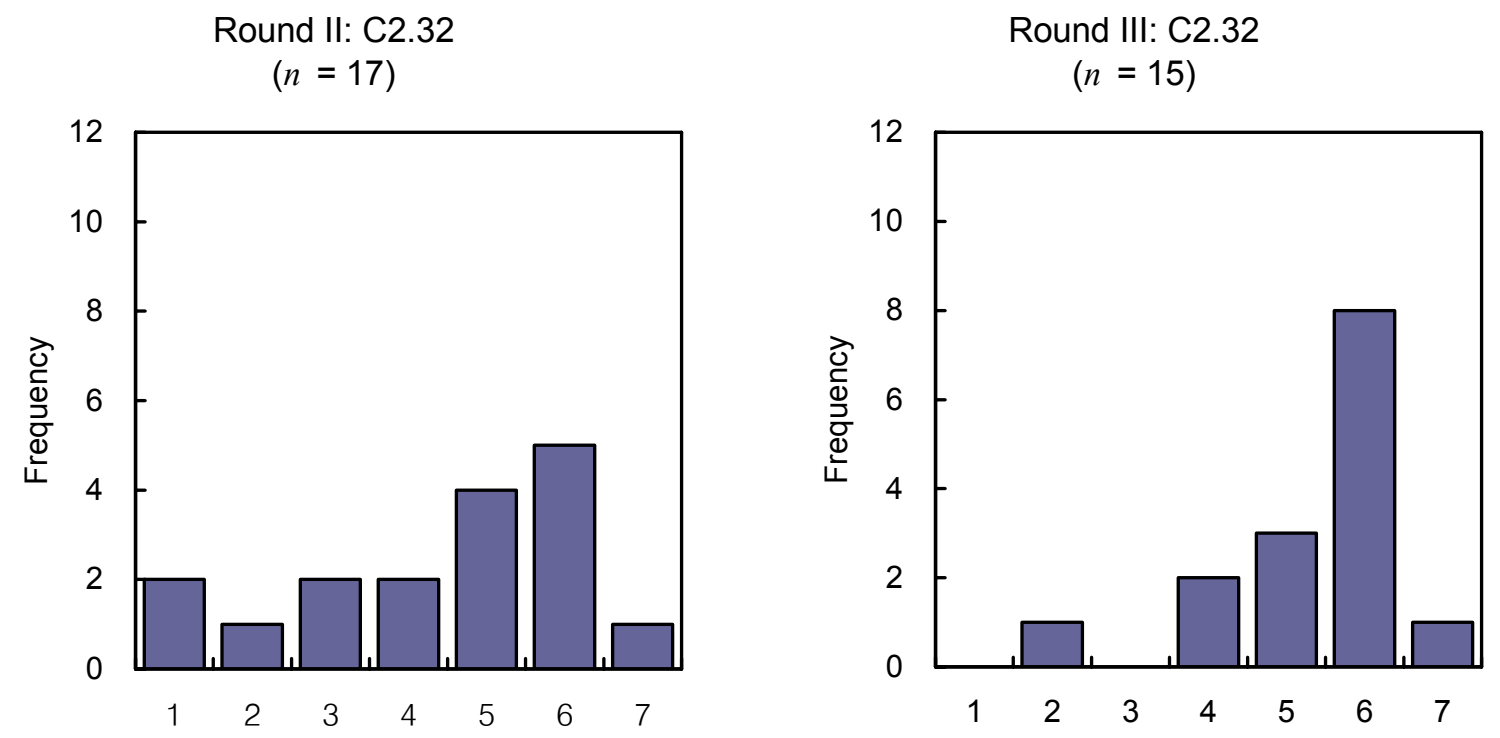

Figure 14. Frequency distribution for C2.32, Stimulating individual/peer/group interaction at each of the Satellite sites. 
Round II: C3.23

$$
(n=17)
$$

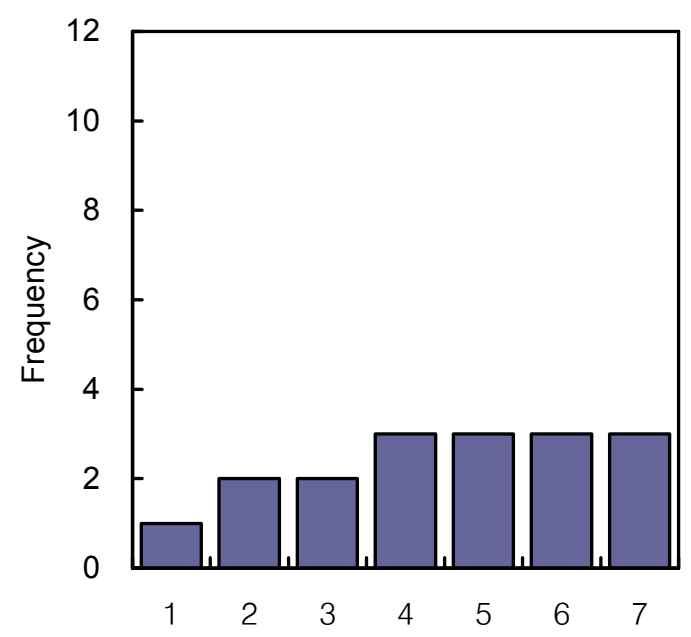

Round III: C3.23

$(n=15)$

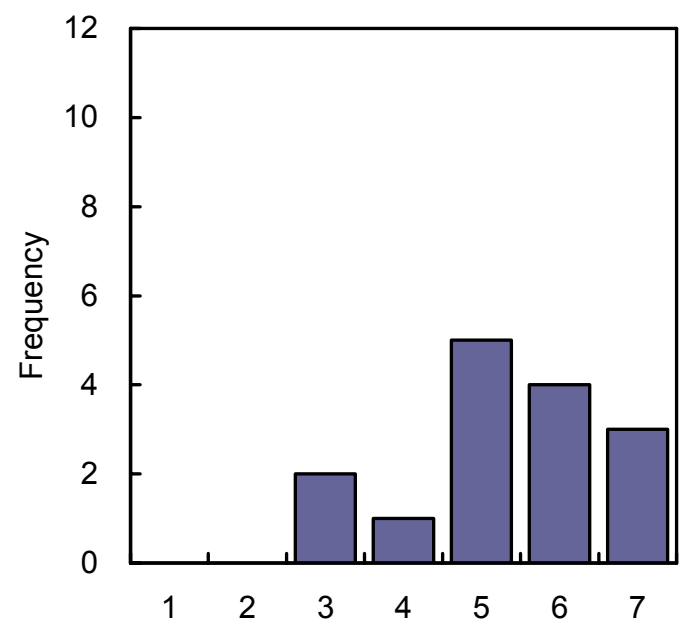

Figure 15. Frequency distribution for C3.23, Using instructional video games and simulations in effective ways.

Seven out of 25 competency statements did not reach consensus. For those seven items, the panel did not significantly change their ratings in Round III. Figures 16, 17, 18, 19, 20, 21, and 22 illustrate the lack of shifting of panel opinion for these competency statements from Round II and Round III.

- C2.11, Incorporating visuals and interaction in meaningful ways, given the constraints of audio chat technology

- C2.31, Stimulating appropriate individual and group discussions with the use of instructional video games and simulations

- C3.4, Archiving and organizing audio/video clips based on content areas

- C3.7, Identifying and analyzing technical issues resulted from equipment malfunction or operator errors

- C3.9, Knowledge of how online text messages may appear to the learners

- C3.21, Using FTP to share and retrieve course resources

- C3.22, Using hypertext to navigate materials in a manner suited to the learner's own learning style 
Round II: C2.11

$(n=17)$

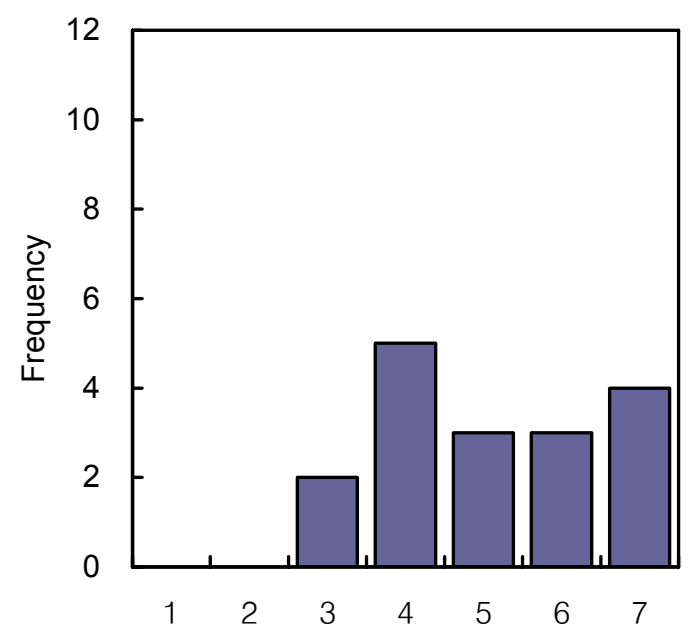

Round III: C2.11

$(n=15)$

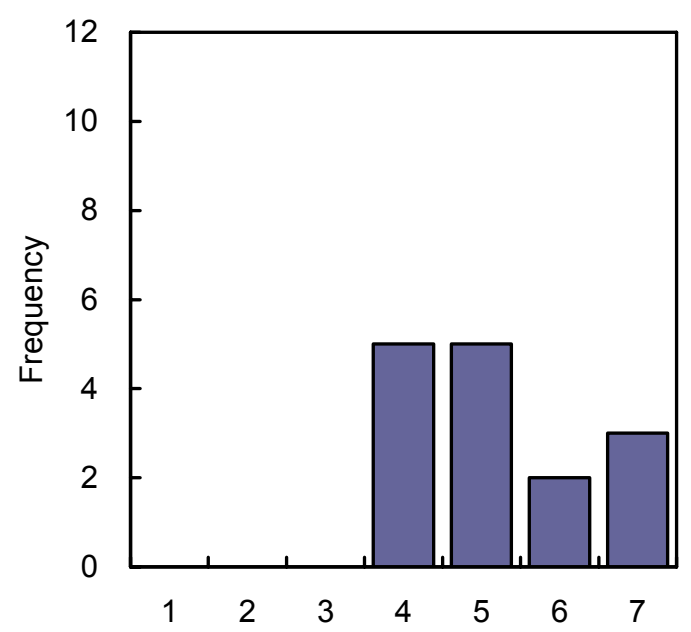

Figure 16. Frequency distribution for C2.11, Incorporating visuals and interaction in meaningful ways, given the constraints of audio chat technology.
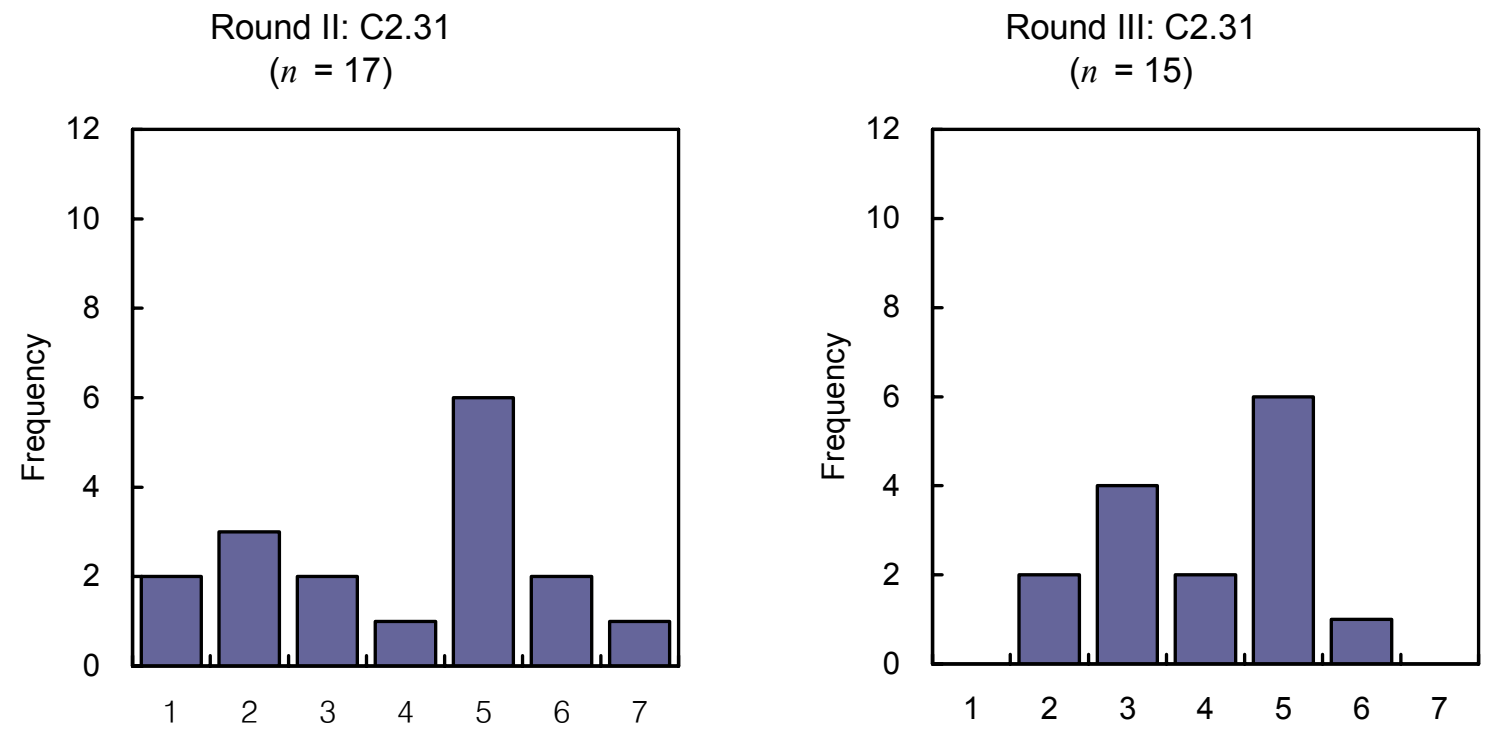

Figure 17. Frequency distribution for C2.31, Stimulating appropriate individual and group discussions with the use of instructional video games and simulations. 

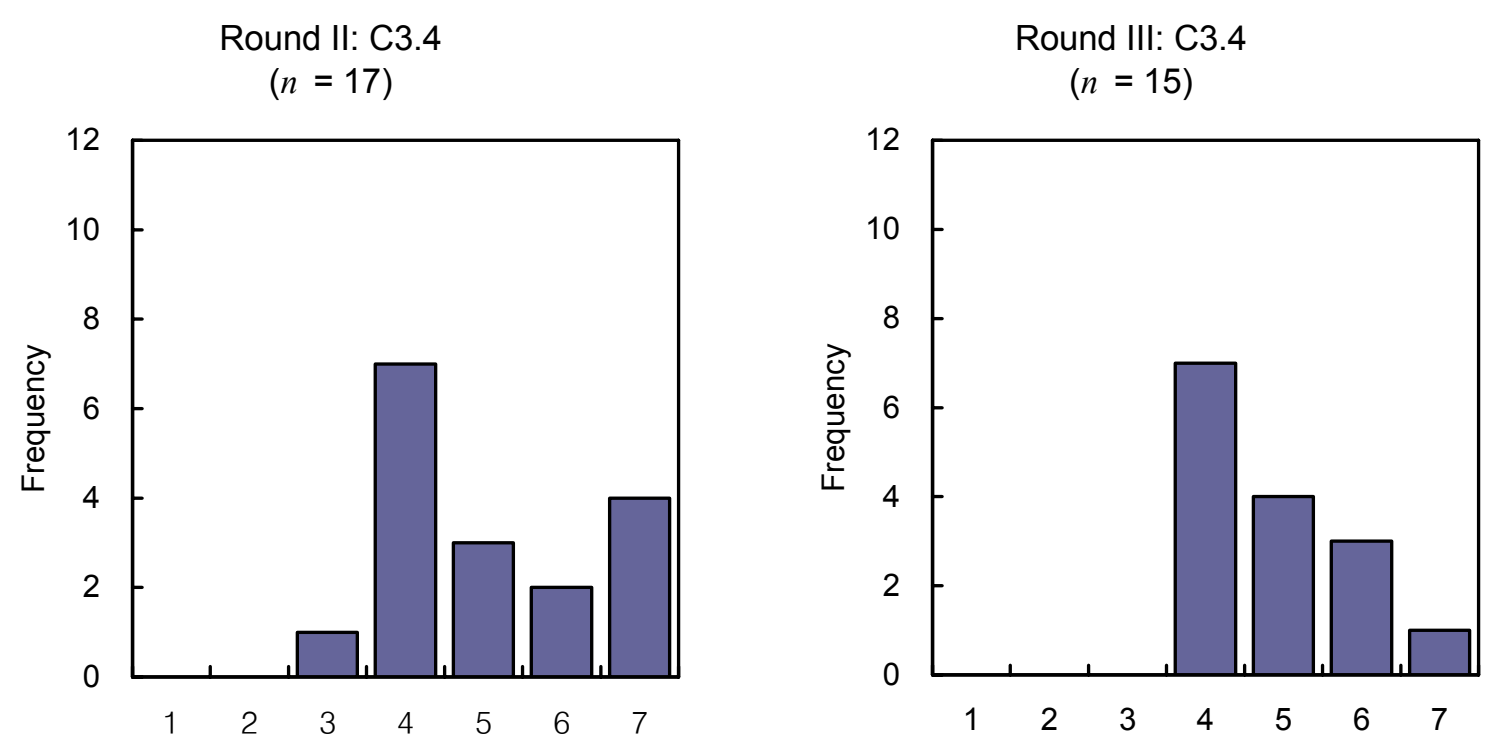

Figure 18. Frequency distribution for C3.4, Archiving and organizing audio/video clips based on content areas.
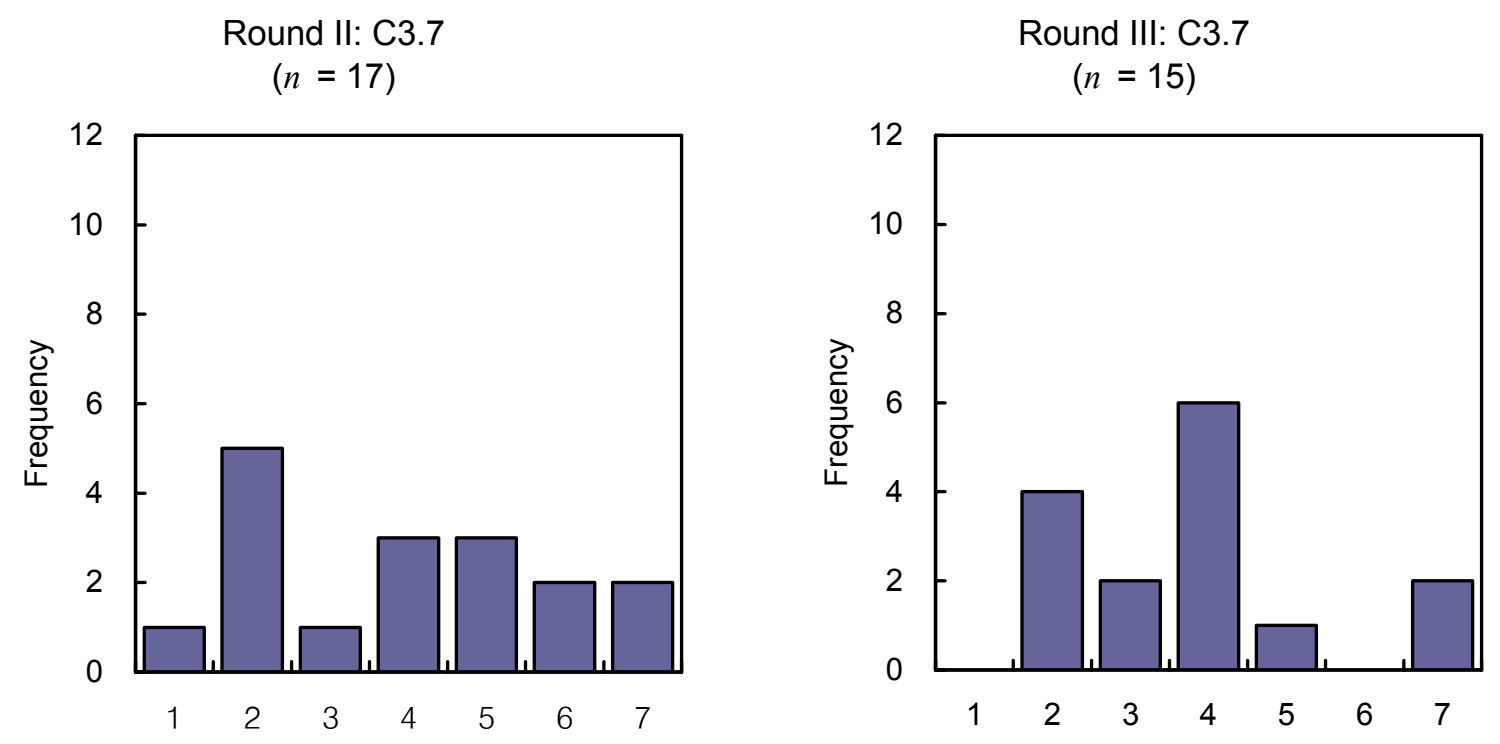

Figure 19. Frequency distribution for C3.7, Identifying and analyzing technical issues resulted from equipment malfunction or operator errors. 

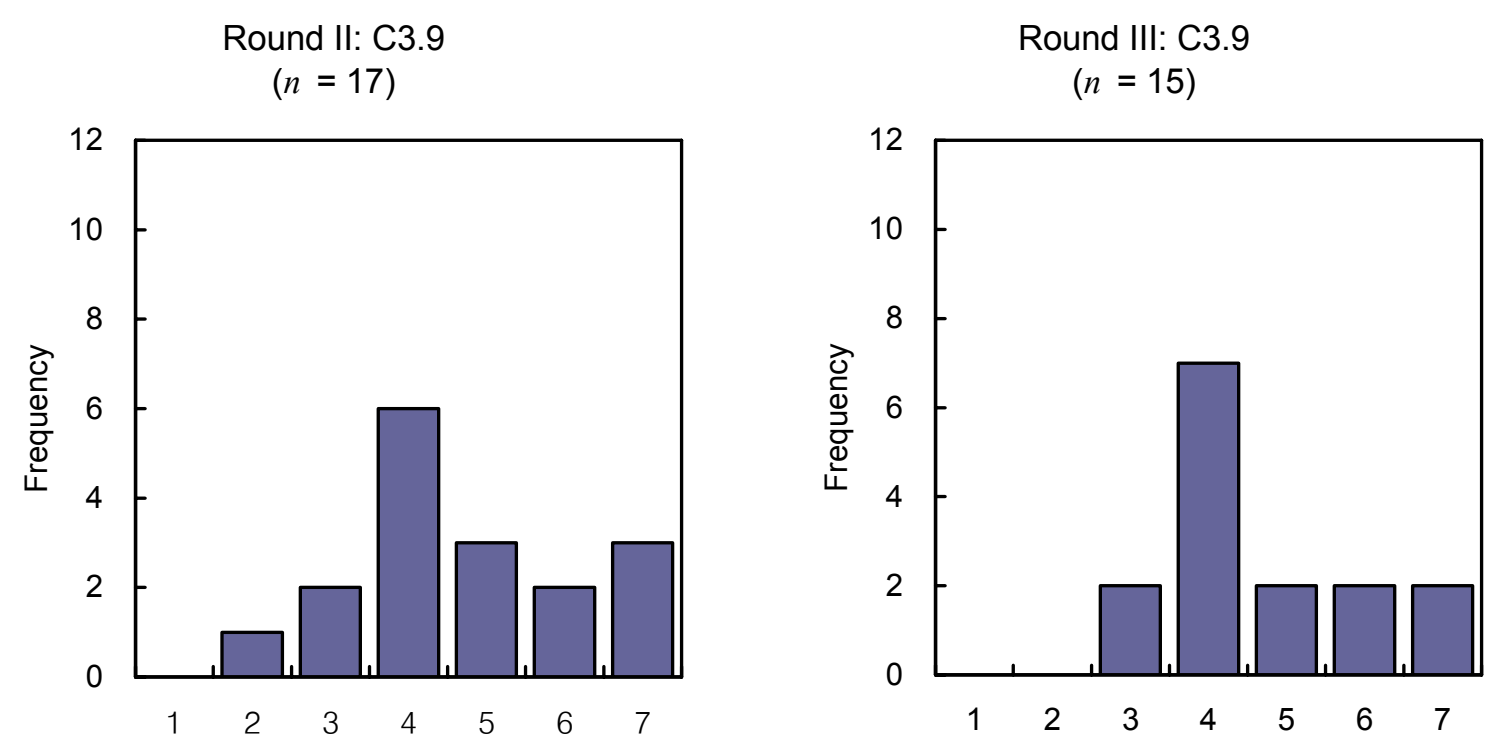

Figure 20. Frequency distribution for C3.9, Knowledge of how online text messages may appear to the learners.
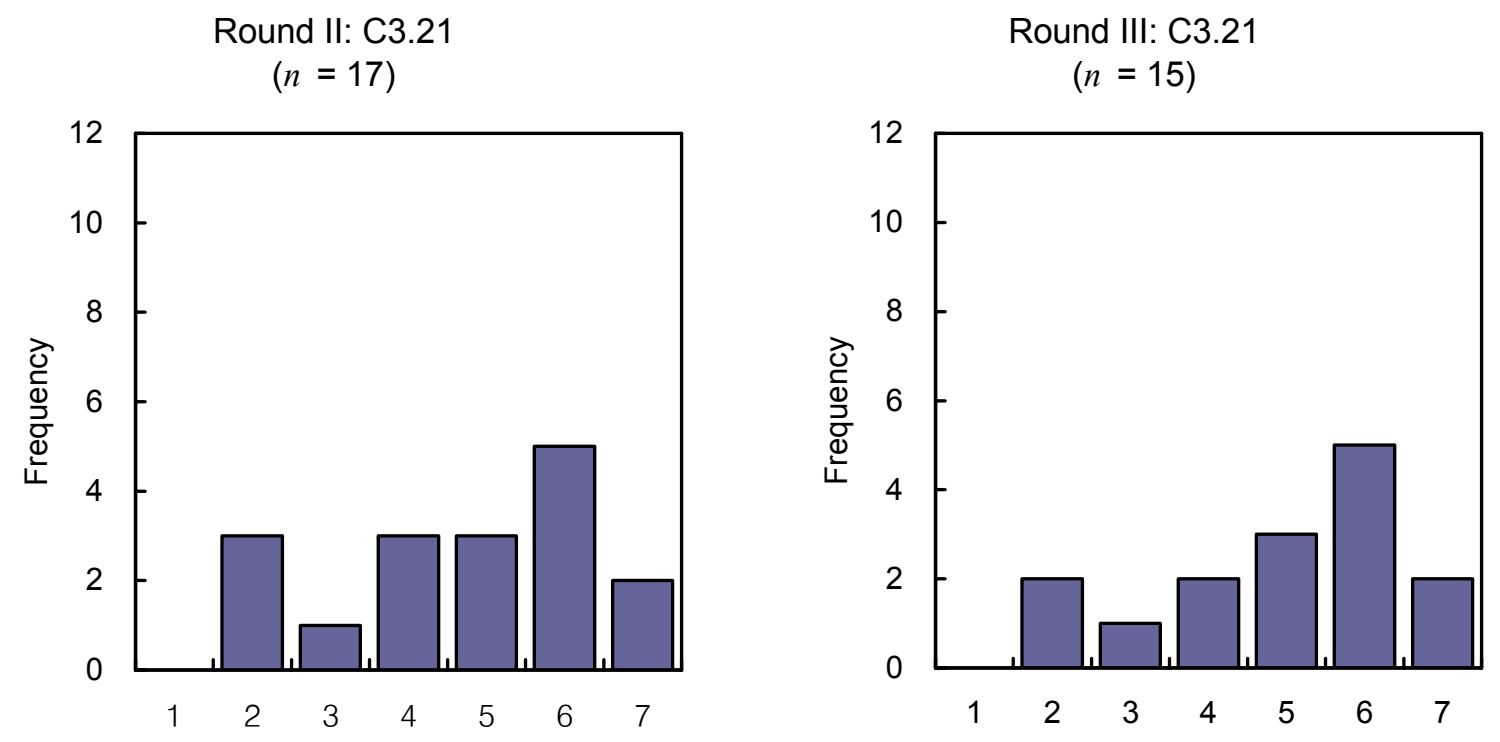

Figure 21. Frequency distribution for C3.21, Using FTP to share and retrieve course resources. 

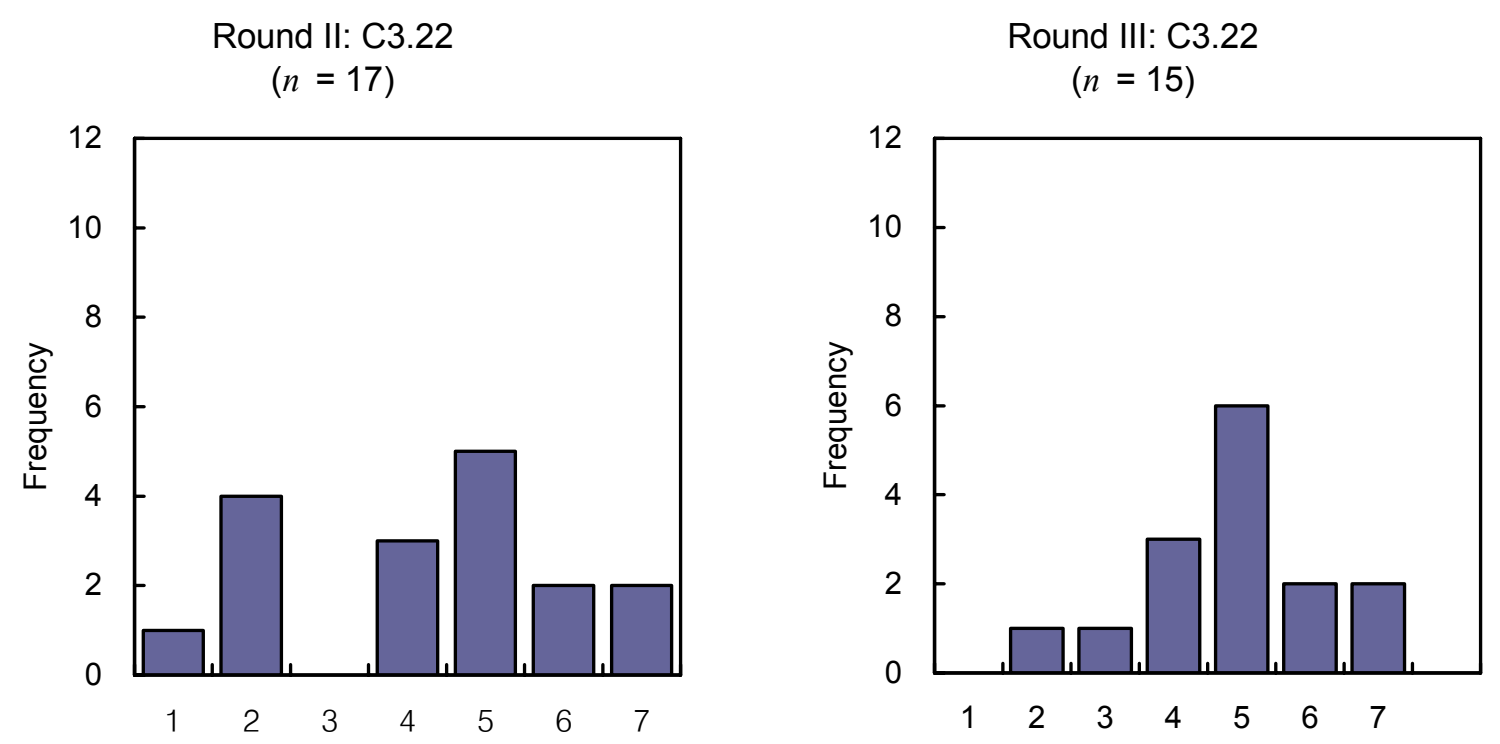

Figure 22. Frequency distribution for C3.22, Using hypertext to navigate materials in a manner suited to the learner's own learning style.

At the completion of Round III the following four competencies from the technology category remained as either no-consensus or neutral. This indicates panel experts could not decide whether the technical skills would be essential for higher education faculty in 2015 .

- C3.4, Archiving and organizing audio/video clips based on content areas

- C3.7, Identifying and analyzing technical issues resulted from equipment malfunction or operator errors

- C3.12, Preparation of graphics and art work

- C3.21, Using FTP to share and retrieve course resources

Figures 23 and 24 are illustrative of panel opinion for the following two competency statements that did not reach consensus or remained as neutral (undecided) after Round III. 

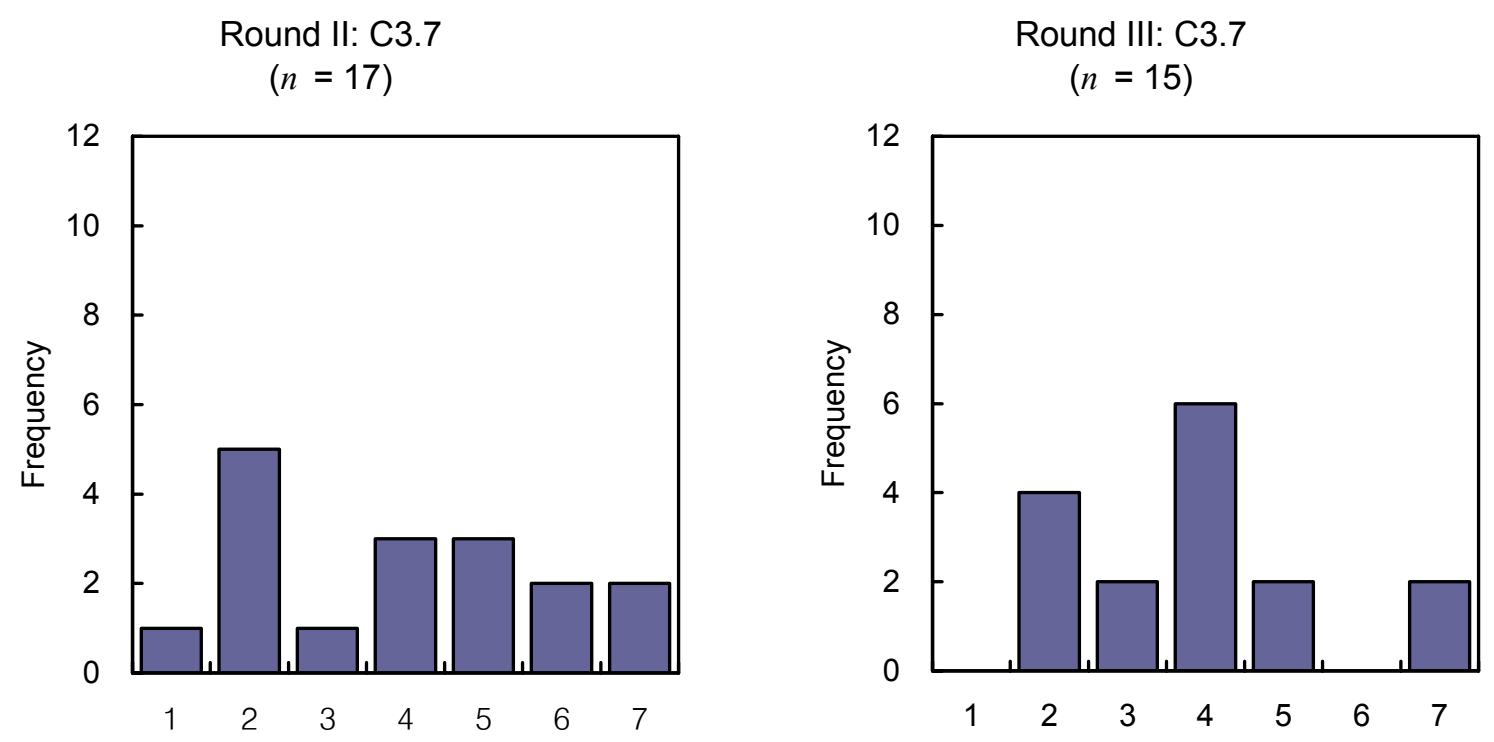

Figure 23. Frequency distribution for C3.7, Identifying and analyzing technical issues resulted from equipment malfunction or operator errors.
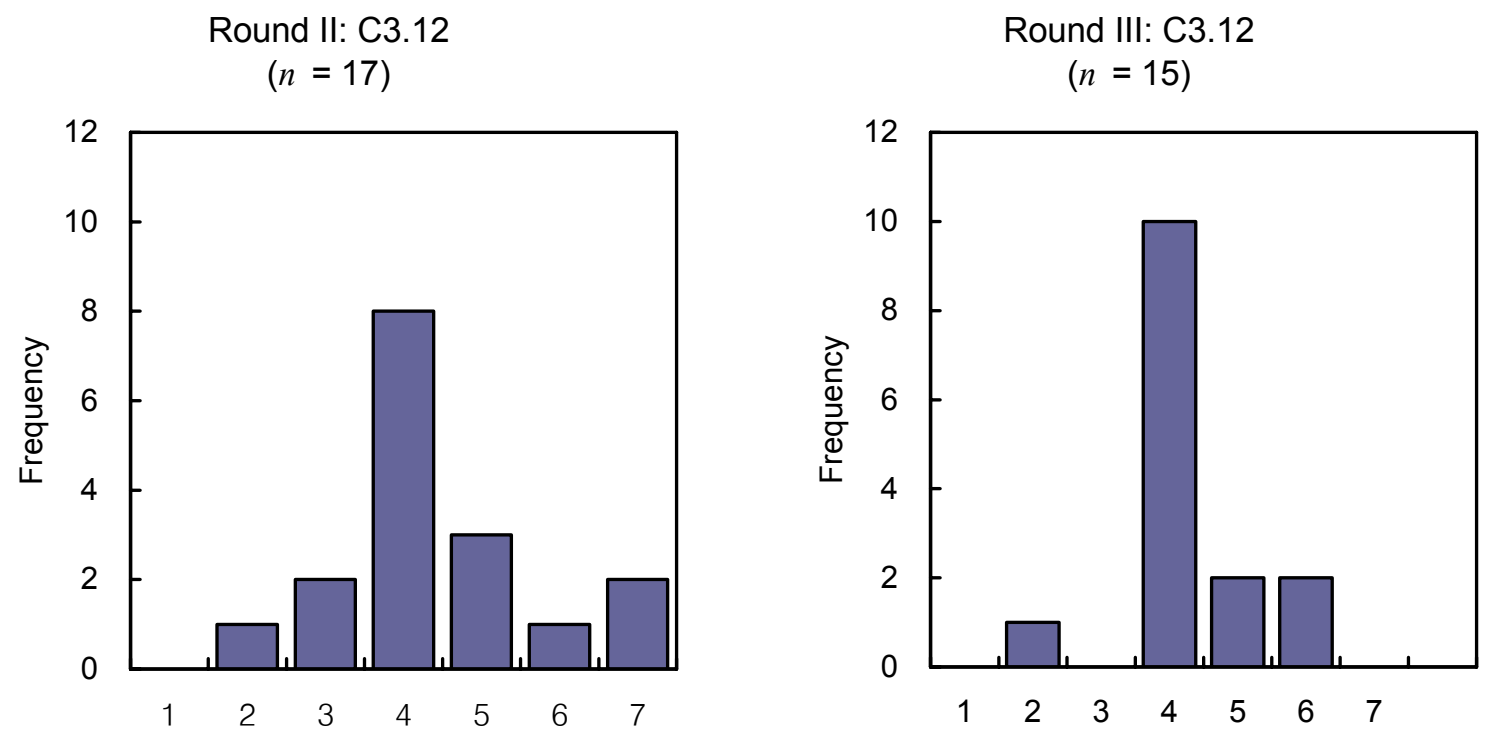

Figure 24. Frequency distribution for C3.12, Preparation of graphics and art work. 


\section{Summary of Delphi Findings}

\section{Delivery Modes}

A total of 42 delivery modes generated from the first round were condensed to 29 delivery modes grouped into seven categories: (a) F2F; (b) F2F + Satellite combo; (c) F2F + Web supplement; (d) Web-asynchronous; (e) Web-synchronous; (f) Webasynchronous/synchronous; and (g) Virtual Reality. Out of 29 sub-delivery modes included, a total of 17 reached consensus for positive agreement (11 from Round II; 6 from Round III). Table 25 illustrates the total number of sub-delivery modes listed under each category, the number of modes that reached consensus for positive agreement, and the total percentage of consensus for each category. At the conclusion of Round III the resulting delivery modes consisted of five categories with a total of 17 delivery modes determined as major delivery mode for higher education faculty in the year 2015 .

Table 25

Summary of Final Delphi Findings on Delivery Modes

Delivery Modes Total Agreed Sub-modes Final Total \% \begin{tabular}{ll}
\multirow{2}{*}{ Sub-modes } & \multicolumn{2}{c}{$/$ Round } \\
\cline { 2 - 3 } & Round II Round III
\end{tabular}

List Consensus

\begin{tabular}{lccccc} 
F2F & 1 & 1 & - & 1 & 100 \\
F2F + Satellite & 1 & 0 & 0 & 0 & 0 \\
F2F + Web & 12 & 6 & 4 & 10 & 83.3 \\
Web-Asynchronous & 4 & 1 & 1 & 2 & 50 \\
Web-Synchronous & 4 & 1 & 0 & 1 & 25 \\
Web-Asynch/Synchronous & 4 & 1 & 2 & 3 & 75 \\
Virtual Reality & 3 & 0 & 0 & 0 & 0 \\
\hline
\end{tabular}


The F2F category included one sub-delivery mode and it reached consensus for positive agreement in Round II. The F2F + Satellite category also included one sub-delivery mode and it reached consensus for negative agreement from Round III. The F2F + Web supplement category had the most number of sub-delivery modes reaching consensus for positive agreement. The movement towards consensus on delivery modes between Round II and Round III is shown in Table 26.

Table 26

Movement towards Consensus on Delivery Modes

\begin{tabular}{|c|c|c|c|c|c|c|c|c|c|c|c|c|}
\hline \multirow[t]{3}{*}{ Delivery Modes } & \multicolumn{4}{|c|}{ Round II $(n=17)$} & \multicolumn{4}{|c|}{ Round III $(n=15)$} & \multicolumn{4}{|c|}{ Final Results } \\
\hline & \multirow[t]{2}{*}{$\underline{\text { Sub-D }}$} & \multicolumn{3}{|c|}{ No.Cons } & \multirow[t]{2}{*}{$\underline{\text { Sub-D }}$} & \multicolumn{3}{|c|}{ No.Cons } & \multirow[t]{2}{*}{$\underline{\text { Sub-D }}$} & \multicolumn{3}{|c|}{ No.Cons } \\
\hline & & $\underline{\mathrm{A}}$ & $\underline{\mathrm{N}}$ & $\underline{D}$ & & $\underline{\mathrm{A}}$ & $\underline{\mathrm{N}}$ & $\underline{\mathrm{D}}$ & & $\underline{\mathrm{A}}$ & $\underline{\mathrm{N}}$ & $\underline{\mathrm{D}}$ \\
\hline $\mathrm{F} 2 \mathrm{~F}$ & 1 & 1 & & & 0 & 0 & & & 1 & 1 & & \\
\hline $\mathrm{F} 2 \mathrm{~F}+$ Satellite & 1 & 0 & & & 1 & 0 & & 1 & 1 & & & 1 \\
\hline $\mathrm{F} 2 \mathrm{~F}+\mathrm{Web}$ & 12 & 6 & & & 6 & 4 & 1 & 1 & 12 & 10 & 1 & 1 \\
\hline Web-Asynchronous & 4 & 1 & & 1 & 2 & 1 & & & 4 & 2 & & 1 \\
\hline Web-Synchronous & 4 & 1 & & 1 & 2 & 0 & & 2 & 4 & 1 & & 3 \\
\hline Web-Asynch/Synch & 4 & 2 & & & 2 & 1 & & 1 & 4 & 3 & & 1 \\
\hline Virtual Reality & 3 & 0 & & & 1 & & 1 & & 1 & & 1 & \\
\hline Total & 29 & 11 & 1 & 3 & 14 & 6 & 2 & 5 & 27 & 17 & 2 & 7 \\
\hline
\end{tabular}

Note: "Sub-D" indicates the number of sub-delivery modes included to the round. "No.Cons" indicates the number of items that reached consensus. A: Agree; N: Neutral (a median of 4); D: Disagree

Out of 12 sub-delivery modes of the F2F + Web supplement category, 10 reached consensus for positive agreement (six from Round II; four from Round III), one sub-delivery mode (Mode 3.2: F2F + Web-Asynchronous Audio Supplement) reached consensus for neutral, and one (Mode 3.6: F2F + Web-Synchronous Audio Supplement) for negative disagreement. The Web-Asynchronous category included four sub-delivery modes. Of these modes, two reached consensus for positive agreement (one from Round II; one from Round III). One sub-delivery mode (Mode 4.2: Web-Asynchronous Audio) reached consensus for negative agreement, and one (Mode 4.3: Web-Asynchronous Video) failed to reach consensus. 
The Web-Synchronous category had the fewest number of sub-delivery modes reaching consensus for positive agreement ( 1 out of 4). Out of four sub-delivery modes of the WebSynchronous category, only one mode, Mode 5.4: Web-Synchronous Text/Audio/Video, reached consensus for positive agreement (from Round III) and the other three sub-delivery modes reached consensus for negative agreement (one from Round II; two from Round III). The WebAsynchronous/Synchronous category also included four sub-delivery modes. Out of those four, three sub-delivery modes reached consensus for positive agreement (two from Round II; one from Round III). One sub-delivery mode, Mode 6.2: Web-Asynchronous/Synchronous Audio, reached consensus for negative agreement. The Virtual Reality category included three subdelivery modes (Self-Guided, Instructor-Led, Community-Led) in Round II and later those submodes were merged into one mode and included as one item in Round III. As shown in Table 26, the total number of sub-delivery modes of Virtual Reality was 3 in Round II but Round III shows 1 under Sub-D column. The virtual reality mode reached consensus for neutral (undecided). In summary, only one out of total 29 delivery modes did not reach consensus. For Mode 4.3, Web-Asynchronous Video, even though some panel members re-rated the item a little higher than in Round II, there was not enough people to meet the consensus criteria $(f, 5-7 \geq$ $70 \%)$. After the third round, F2F + Satellite combo was removed from the final list as it reached consensus for negative agreement (median of 3; IQR of 2.0; 73\% of the ratings were within the 1-3 range) of the panel. The Virtual Reality category was also removed because it reached consensus for neutral (median of 4; IQR of 0 ). As one panelist commented, although it could be "the mode of the future," most panelists were not sure about the definite use of the course delivery mode in 10 years. 
The final list of delivery modes identified by panel experts is rank-ordered according to $\% f, 5-7$ and then according to the median within the category as shown in Table 27 . Not all the items in the final list reached consensus in the same round. The median of the items that reached consensus in Round III tends to be stronger than the ones that reached consensus in Round II. For example, Face-to-Face mode reached consensus with the median rating of 6 in Round II. If this item had reached consensus in Round III, the median rating would have gone up. All of F2F

+ Web sub-delivery modes, except two, reached consensus for positive agreement. Therefore, only the main category name, F2F + Web supplement is shown in the final list of delivery modes.

Table 27

Final List of Delivery Modes

\begin{tabular}{|c|c|c|c|c|}
\hline Delivery Modes & & Description & $\% f, 5-7$ & Mdn \\
\hline Face-to-Face & & $\begin{array}{l}\text { Traditional Face-to-Face Instruction } \\
\text { (everyone in the same room) }\end{array}$ & 94.1 & 6 \\
\hline F2F + Web Supplement & $\begin{array}{l}\text { Text } \\
\text { Video } \\
\text { Text/Audio/Video }\end{array}$ & $\begin{array}{l}\text { Blended instruction which includes a } \\
\text { combination of Face-to-Face (F2F) and } \\
\text { various Web-Supplemented modes of } \\
\text { instruction (asynchronous and } \\
\text { synchronous). Course information and } \\
\text { activities on the web but the course itself } \\
\text { is delivered in a traditional face-to-face } \\
\text { manner. }\end{array}$ & 88.2 & 6 \\
\hline $\begin{array}{l}\text { Web- } \\
\text { Asynchronous/Synchronous }\end{array}$ & Text/Audio/Video & $\begin{array}{l}\text { Web-based multi-mode instruction which } \\
\text { is delivered through all possible } \\
\text { combinations of text, audio, and video } \\
\text { based synchronous and asynchronous } \\
\text { communications, such as audio/video } \\
\text { clips, streaming audio/video, } \\
\text { teleconferencing, audio/video chat, } \\
\text { hypertext documents, email, Weblogs, } \\
\text { whiteboard, instant messaging, etc. }\end{array}$ & 82.3 & $7 *$ \\
\hline $\begin{array}{l}\text { Web- } \\
\text { Asynchronous/Synchronous }\end{array}$ & Text & $\begin{array}{l}\text { Web-based instruction (no F2F contact) } \\
\text { which is delivered through a combination } \\
\text { of asynchronous and synchronous text } \\
\text { based communications, such as hypertext } \\
\text { documents, email, listserv, weblogs, } \\
\text { whiteboard, and instant messaging. }\end{array}$ & 82.3 & 6 \\
\hline
\end{tabular}


Table 27 (continued)

\begin{tabular}{|c|c|c|c|c|}
\hline Delivery Modes & & Description & $\% f, 5-7$ & Mdn \\
\hline Web-Synchronous & Text/Audio/Video & $\begin{array}{l}\text { Web-based instruction which is delivered } \\
\text { through the combination of text, audio, } \\
\text { and video based synchronous } \\
\text { communications in real time, such as } \\
\text { streaming audio/video, audio/video chat, } \\
\text { audio/video conferencing, whiteboard, } \\
\text { instant messaging, etc. }\end{array}$ & 76.5 & 5 \\
\hline Web-Asynchronous & Text/Audio/Video & $\begin{array}{l}\text { Web-based instruction which is delivered } \\
\text { through a combination of text, audio, and } \\
\text { video based asynchronous } \\
\text { communications, such as audio/video } \\
\text { clips, audio/video libraries, still images, } \\
\text { hypertext documents, discussion boards, } \\
\text { listserv, email, Weblogs, etc. One } \\
\text { example could be online course } \\
\text { management tools, such as WebCT or } \\
\text { Blackboard. }\end{array}$ & 76.4 & 6 \\
\hline Web-Asynchronous & Text & $\begin{array}{l}\text { Web-based instruction delivered only } \\
\text { through asynchronous text based } \\
\text { communications, such as hypertext } \\
\text { documents, discussion boards, email, } \\
\text { listserv, Weblogs, etc. Students progress } \\
\text { at their own pace and may access the } \\
\text { course materials independent of other } \\
\text { students and at different times. }\end{array}$ & 73.3 & 6 \\
\hline $\begin{array}{l}\text { Web- } \\
\text { Asynchronous/Synchronous }\end{array}$ & Video & $\begin{array}{l}\text { Web-based instruction which is delivered } \\
\text { through a combination of asynchronous } \\
\text { and synchronous video based } \\
\text { communications only, such as video clips, } \\
\text { video resources, Web video conference, } \\
\text { video chat, etc. }\end{array}$ & 53.3 & $5 *$ \\
\hline
\end{tabular}

Note. Judgments were made on 7-point scales $(1=$ strongly disagree, $7=$ strongly agree $)$. The higher IQR score, the wider range of panel ratings. $\%$ f, 5-7 indicates the percentage of frequency for scores, 5-7. * indicates the items that reached consensus in Round III.

\section{Teaching Competencies}

A total of 167 competency statements generated from the first round were grouped into five categories: (a) Planning and Designing Learning Environment, (b) Teaching and Learning; (c) Technology; (d) Assessment and Evaluation; and (e) Cultural Ethical issues. Round II Questionnaire contained 89 competency statements, which were rated by the panel experts. As summarized in Table 28, out of 89 competency statements, a total of 77 reached consensus for 
positive agreement (64 from Round II; 13 from Round III).

Table 28

Summary of Final Delphi Findings on Teaching Competencies

\begin{tabular}{|c|c|c|c|c|}
\hline \multirow{2}{*}{ Competency Categories } & \multirow{2}{*}{$\begin{array}{c}\text { Total } \\
\text { Sub-C }\end{array}$} & Agreed Sub-C/Round & \multirow{2}{*}{$\begin{array}{l}\text { Fina } \\
\text { List }\end{array}$} & \multirow{2}{*}{$\begin{array}{c}\text { Total \% } \\
\text { Consensus }\end{array}$} \\
\hline & & & & \\
\hline
\end{tabular}

\begin{tabular}{lccccc}
$\begin{array}{l}\text { Planning and Designing } \\
\text { Learning Environment }\end{array}$ & 12 & 11 & 1 & 12 & 100 \\
$\begin{array}{l}\text { Teaching and Learning } \\
\text { Technology }\end{array}$ & 36 & 27 & 5 & 32 & 88.9 \\
Assessment and Evaluation & 6 & 16 & 5 & 21 & 72.4 \\
Cultural Ethical Issues & 6 & 6 & 0 & 6 & 100 \\
$\begin{array}{l}\text { Total Number of } \\
\text { Competencies }\end{array}$ & 89 & 64 & 13 & 77 & 86.5 \\
\hline
\end{tabular}

Note: "Sub-C" indicates the number of sub-competencies.

The number of sub-competencies listed under each category in Round II and Round III is shown in Table 29. Twelve competency statements were included in the Planning and Designing Table 29

Movement towards Consensus on Teaching Competencies

\begin{tabular}{|c|c|c|c|c|c|c|c|c|c|c|c|c|}
\hline \multirow[t]{3}{*}{ Competencies } & \multicolumn{4}{|c|}{ Round II $(n=17)$} & \multicolumn{4}{|c|}{ Round III $(n=15)$} & \multicolumn{4}{|c|}{ Final Results } \\
\hline & \multirow[t]{2}{*}{$\underline{\text { Sub-C }}$} & \multicolumn{3}{|c|}{ No.Cons } & \multirow[t]{2}{*}{$\underline{\text { Sub-C }}$} & \multicolumn{3}{|c|}{ No.Cons } & \multirow[t]{2}{*}{$\underline{\text { Sub-C }}$} & \multicolumn{3}{|c|}{ No.Cons } \\
\hline & & $\underline{\mathrm{A}}$ & $\underline{\mathrm{N}}$ & $\underline{D}$ & & $\underline{\mathrm{A}}$ & $\underline{N}$ & $\underline{\mathrm{D}}$ & & $\underline{\mathrm{A}}$ & $\underline{N}$ & $\underline{D}$ \\
\hline $\begin{array}{l}\text { Planning and Designing } \\
\text { Learning Environment }\end{array}$ & 12 & 11 & & 0 & 1 & 1 & & & 12 & 12 & 0 & 0 \\
\hline Teaching and Learning & 36 & 27 & & 0 & 9 & 5 & 1 & 1 & 36 & 32 & 1 & 1 \\
\hline Technology & 29 & 16 & & 0 & 13 & 5 & 2 & 1 & 29 & 21 & 2 & 1 \\
\hline Assessment and Evaluation & 6 & 6 & & 0 & 0 & 0 & & & 6 & 6 & & 0 \\
\hline Cultural Ethical Issues & 6 & 4 & & 0 & 2 & 2 & & 0 & 6 & 6 & & 0 \\
\hline Total & 89 & 64 & 2 & 0 & 25 & 13 & 3 & 2 & 89 & 77 & 3 & 2 \\
\hline
\end{tabular}

Note: "Sub-C" indicates the number of sub-competencies for each category included to the round. "No.Cons" indicates the number of items that reached consensus. A: Agree; N: Neutral (a median of 4); D: Disagree 
Learning Environment category. All 12 competencies reached consensus for positive agreement (11 from Round II; one from Round III). The panelist agreed that all of the competencies in this category would be needed by teacher educators in 10 years. The panel judged eight items to be most essential and four were viewed as essential.

The Teaching and Learning category included 36 competency statements, the largest number when compared to other categories. Of these competency statements, 32 reached consensus for positive agreement (27 from Round II; five from Round III). The panel judged 15 items to be most essential. Of the remaining 17 items, the panel considered nine essential; six were viewed as moderately essential, and the panel was undecided about two items; "Preparation of graphics and art work" and "Using FTP to share and retrieve course resources." Twenty-nine competency statements were included in the technology category. Of these statements, 21 reached consensus for positive agreement (16 from Round II; 5 from Round III). The panel judged only six items to be most essential. Of the remaining 15 items, the panel considered 8 as essential, 7 as moderately essential, and was undecided about one item, "Moderating audio discussions over the Web phone using established procedures and policies." The assessment and evaluation category included six competency statements. All six competency statements reached consensus in Round II. The cultural ethical issues category also included six competency statements. All six of the competency statements for this category also reached consensus (four from Round II; two from Round III). At the end of Round III the resulting competencies consisted of five categories with a total of 77 teaching competencies found essential for higher education faculty in the year 2015 . 
The final list of 77 teaching competencies reaching consensus on being essential in the year 2015, as identified by panel experts, is presented in Table 30. The competency statements are rank-ordered from the highest to the lowest frequency and then by the median scores within category. The median was used because not all the items in the final list reached consensus in the same round. The median of the items that reached consensus in Round III tends to be stronger than the ones that reached consensus in Round II. For example, C1.5 reached consensus with the median rating of 6 in Round II. If this item had reached consensus in Round III, the median rating would have gone up.

Table 30

Final List of Teaching Competencies Teaching Competencies $\% f, 5-7 \quad M d n$

Category 1: Planning and Designing Learning Environment (12)

C1.1 Basic instructional design skills in planning teaching and learning materials/activities

Design of appropriate learning activities and instructional materials based on students' ability

$100 \quad 7$

C1.9* Evaluation of computer software for educational purposes

C1.10 Selecting lessons and content matched to a delivery method

C1.4 Creating an effective online syllabus

$100 \quad 7$

C1.7 Determining when face-to-face instruction is optimum mode of

$94.1 \quad 7$
delivery within a course scope and sequence

$94.1 \quad 7$

C1.8 Developing lessons that incorporate audio and video in meaningful ways

$94.1 \quad 7$

Using web based course management tools such as WebCT and

C1.12 Blackboard

$94.1 \quad 7$

C1.2 Compiling appropriate curriculum resources in online formats

$94.1 \quad 6$

C1.3 Conducting research on the web

$94.1 \quad 6$

C1.11 Converting existing course materials into appropriate Web formats

C1.5 Creating text-based web pages to supplement teaching

$88.2 \quad 6$

Category 2: Teaching and Learning (32)

C2.2 Clear presentations and delivery of content based on important ideas, principles and concepts 100

82.4

C2.5 Effective communication using both verbal and non-verbal skills

$\mathrm{C} 2.22$

Promoting student participation in face-to-face instruction

100

7

$\mathrm{C} 2.24$

Providing clear objectives, expectations, and policies

100

7

$\mathrm{C} 2.28$

Providing students prompt, constant and constructive feedback

100

7

C2.29

Questioning technique to elicit learner participation and growth

100

7

$\mathrm{C} 2.35$

Using the web as a resource

100 
Table 30 (continued)

\begin{tabular}{|c|c|c|c|}
\hline & Teaching Competencies & $\% f, 5-7$ & $M d n$ \\
\hline \multicolumn{4}{|c|}{ Category 2: Teaching and Learning (32) } \\
\hline $\mathrm{C} 2.36$ & Using videos and audios in effective ways & 100 & 7 \\
\hline $\mathrm{C} 2.4$ & Developing reciprocity and cooperation among students & 94.1 & 7 \\
\hline $\mathrm{C} 2.9$ & Facilitating face-to-face classroom discussion & 94.1 & 7 \\
\hline $\mathrm{C} 2.18$ & Monitoring each individual's participation & 94.1 & 7 \\
\hline $\mathrm{C} 2.7$ & $\begin{array}{l}\text { Encouraging students to bring real-life examples into the online } \\
\text { classroom }\end{array}$ & 94.1 & 6 \\
\hline $\mathrm{C} 2.13$ & Managing group work online & 94.1 & 6 \\
\hline $\mathrm{C} 2.33$ & Tracking students' activities online & 94.1 & 6 \\
\hline $\mathrm{C} 2.17 *$ & $\begin{array}{l}\text { Monitoring and structuring student learning in virtual } \\
\text { environment }\end{array}$ & 93.3 & 7 \\
\hline $\mathrm{C} 2.16$ & $\begin{array}{l}\text { Moderating online discussions to achieve effective levels of } \\
\text { student-student interaction }\end{array}$ & 88.2 & 7 \\
\hline $\mathrm{C} 2.8$ & $\begin{array}{l}\text { Facilitating discussions in the two way audio and video } \\
\text { environment }\end{array}$ & 88.2 & 6 \\
\hline $\mathrm{C} 2.12$ & Leading online discussions between students/learners and guests & 88.2 & 6 \\
\hline $\mathrm{C} 2.27$ & $\begin{array}{l}\text { Providing structure for students but allow for flexibility and } \\
\text { negotiation in online course }\end{array}$ & 88.2 & 6 \\
\hline $\mathrm{C} 2.14^{*}$ & Managing non-verbal exchange in virtual environment & 86.7 & 6 \\
\hline $\mathrm{C} 2.21$ & Promoting collaborative learning online & 82.4 & 7 \\
\hline $\mathrm{C} 2.1$ & Building online learning communities & 82.3 & 7 \\
\hline $\mathrm{C} 2.32 *$ & Stimulating individual/peer/group interaction at each of the & & \\
\hline & Satellite sites & 80.0 & 6 \\
\hline $\mathrm{C} 2.20^{*}$ & Posting customized assignments in online environment & 80.0 & 5 \\
\hline $\mathrm{C} 2.6$ & $\begin{array}{l}\text { Encouraging interaction among receiving sites and among } \\
\text { students and with the teacher }\end{array}$ & 76.5 & 6 \\
\hline $\mathrm{C} 2.3$ & Coordinating student access to online curriculum resources & 76.5 & 5 \\
\hline $\mathrm{C} 2.10$ & $\begin{array}{l}\text { Facilitating individual and group discussions with the use of } \\
\text { video streaming }\end{array}$ & 76.5 & 5 \\
\hline $\mathrm{C} 2.25$ & $\begin{array}{l}\text { Providing examples of model interactions with other students } \\
\text { without betraying confidence }\end{array}$ & 76.5 & 5 \\
\hline $\mathrm{C} 2.30$ & Realistic expectations for workload & 76.5 & 5 \\
\hline $\mathrm{C} 2.34^{*}$ & $\begin{array}{l}\text { Using appropriate vocal inflections and modulation to maintain } \\
\text { learners' attention and interest }\end{array}$ & 73.3 & 5 \\
\hline $\mathrm{C} 2.19$ & Personalizing the course based on students' learning style & 70.6 & 5 \\
\hline $\mathrm{C} 2.26$ & $\begin{array}{l}\text { Providing motivation to distance learners to keep up with their } \\
\text { peers moves for assessment purposes }\end{array}$ & 70.6 & 5 \\
\hline Category 3: Tec & inology $(21)$ & & \\
\hline $\mathrm{C} 3.28$ & Using the Internet effectively & 100 & 7 \\
\hline $\mathrm{C} 3.1$ & Ability to follow developments in online teaching techniques & 100 & 6 \\
\hline $\mathrm{C} 3.2$ & Adopting new technologies into courses & 95.1 & 7 \\
\hline C3.17 & Sending and receiving email & 88.2 & 7 \\
\hline C3.26 & Using multiple technology devices in face-to-face instruction & 88.2 & 7 \\
\hline C3.29 & Visual presentation skills in face-to-face instruction & 88.2 & 7 \\
\hline C3.27 & $\begin{array}{l}\text { Using synchronized communications including chat room, ICQ, } \\
\text { NetMeeting, etc. }\end{array}$ & 88.2 & 6 \\
\hline $\mathrm{C} 3.14^{*}$ & Proficiency with all technical systems used in the course & 86.6 & 5 \\
\hline
\end{tabular}


Table 30 (continued)

\begin{tabular}{|c|c|c|c|}
\hline & Teaching Competencies & $\% f, 5-7$ & $M d n$ \\
\hline \multicolumn{4}{|c|}{ Category 3: Technology (21) } \\
\hline $\mathrm{C} 3.15^{*}$ & $\begin{array}{l}\text { Publishing multimedia such as audio, video and/or still images } \\
\text { online }\end{array}$ & 86.6 & 5 \\
\hline C3.16 & Selecting and evaluating technology based on learning materials & 82.4 & 6 \\
\hline \multirow[t]{2}{*}{ C 3.20} & $\begin{array}{l}\text { Using asynchronous communications, such as Listserv, } \\
\text { Discussion Boards and Weblogs to enhance teaching }\end{array}$ & & \\
\hline & effectiveness & 82.3 & 7 \\
\hline C3.11 & Online navigation and search technique & 82.3 & 6 \\
\hline $\mathrm{C} 3.23$ & $\begin{array}{l}\text { Using instructional video games and simulations in effective } \\
\text { ways }\end{array}$ & 80.8 & 5 \\
\hline $\mathrm{C} 3.13^{*}$ & Preparation of lecture presentation using presentation software & 80.0 & 6 \\
\hline $\mathrm{C} 3.10^{*}$ & Online file management & 80.0 & 5 \\
\hline $\mathrm{C} 3.3$ & $\begin{array}{l}\text { Advising students on multi-media and note-taking using mobile } \\
\text { technologies in classroom }\end{array}$ & 76.5 & 6 \\
\hline C3.24 & Using interactive presentations on web & 76.5 & 6 \\
\hline $\mathrm{C} 3.8$ & $\begin{array}{l}\text { Knowledge of a variety of interactive techniques (small group } \\
\text { work, projection devices, handheld) appropriate for the course } \\
\text { environment }\end{array}$ & 76.4 & 6 \\
\hline C3.25 & $\begin{array}{l}\text { Using local network to transfer, retrieve, and save teaching and } \\
\text { learning materials and to share them among teachers and/or } \\
\text { students }\end{array}$ & 70.6 & 5 \\
\hline $\mathrm{C} 3.5$ & Archiving course sessions & 52.9 & 5 \\
\hline C3.18 & Streaming audio/video & 52.9 & 5 \\
\hline \multicolumn{4}{|c|}{ Category 4: Assessment and Evaluation (6) } \\
\hline $\mathrm{C} 4.3$ & $\begin{array}{l}\text { Assessment of student learning of core course knowledge as well } \\
\text { as exemplary learning that reach beyond established course } \\
\text { knowledge }\end{array}$ & 94.1 & 7 \\
\hline $\mathrm{C} 4.4$ & Defining participation and grading criteria & 94.1 & 7 \\
\hline $\mathrm{C} 4.6$ & Performing Needs Assessment and selecting instructional goals & 94.1 & 7 \\
\hline C4.1 & Administering appropriate assessments based on a delivery mode & 88.2 & 7 \\
\hline $\mathrm{C} 4.2$ & Assessing and evaluating strategies for data collection & 88.2 & 6 \\
\hline $\mathrm{C} 4.5$ & $\begin{array}{l}\text { Designing and developing assessment strategies appropriate for } \\
\text { learning objectives and the online environment }\end{array}$ & 82.3 & 7 \\
\hline \multicolumn{4}{|c|}{ Category 5: Cultural Ethical Issues (6) } \\
\hline C5.2 & Awareness of cultural differences & 100 & 7 \\
\hline C5.4 & Respecting privacy issues online & 100 & 7 \\
\hline C5.1 & Advising students on how to determine relevant online sources & 100 & 6 \\
\hline $\mathrm{C} 5.3$ & $\begin{array}{l}\text { Referring problems to appropriate Web resources and follow up } \\
\text { to assure resolution }\end{array}$ & 88.2 & 6 \\
\hline $\mathrm{C} 5.5^{*}$ & Reviewing demographic data on student & 73.3 & 5 \\
\hline C5.6* & Setting up model searches online & 73.3 & 5 \\
\hline
\end{tabular}

Note. Judgments were made on 7-point scales $(1=$ not necessary, 7 = essential $) .{ }^{*}$ indicates the items that reached consensus in the third round. $\% f, 5-7$ indicates the percentage of frequency for the scale 5-7. 
Data comparison between Round II and III indicated that no further rounds were necessary. Looking between rounds not only showed whether any consensus agreement was achieved and what the final opinion was, but it also showed whether the consensus agreement existed throughout each round or was reached in the later rounds. This demonstrates that as a result of this process, collective group opinion changed. Analysis of data indicates similar consensus patterns between delivery mode and competency categories. A review of the responses and comments made by the panel members suggests that interesting conclusions can be drawn from the study. The following chapter will present these conclusions, discuss implications based on conclusions, and make recommendations for future research. 


\section{CHAPTER V: CONCLUSIONS, IMPLICATIONS, AND RECOMMENDATIONS}

This chapter is divided in the following sections: (a) conclusions driven by data collected to answer the stated research questions, (b) implications derived from those conclusions, and (c) recommendations for future research to address gaps revealed by the study.

\section{Conclusions}

The purpose of the study was to reach consensus on future course delivery modes and recommended teaching competencies that would be needed by teacher education faculty for teaching environments in the year 2015. A three-round, online modified Delphi study was used to answer the following research questions: (a) Research Question 1: What course delivery modes will teacher education faculty of traditional colleges and universities be using in 2015?, and (b) Research Question 2: What competencies will teacher education faculty of traditional colleges and universities need to teach using these delivery modes? General teaching competencies were determined as a result of consensus from a panel of 17 educational experts drawn from institutions within the National Council for Accreditation of Teacher Education (NCATE) and other educational organizations. Three Delphi rounds were required before reaching stability in group responses. Upon completion of the Delphi data analysis, conclusions were drawn to answer the two research questions.

\section{Research Question 1}

The first research question was examined through data collected from the "Part I: Delivery Modes" section of the Delphi instruments (see Appendix E, G, and H). Data analysis after the third and final round indicated that the Face-to-Face + Satellite combo and Virtual Reality course delivery modes will not be seen in traditional colleges and universities in 2015 . As commented by one panelist, Satellite course delivery "will turn out to be a dead end and 
eventually be an old technology after 10 years.” Additional comments made by some panelists indicate that Virtual Reality is believed to be a good teaching tool but prohibitive because of the associated expenses. This uncertainty towards Virtual Reality is further evidenced in the comments made by two other panelists:

- "This is definitely the mode of the future; just not sure we will be there in 10 years. May take longer."

- "They'll never buy it."

It is evident that a single mode instructional option such as text, audio, or video only will not be used in future teaching environments. According to the study results, sub-modes F2F + Web-Asynchronous Audio and F2F + Web-Synchronous Audio Supplement will not be major delivery modes 10 years from now. Nor will Web-Asynchronous Audio, Web-Asynchronous Video, Web-Synchronous Text, Web-Synchronous Audio, Web-Synchronous Video, and WebAsynchronous/Synchronous Audio be used as a major delivery mode. Panelists' comments such as, "Asynchronous audio is as bad as a lecture except you can do it on your own...I expect text only will still have a strong presence, but the combination strategies will become more common" shows that the audio instruction option is also not likely to be integrated as a web supplemental media. This finding implies that future teaching environments will use multiple delivery modes using text, audio, video, and graphics concurrently rather than as single delivery mode options.

Face-to-Face traditional course delivery will remain as a major delivery mode 10 years from now. This finding contradicts the literature reviewed which predicted teaching would occur outside of a traditional classroom environment and instead occur in a virtual classroom largely facilitated by Internet technologies (Sherer \& Shea, 2002). The participants of this Delphi study clearly favored traditional Face-to-Face course delivery methods over fully online methods. 
From the majority of comments panelists made regarding Face-to-Face delivery mode, it is apparent that teacher educators in traditional colleges and universities will continue to deliver their courses involving some variation of the Face-to-Face teaching environment. "I don't think this will go away entirely...rather it will be supplemented by other things... and the face-to-face mode will still be present in internships and field experiences..." Such comments lead this researcher to believe that they still want to have some elements of face-to-face contact with their students reminiscent of the traditional classroom. Therefore, it is safe to say that the F2F mode will not go away entirely, but rather that it will continue to be supplemented by the Web to some extent.

The use of blended delivery modes, such as Face-to-Face + Web (asynchronous and synchronous), will increase. The variety of Web-based delivery modes such as WebAsynchronous Text/Audio/Video, Web-Synchronous Text/Audio/Video, Web-Asynchronous/ Synchronous Text, Web-Asynchronous/Synchronous Video, Web-Asynchronous/Synchronous Text/Audio/Video will continue to be used by teacher education faculty of traditional colleges in 2015. Contrary to current literature that promotes the future use of synchronous online course delivery methods, the Web-synchronous delivery option was the least popular choice among the panelists participating in this Delphi study. Moreover, it is important to point out that the results of the study do indicate that higher education faculty in the future will make more use of online technology in teaching, though in specific types of blended modes. Information technologies are becoming increasingly easier to integrate into both online and F2F classroom settings. And, as this trend continues it is expected that asynchronous online strategies will become more integral to course web environments than synchronous ones, requiring faculty to become increasingly familiar using both asynchronous and synchronous approaches. 
It should be noted that one limitation of this study was the panel itself. Although collectively the breadth of panel expertise was strong, none of the members were representative of the high technology industry, and may account for why panel members could not envision the use of such modes as Virtual Reality for the future. The problem with using the Virtual Reality delivery mode is one of not having well designed virtual reality places that fit curricular needs. As stated by one panelist, "This stuff always sounds good. Maybe in 10 years. But right now the problem is that there have to be 'places' worth visiting and the visits need to fit curricular demands." And even though a few panel experts responded in the first round that Virtual Reality is "definitely the mode of the future," they were persuaded to change their ratings in subsequent rounds after having reviewed other panel member comments.

In conclusion, teacher education faculty of traditional colleges and universities in 2015 will integrate more online technologies into their Face-to-Face classroom-based teaching environment. Blended course delivery modes integrating online components was strongly supported by the panel experts who participated in the study. Among various online approaches, the asynchronous or combination of asynchronous and synchronous mode will be more used than the synchronous mode alone.

\section{Research Question 2}

The second research question was examined through the data collected from the "Part II: Teaching Competencies" section of the Delphi instruments (see Appendix E, G, and H). The panel experts identified a total of 77 teaching competencies that would be needed by higher education faculty in the teaching environments of 2015.

The study identifies certain online technology competencies as being essential to future teacher education faculty attempting to integrate online technologies into their traditional modes 
of instruction. It is clear that with the integration of online technologies into traditional F2F classroom environments teachers will have to set clear learning objectives and think through multi-modal combinations when delivering content. Higher education faculty in the future will need online technology competencies for professional activities such as lesson planning and preparation of teaching materials. This is consistent with the existing literature which highlights the importance of online teaching competencies required in the future higher education teaching environment. Furthermore, with the increased use of blended delivery modes, basic online technology competencies will become more essential for teacher educators than technical technology competencies. It was suggested by panel members that teachers should be able to know how to use the Web as a supplementary media, and how to design multiple Web-based components (text/audio/video/graphics). Panelists also agreed that future teacher education faculty should know how to use Web based course management tools such as WebCT and Blackboard.

Through a review of the final list of teaching competencies on which panelists reached consensus, three general skill sets were observed; (a) instructional design skills, (b) communication skills, and (c) skills in facilitating class discussion. The three skill sets observed within the final list indicate that traditional pedagogical knowledge would continue to be essential in planning, designing, and teaching regardless of the course delivery mode. Basic instructional design skills such as personalizing the course based on students' learning style, designing appropriate learning activities and instructional materials based on students' ability, and clear presentation and delivery of content based on important ideas, principles and concepts would continue to be essential for future teacher education faculty. The panel suggested that faculty should be able to facilitate or moderate student discussion in any teaching environment. 
More specifically, the following general communication skills were considered to be essential both in F2F and online teaching environment: (a) effective communication using both verbal and non-verbal skills, (b) building online learning communities, and (c) using appropriate vocal inflections and modulation to maintain learners' attention and interest. A number of additional competencies related to facilitating classroom discussion can be observed in the final list of teaching competencies identified by this study:

- Facilitating student discussion competencies such as facilitating discussions in the two way audio and video environment

- Facilitating face-to-face classroom discussion

- Facilitating individual and group discussions with the use of video streaming

- Leading online discussions between students/learners and guests

- Promoting collaborative learning online

- Promoting student participation in face-to-face instruction

- Moderating online discussions to achieve effective levels of student-student interaction

- Questioning technique to elicit learner participation and growth.

Although the study indicated that basic online technology competencies would be essential in teaching environments a decade from now, there was no consensus as to whether the more technical competencies should be required for future higher education teachers. In fact this study clearly indicates that the more technical competencies, such as archiving online course materials, using Telnet through the Web browser, identifying and analyzing technical issues resulting from equipment malfunction or operator errors, preparation of graphics and art work, troubleshooting technical problems, using FTP to retrieve course resources, would not be essential competencies for future higher education faculty. The clear conclusion drawn from this is that the future teacher education faculty will not be expected to perform all the technical tasks 
a technician would do in planning, designing, and delivering their course materials.

This is supported by comments from two panelists:

- "this is a huge demand on them, I do not think they also should be responsible for technical maintenance and technical set up"

- "Most of my answers here are again based on the presumed heightened presence of technical support through instructional technology centers...people will need to know how to drive the car but not necessarily how the car actually works or how to fix it."

In summary, although F2F will not entirely go away, online teaching and learning in teacher education will become more essential. More online technologies will be integrated into teaching environments of traditional colleges or universities by 2015. As a result teacher education faculty in the future will find it necessary to acquire specific online teaching competencies in addition to the traditional teaching competencies currently developed.

Implications

While reflecting upon the findings and conclusions drawn from the data analysis of this study, a number of implications became evident.

A clear implication stemming from the data indicates that future teaching environments will incorporate multiple modes using a blend of text, audio, video, and graphics concurrently rather than separately as a single delivery mode option. This implies that the increased use of online multi-modal instructional options will require teacher education faculty to learn how to incorporate those modes concurrently in their courses, either in blended or in fully online delivery environments. Moreover, with the anticipated increased use of blended instructional modes (Face-to-Face + Web), faculty will be expected to deliver their courses using Web-based course authoring or management tools such as WebCT and BlackBoard, which includes designing various instructional components in online format. The implication is that in order to 
acquire theses skills ongoing professional development programs must be in place to provide instruction on how to utilize the Web courseware tools more efficiently.

A second implication based on the conclusions is that higher education institutions in the future must continue to invest heavily in online course delivery systems. Given current trends, building online course delivery systems is an expensive venture and will continue to be. Therefore, higher education institutions will have to make significant investments in building their online teaching environments; purchasing software, hardware and communication infrastructures.

A third implication from this study is that if the identified delivery modes for the year 2015 are to be truly integral elements of the teaching practice, then teacher educators and curriculum planners must modify their teacher preparation programs to prepare teachers to deal with emerging technologies and resulting changes in traditional pedagogical principles. In addition, higher education institutions will need to incorporate the essential competencies identified by this study in such teacher preparation programs. At the pre-service level, those competencies might be taught in a required course as part of the teacher preparation program. At the in-service level, practicing teachers will need ongoing opportunities for obtaining those identified competencies from professional development programs. In addition, to promote a more systemic awareness the teaching competencies identified through this study should be used to inform those organizations responsible for standards development such as the ISTE National Educational Technology Standards (NETS) for Teachers (NETS-T), Interstate New Teacher Assessment and Support Consortium (INTASC) standards, and the National Board for Professional Teaching Standards (NBPTS) Five Core Standards. 
Finally, as teacher educators do not consider being the on-site technician as their major role in the future, traditional colleges and universities will have to plan ahead to provide their faculty with the necessary administrative and technical support for faculty integration and use of the online technologies in their courses. This way faculty can invest their time on preparing for their primary role - to teach. The roles and competencies of teacher education faculty who teach in F2F classrooms will be different from those who teach in virtual classrooms. With the great demand for blended delivery modes $(\mathrm{F} 2 \mathrm{~F}+\mathrm{Web})$, there is an urgent necessity to reflect upon the competencies of future teachers who will be required to integrate online technologies into their traditional courses. Each delivery mode and technical medium requires that different instructional approaches be used. Teachers will need to be trained to work online and 'instructed' in a manner that allows them to achieve their pedagogical goals in a more effective, creative and innovative way when practicing in online learning environments.

\section{Recommendations}

Based on the conclusions and implications of this study discussed above, the following recommendations are made for future research.

Teaching competencies are reflective of instructional delivery modes and environments. This study did not start with a set of designated delivery modes for which specific teaching competencies would be sought. Instead, future teaching modes were solicited, and were then used to identify teaching competencies essential for each. Since the teaching environment is important in shaping a teacher's approach to teaching, it might be more informative if teaching competencies were identified for only a single course delivery method. Based on this study and current literature, a future study to identify teaching competencies individually for each potential delivery mode should be conducted. 
It is highly recommended that higher education institutions continue with large investments in building up the online course delivery system and also setting up proper administrative and technical support for their faculty. For example, they should continue to hire technology savvy instructional development specialists to assist faculty with developing multimodal instructional components, archiving courses, streaming audios and videos, managing the local network, and so on. Future research should be conducted to identify the kinds of technical assistance or support faculty will need in order to deliver the course with minimal technical requirements.

As noted earlier, the panel itself was a limitation in this study. The panel was relatively small $(\mathrm{n}=17)$, and perhaps not representative enough. As such, there is uncertainty as to whether or not the same results would have been achieved with a different panel selected using the same criteria. Therefore, it is recommended to further validate the delivery modes and teaching competencies identified in this study with a different composition of panel members drawn from a larger pool of participants.

The online Delphi procedure used for this study was found to be an effective means for reaching consensus on the instructional needs of future faculty in higher education programs. Utilizing the Internet and Web-based survey instruments provides a rapid way to reach consensus among a geographically dispersed group of experts and a viable means of forecasting emerging educational technologies. Therefore, based on the success of the methodology chosen for this study, coupled with the continually advancing capabilities of the Internet and World Wide Web, a final recommendation would be that future researchers perfect and employ this forecasting approach in ongoing efforts to better plan for future educational environments. 


\section{BIBLIOGRAPHY}

Adams, S. J. (2001). Projecting the next decade in safety management: A Delphi technique study. American Society of Safety Engineers, 10, 26-29.

Allen, E. \& Seaman, J. (2004). Entering the Mainstream: The Quality and Extent of Online Education in the United States, 2003 and 2004. The Sloan Consortium, The Sloan Center for Online Education (SCOLE) at Olin and Babson Colleges.

Alley, L. (February 1999). Cloning the Ivy Tower on Wall Street. Paper presented at the National Learning Infrastructure Initiative Conference, New Orleans, LA.

Alley, L. (1996). Technology precipitates reflective teaching: An instructional epiphany. Change, 28(2), 49-55.

Alexandrov, A. V., Pullicino, P. M., Meslin, E. M., \& Norris, J. W. (1996). Agreement on diseasespecific criteria for do-not-resuscitate orders in acute stroke. Stroke, 27, 232-237.

Amara, R. \& Salanik, G. (1972). Forecasting: From conjectural art toward science. Technological Forecasting and Social Change, 3(3), 415-426.

Andrews, C. \& Allen, J. (2002). Utilization of technology-enhanced Delphi techniques. Workforce Education Forum, 29(1), 1-15.

Armitage, W. \& Rodrigues, M. (2002). Toward paperless course and beyond. Panel Discussion. Consortium for Computing in Small Colleges. Northeastern Conference. 212-213. Association of American Medical Colleges. (2001, October). Better Health 2010 Report. Retrieved November 23, 2003, from the AAMC Web site: http://www.aamc.org Barone, A. C., \& Luker, A. M. (1999). The role of advanced networks in the education of the future. Educom Review, November/December. Retrieved October 13, 2003, from http://www.educause.edu/ir/library/html/erm9968.html 
Beckstrand, S. \& Van Schaik, P. (2003). A comparison of on-campus and online course delivery methods in Southern Nevada. Innovations in Education \& Teaching International, 40(1), $5-15$.

Benjamin, R., Carroll, S., Dewar, J., Lempert, R., \& Stockly, S. (2000). Achieving the Texas higher education vision. RAND Corporation. Texas Higher Education Coordinating Board.

Black, G. (2001). A comparison of traditional, online and hybrid methods of course delivery. International Conference on Teaching Online in Higher Education: "Synthesizing Online Teaching Strategies". November 12-14, 2001. Conference paper.

Carman, W. H. (1999). An application of the Delphi method of forecasting to the future of technology infrastructure in West Virginia high schools. Unpublished doctoral dissertation, West Virginia University, Morgantown, WV.

Chickering, A.W., \& Gamson, A.F., (1987). Seven principles for good practice in undergraduate education. Racine, WI: The Johnson Foundation, Inc..

Churchill, E. F. \& Munro, A. J. (2002). Work/place: mobile technologies and arenas of activity. ACM SIGGROUP Bulletin, 22(3), 3-9.

Clayton, M. J. (1997). Delphi: A technique to harness expert opinion for critical decision-making tasks in education. Educational Psychology, 17(4), 373-386.

Coates, J. (1999). Boom time in forecasting. Technological Forecasting and Social Change, 62, 37-40.

Conhaim, W. W. (2003). Education ain't what it used to be. Information Technology, 20(11), 3738.

Crisp, J., Pelletier, D., Duffield, C., Adams, A., \& Nagy, S. (1997). The Delphi method? Nursing Research, 46, 116-118. 
Critcher, C., \& Gladstone, B. (1998). Utilizing the Delphi technique in policy discussion: A case study of a privatized utility in Britain. Public Administration, 76, 431-449.

Cyrs, T. E. (1997). Competence in teaching at a distance. New Directions for Teaching \& Learning, 71, 15-18.

Dalkey, N. C., \& Helmer, O. (1963). An experimental application of the Delphi method to the use of experts, Management Science 9, 458-67.

Dalkey, N.C., Rourke, D.L., Lewis, R. \& Snyder, D. (1972). Studies in the quality of life. Lexington, Massachusetts: Lexington Books.

Delbecq, L., Van deVen, H, \& Gustafson, H. (1975). Group Techniques for Program Planning: A Guide to Nominal Group and Delphi Processes. New York: Scott-Foresman.

Duderstadt, J. (2001). A University for the $21^{\text {st }}$ Century. Ann Arbor: University of Michigan Press.

Duderstadt, J., \& Wulf, W. (Eds.) (2002). The Impact of Information Technology on the Future of the Research University. Washington, DC: National Academy Press.

Eaton, M. (2002 ). Searching for the 'New University': changing faculty roles. Project on the Future of Higher Education. Retrieved November 20, 2003, from http://www.pfhe.org

Ewell, P. (2002). Three "Dialectics" in higher education's future. Project on the Future of Higher Education. Retrieved November 20, 2003, from http://www.pfhe.org

Gold, S. (2001). A constructivist approach to online training for online teachers. Journal of Asynchronous Learning Networks, 5(1). [Online] Retrieved May 1, 2004 from http://www.aln.org/alnweb/journal/Vol5 issue1/Gold/gold.htm

Groves, M., \& Zemel, P. (2000). Instructional technology adoption in higher education: An action research case study. International Journal of Instructional Media, 27(1). 15-18. 
Guskin, A. \& Marcy, M. (2001). Facing the future: Faculty work, student learning and fundamental reform. Project on the future of higher education. Retrieved November 20, 2003, from http://www.pfhe.org

Hahn, E. J., \& Rayens, M. K. (2000). Building consensus using the policy Delphi method. Policy, Politics, \& Nursing Practice, 1(4), 308-315.

Harley, D. (2001). Higher Education in the Digital Age: Planning for an uncertain future. Syllabus, 15(2), 10-12.

Horgan, B. (1998). Faculty, instruction, and information technology. Microsoft in Education. Retrieved Feburuary 23, 2004, from http://www.microsoft.com/edu

IMS Global Learning Consortium (2001). Reusable Competency Definitions Information Model. IMS Global Learning Consortium, Inc. Public draft available online at http://www.imsproject.org

International Society for Technology in Education. (2002). Technology competencies for teacher certification: A survey of the states. Retrieved May 9, 2004, from http://www.iste.org/Content/NavigationMenu/NETS/NCATE_Standards/National_Standar ds_for_Technology_in_Teacher_Preparation.htm

Iverson, M. I. (1993). Futures studies as curriculum building blocks for the $21^{\text {st }}$ century. The Agricultural Education Journal, 66(1), 15-17.

Iwu, H. O. (1988). Computer competencies needed for the certification of secondary school business teachers. Unpublished doctoral dissertation. University of Nebraska, Lincoln. James, D., Lisa, B. \& Anna, B. (2003). A Delphi study of agriculture teacher perceptions of problems in student retention. Journal of Agricultural Education, 44(2), 87-95. 
Johnstone, S. (2002, November/December). Signs for the Time: Change is coming for ELearning. Educause, 15- 24.

KnowledgeNet. (2002). Glossary. December 12, 2003, From http://www.knowledgenet.com

Kovel-Jarboe, P. (2000). The changing contexts of higher education and four possible futures for distance education. Horizon. Retrieved October 20, 2003, from http://horizon.unc.edu/projects/issues/papers/kovel.asp

Lang, T. (1998). An overview of four futures methodologies. Retrieved September 4, 2003, from http://www.soc.hamaii.edu/ future/j7/LANG.html

Lightfoot, E., \& Ihrig, W. (2002). The next generation infrastructure [Electronic Version]. EDUCAUSE November/December 2002, 52-61.

Linstone, H., \& Turoff, M. (Eds.). (1975). The Delphi Method: Techniques and Applications. Reading, MA: Addison-Wesley Pub. Co..

Ludwig, B. (1997). Predicting the Future: Have you considered using the Delphi Methodology? Journal of Extension, 35(5). Retrieved November 12, 2003, from $\underline{\text { http://www.joe.org/joe/1997october/tt2.html }}$

Luppicini, R. (2003). Categories of virtual learning communities for educational design. The Quarterly Review of Distance Education, 4(4). 409-416.

Martino, J. (1993). Technological Forecasting for Decision Making. New York: Elsevier Science Publishing Company.

Massy, W. (1998). Understanding new faculty roles and work patterns. Technology and Its Ramifications for Data Systems: Report of the Policy Panel on Technology. NCES, 98-279. Washington, D.C.: U.S. Department of Education. 
Mayring, P. (2000). Qualitative Content Analysis. Forum: Qualitative Social Research [On-line Journal], 1(2). Retrieved February 15, 2006, from http://www.qualitative-research.net/fqstexte/2-00/2-00mayring-e.htm

McCombs, B., \& McNabb, M. (2003). Designs for e-learning: A vision and emerging framework. Retrieved September 21, 2003 from http://www.pt3.org/technology/visquest monabb.html

McCoy, R. (2001). Computer competencies for the $21^{\text {st }}$ century information systems educator. Information Technology, Learning, and Performance Journal, 19(2). 21-35.

McKenna, H. P. (1989). The selection by ward managers of an appropriate nursing model for long-stay psychiatric patient care. Journal of Advanced Nursing, 14, 762-775.

McKenna, H. P. (1994). The Delphi technique: Aworthwhile research approach for nursing? Journal of Advanced Nursing, 19, 1221-1225.

Michigan State University (2001, August 6). Certificate in teaching of college science \& mathematics. Retrieved May 9, 2004, College of Natural Science web site from http://www.ns.msu.edu/TAcertificate/Default.htm

Morrison, J. L. (1996). Anticipating the future. On the Horizon, 4(3), 2-3.

Morrison, J. L., Ericson, J., \& Kohler, B. (2003). Critical trends affecting the future of higher education in Minnesota. Horizon. Retrieved October 6, 2003, from http://horizon.unc.edu/projects/seminars/SCUP.asp

Morrison, J. L., Renfro, W. L., \& Boucher, W. I. (1984). Futures research and the strategic planning process: Implication for higher education. ERIC Clearinghouse, Report 9.

Murphy, P. (2002). The hybrid strategy: Blending face-to-face with virtual instruction to improve large lecture courses. UC TLtC: News and Events. University of California Regents. April 8, 2004. Retrieved from http://www.uctltc.org 
Murray, J. \& Hammons, J. O. (1995). Delphi: A versatile methodology for conducting qualitative research. The Review of Higher Education, 18(4), 423-436.

Musto, J. N. (1995). High-tech future: A scenario for higher education. The NEA Higher Education Journal. 99-104.

National Board for Professional Teaching Standards. (2001, October). A survey of institutions of higher education: Improving teaching and learning. Retrieved May 6, 2004, from http://www.nbpts.org/pdf/ihesurvey01.pdf

Nesbary, Dale K. (2000). Survey Research and the World Wide Web. Boston: Allen and Bacon.

Newman, F. \& Scurry, J. E. (2001). Online learning pushes teaching and learning to the forefront. The Chronicle of Higher Education. B7-B10.

Noble, D. (1998). The coming battle over online instruction. Digital Diploma Mills. January 17, 2004. Retrieved from http://communication.ucsd.edu/dl/ddm2.html

Olsen, Florence, Carlson, Scott, Carnevale, Dan, Foster, Andrea, L. (2004). 10 challenges for the next 10 years. The Chronicle of Higher Education, 50(21), B1-5C.

Osguthorpe, R. T. \& Graham, C. R. (2003). Blended learning environments: Definitions and directions. The Quarterly Review of Distance Education, 4(3), 227-233.

Park, E. (2000). Hybrid instruction. SLAIT Program, University of South Florida. April 8, 2004. Retrieved from http://www.coedu.usf.edu

Queiroz, V. (2003). Roles and competencies of online teachers. The Internet TESL Journal, 9(7). May, 2004. Retrieved from http://iteslj.org

Raskin, M. S. (1994). The Delphi study in field instruction revisited: Expert consensus on issues and research priorities. Journal of Social Work Education, 30, 75-89. 
Richey, R. C., Fields, D. C., \& Foxon, M. (2001). Instructional design competencies: The standards $\left(3^{\text {rd }}\right.$ ed.). Syracuse, NY: ERIC Clearinghouse on Information and Technology. ED453803.

Rickman, L. L. (1987). A Delphi study to identify the emerging competencies needed by the information processing employee for the automated office in the year 2000. Unpublished doctoral dissertation, University of Missouri, Columbia.

Rickman, J., Todd, K., Verbick, T. \& Miller, M. (2003). The Evolution Of The Electronic Campus: From A Communication System To An Educational Delivery System. New York, NY: Association for Computing Machinery Press. 65- 69.

Riel, M. (1998). Teaching and learning in the educational communities of the future. in Chris Dede (Ed.) ASCD Yearbook 1998, Association for Curriculum Development, 171-198.

Riggs, W. (1983). The Delphi Technique: An experimental evaluation. Technological Forecasting and Social Change, 23(1), 89-94.

Rosenberg, M. J. (2001). E-learning: Strategies for delivering knowledge in the digital age. New York: McGraw Hill.

Rossman, P. (2002). The Future of Higher (Lifelong) Education: For All Worldwide, A Holistic View. Retrieved September 16, 2003 from University of Missouri Web site: http://ecolecon.missouri.edu/globalresearch/chapters/1-03.html

Sackman, H. (1975). Delphi Critique. Lexington, MA: Lexington Books.

Sherer, P. \& Shea, T. (2002). Designing courses outside the classroom: New opportunities with the electronic delivery toolkit. College Teaching, 50(1), 15-21.

Smith, K. S., \& Simpson, R. D. (1995). Validating teaching competencies for faculty members in higher education: a national study using the Delphi method. Innovative Higher Education, 
19(3), 223-234.

Spector, J. M. (2001). Competencies for Online Teaching. Syracuse, NY: Information and Technology (ERIC Document Reproduction Service No. ED456841)

Spinelli, T. (1983). The Delphi decision-making process. Journal of Psychology, 113, 73-80.

Stead, F. L. (1975). An application of the Delphi method of forecasting to nursing education planning in West Virginia. Unpublished thesis, West Virginia University.

Stillwell, C. (1999). A Delphi study on critical issues facing higher education for the first decade of the 21 st century based on the perspectives of the International Association of University Presidents. Arise Fall 1999 Research Forum. Retrieved from http://www.gwu.edu/ arise/activities/fall99/abstract_stillwell.htm

Teichler, U. (1999). Lifelong learning as challenge for higher education: The state of knowledge and future research tasks. Higher Education Management, 11(1), 37-53.

Thomas, K. R. (2001). Strategies to ease the negative effects of mobility on academic achievement. Unpublished doctoral dissertation, East Tennessee State University.

Trotter, A. \& Zehr, M. (2000). Preparing teachers for the digital age. Education Week, 19(4), 3743.

Turner, J., \& Turner, D. (1999). Using the Internet to perform survey research. Syllabus, 12(5), $55-56$.

Ulschak, F. L. (1983). Human resource development: the theory and practice of need assessment. Reston, Virginia: Reston Publishing Company, Inc.

Vest, C. M. (2004). Why MIT decided to give away all its course materials via the Internet. Chronicle of Higher Education, 50(21), B20-1c. 
Waits, T., and Lewis, L. (2003). Enrollment in Postsecondary Institutions, Fall 2001 and Financial Statistics, Fiscal Year 2001. Education Statistics Quarterly, Vol 5(3), 76-81.

Watt, J. H. (1999). Internet-based surveys. Upgrade: The Magazine for the Software and Information Industry Association, 20, 83-87.

Weaver, W. T. (1971). The Delphi forecasting method. Phi Delta Kappan, 52(5), 267-273.

Wells, J. G. (1992). Establishment of a Taxonometric Structure for the Study of Biotechnology as a Secondary School Component of Technology Education. Unpublished doctoral dissertation, Virginia Polytechnic Institute \& State University, Blacksburg, VA.

Welty, G. (1973). Some problems of selecting Delphi experts for educational planning and forecasting exercises. California Journal of Educational Research, 24(3), 129-134.

Western Governors University. Retrieved April 13, 2004, from http://www.wgu.edu/wgu/smartcatalog/help-modes.html

White, J., \& Dailey, K. (2001). Web-based instrumentation in educational survey research. WebNet Journal: Internet Technologies, Applications and Issues, (In Press).

Williams, P. E. (2000). Roles and Competencies for Distance Education Programs in Higher Education Institutions. American Journal of Distance Education, 17(1), 45-57.

Williams, P. \& Webb, C. (1994). The Delphi technique: A methodological discussion. Journal of Advanced Nursing, 19(2), 180-186.

Wilson, B. (2001). Trends and futures of education: Implications for distance education. The Quarterly Review of Distance Education, 4(1). 1-14.

Woudenberg, F. (1991). An evaluation of Delphi. Technological Forecasting and Social Change,40, 131-150. 
APPENDICES 
Appendix A

List of the Source Organizations 
List of the Source Organizations

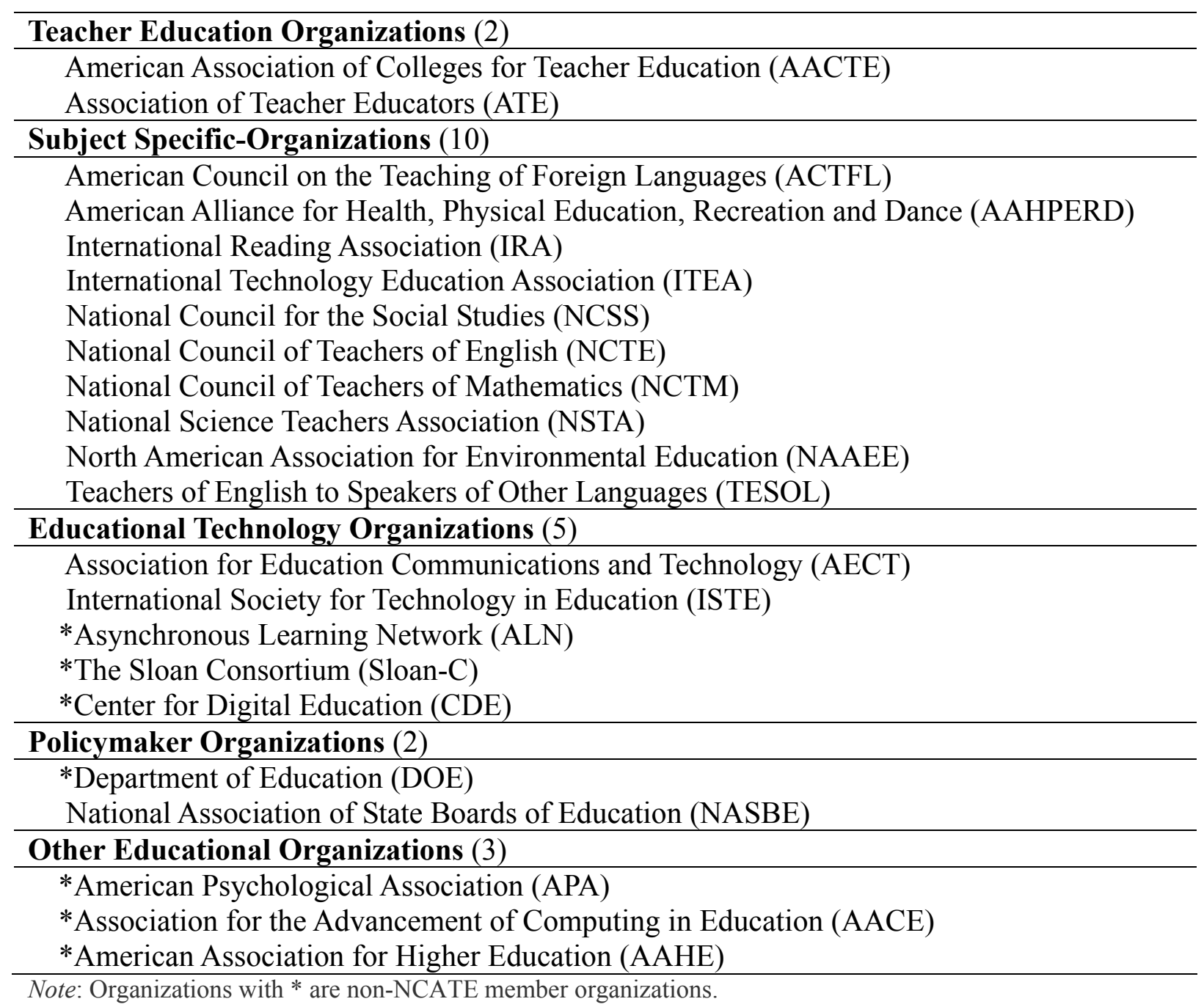

Note: Organizations with * are non-NCATE member organizations. 
Appendix B

Delphi Round I Invitation Letter 


\section{Delphi Round I Invitation Letter}

Dear

Following up our e-mail conversation, I would like to invite you to be a member of the panel of experts in the Delphi study. Thank you very much for agreeing to work with me on my study to determine teaching competencies of teacher education faculty within a ten-year cycle (2015). Your expert opinion based on your experience in the field is of critical importance to the study.

Please see Study Overview attached for details.

The participation to this research is voluntary and you may withdraw from the study at any time without any negative consequences. Being a member of the panel will involve no more than completing a 20-30 minute questionnaire every two weeks. The identities of the panel members will be kept confidential throughout the study, and each panel member will be assigned a unique identity that keeps the panel expert anonymous to the other participating panel members. The intention of this is simply to remove the influence of peer pressure and group dynamics from the research. All the responses from the subjects will be kept anonymous. You do not have to answer every question.

Please complete the Round I Questionnaire and the Study Participation Agreement and return it to me by May 13, 2005.

Round I; the questionnaire, in a rich format (.rtf), contains one open-ended question.

Thank you.

Best Regards,

Sonhwa $\mathrm{Na}$

Doctoral Candidate, Technology Education, West Virginia University 
Appendix C

Study Overview 


\section{Study Overview}

Title:

A Delphi Study to Identify Teaching Competencies of Teacher Education Faculty in 2015 Researcher: Sonhwa Na, Doctoral Candidate

School: West Virginia University

Major: Technology Education

Redesigning the current teacher-training model to accommodate the emerging course delivery modes has been the focus for discussion in Higher Education (Trotter \& Zehr, 2000). Therefore, it is essential to identify a framework of adequate competencies to teach using the emerging delivery modes. Moreover, it is important to validate a framework for teaching competencies through involvement of educational experts. Educational experts, who have knowledge of important aspects of teaching from their theoretical and practical experience, are a useful source of information to develop and validate the framework.

The purpose of the study is to determine a consensus on recommended teaching competencies that would be required for future course delivery environment. The study will identify the emerging competencies needed by teacher education faculty for the teaching environment in the year 2015.

The study data will be essential to making informed decisions about how to structure teacher education. It is expected that the competencies determined by the study would be beneficial to teacher educators planning the curriculum for training future employees being prepared to work in the changing environment of teaching. Educators who are involved in teacher preparation programs may use the results to design a curriculum in order to address competencies that would be required to teach in future teaching environment. Existing in-service and pre-service training programs for college professionals can be updated based on the competencies identified in this study.

Method: Web-based Delphi method will be used to generate statements and reach consensus on teaching competencies. 
Appendix D

Study Participation Agreement 
Study Participation Agreement

I, _ have read the study overview provided by the researcher (Sonhwa Na). I pledge that I fully understand the nature of my commitment and intend to do my best to fulfill all of the obligations of participation. I also understand that I may withdraw my participation in said study at any time without any negative consequences.

Date:

Organization:

Title:

Name:

Signature:

E-mail:

Phone Number: Day Time: $\left({ }_{(}\right)$ 
Appendix E

Round I Instructions and Questionnaire 


\section{Round I Instructions and Questionnaire}

Dear Delphi Panel Members,

Thank you for agreeing to work with me on my study to determine teaching competencies of teacher education faculty within a ten-year cycle (2015). Your expert opinion based on your experience in the field is of critical importance to the study.

Attached is Round I; the questionnaire, in a rich format (.rtf), contains one open-ended question. It will take 15-20 minutes to complete the questionnaire. Please complete the attached questionnaire within 2 weeks and return it to me via e-mail. Please answer the question as fully as possible. I will compile a list of your responses. Round II of the questionnaire will be posted on a web site. I will notify you, when it is available online.

Please use the following definition when you complete the questionnaire.

- Delivery mode refers to the means whereby teaching methods are implemented, focusing on the forms of communication used. In addition to the traditional delivery modes such as lectures and seminars, there are delivery modes that use technology including audiovisual media (e.g., audio tape, video tape), computer-based media (e.g., hypertext, interactive multimedia and the internet) and teleconferencing media (e.g., audio-teleconferencing, audio-graphics) (Park, 2000).

- Teaching competencies are defined as an integrated set of personal characteristics, knowledge, skills and attitudes that are needed for effective performance in various teaching contexts (Smith \& Simpson, 1995).

Sincerely,

Sonhwa $\mathrm{Na}$

Doctoral Candidate, Technology Education

West Virginia University 


\section{Round I Questionnaire}

Reflecting on the anticipated future advancement of information technology, what course delivery modes will the teacher education faculty use in 2015? Please list all possible delivery modes that might be developed over the next ten years. Give the specific description of each mode and list teaching competencies required for the mode. Please feel free to expand the text box, if necessary.

\# Example

A. Name of Delivery Mode: Online real time chat

B. Description: This mode employs text chat rooms to communicate between students and faculty in real time by typing comments on the computer keyboard.

C. Teaching Competencies:

a. Faculty must be able to interact actively with students and give them constant feedback.

b. Faculty must be able to know how online text messages may appear to distant learners.

c. Faculty must be able to establish ground rules for discussion.

\#1.

A. Name of Delivery Mode:

B. Description:

C. Teaching Competencies:
a.
b.
c.
d.
e. 
\# 2.

A. Name of Delivery Mode:

B. Description:

C. Teaching Competencies:

a.

b.

c.

d.

e.

\# 3 .

A. Name of Delivery Mode:

B. Description:

C. Teaching Competencies:
a.
b.
c.
d.
e. 
\# 4.

A. Name of Delivery Mode:

B. Description:

C. Teaching Competencies:

a.

b.

c.

d.

e.

\# 5.

A. Name of Delivery Mode:

B. Description:

C. Teaching Competencies:

a.

b.

c.

d.

e. 
Appendix F

Round I Data Color Coding Scheme: Delivery Modes and Description 
Round I Data Color Coding Scheme: Delivery Modes and Description

\begin{tabular}{|c|c|c|c|}
\hline $\begin{array}{c}\text { Par. } \\
\text { ID }\end{array}$ & Name of Delivery Mode & Coding Scheme & Description \\
\hline \multirow[t]{3}{*}{1} & Online Methods Courses & Web Based Multi-Mode & $\begin{array}{l}\text { Instruction will be delivered online for } \\
\text { methods courses (and others) that will } \\
\text { facilitate tailoring instruction for teachers of } \\
\text { specific languages, i.e., Classical Languages, } \\
\text { American Sign Language (ASL), Less } \\
\text { Commonly Taught Languages, etc. }\end{array}$ \\
\hline & Distance Learning via Satellite & Satellite & $\begin{array}{l}\text { Distance learning courses in which there may } \\
\text { be some students on-site with the teacher and } \\
\text { others tuning in from a remote site or all } \\
\text { students in remote sites. }\end{array}$ \\
\hline & $\begin{array}{l}\text { Individualized Computer- } \\
\text { delivered courses }\end{array}$ & Web Based Multi-Mode & $\begin{array}{l}\text { Courses in which students work independently } \\
\text { at their own pace. }\end{array}$ \\
\hline 2 & Online real time chat & Computer Conferencing & $\begin{array}{l}\text { This mode employs text chat rooms to } \\
\text { communicate between students and faculty in } \\
\text { real time by typing comments on the } \\
\text { *computer* keyboard. }\end{array}$ \\
\hline \multirow[t]{2}{*}{3} & Class Discourse & Traditional & $\begin{array}{l}\text { Teacher orchestrated discussion based upon } \\
\text { worthwhile pedagogical cases or dilemmas. }\end{array}$ \\
\hline & Multi-media presentation & Web Based Multi-Mode & $\begin{array}{l}\text { Using presentation software, still images, } \\
\text { video images, and audio to assist students in } \\
\text { conceptualizing basic pedagogical principles. }\end{array}$ \\
\hline \multirow[t]{3}{*}{4} & $\begin{array}{l}\text { Real-time interactive } \\
\text { community video sessions }\end{array}$ & $\begin{array}{l}\text { Digital Video Interactive } \\
\text { (DVI) }\end{array}$ & $\begin{array}{l}\text { This mode is a just-in-time, real-time } \\
\text { interactive video environment that interacts } \\
\text { seamlessly between all students and faculty, } \\
\text { with assistive/adaptive technologies } \\
\text { seamlessly integrated. }\end{array}$ \\
\hline & $\begin{array}{l}\text { Real-time, interactive } \\
\text { multimedia learning } \\
\text { components }\end{array}$ & Web Based Multi-Mode & $\begin{array}{l}\text { This mode emphasizes not merely a database- } \\
\text { driven multimedia component, such as would } \\
\text { be considered a Flash component in today's } \\
\text { learning environment, but an environment that } \\
\text { would emphasize real-time, interactive } \\
\text { multimedia learning components as an } \\
\text { available option. }\end{array}$ \\
\hline & $\begin{array}{l}\text { Instructional Games } \\
\text { ("Edutainment") }\end{array}$ & Virtual Reality & $\begin{array}{l}\text { Instructional games, now crudely termed } \\
\text { "edutainment" or some other such silly label, } \\
\text { offer an interactive digital game through } \\
\text { which students/learners may learn/obtain } \\
\text { knowledge, skills and understanding that are } \\
\text { based upon learning objectives and } \\
\text { professional standards delineations, while the } \\
\text { students/learners judge that their gaming is } \\
\text { also entertaining. The instructional gaming } \\
\text { environment will emphasize real-time, } \\
\text { interactive instructional gaming; however, the } \\
\text { learner does have the ability to play as a lone } \\
\text { player. }\end{array}$ \\
\hline
\end{tabular}




\begin{tabular}{|c|c|c|c|}
\hline $\begin{array}{l}\text { Par. } \\
\text { ID }\end{array}$ & Name of Delivery Mode & Coding Scheme & Description \\
\hline 4 & Co-Learning Environments & $\begin{array}{l}\text { Web-Based Team-Taught } \\
\text { Distance Education }\end{array}$ & $\begin{array}{l}\text { Learning environments wherein } \\
\text { parents/guardians and students/learners will } \\
\text { work in harmony with other similarly-focused } \\
\text { end-users (other parents/guardians and } \\
\text { students/learners); at the same time, at least } \\
\text { one instructor/facilitator will be available to } \\
\text { interact in a real-time fashion. This will } \\
\text { emphasize everything from PreK-12 } \\
\text { competencies/objectives through higher } \\
\text { education, through business/industry training } \\
\text { and certifications. The focus of these co- } \\
\text { learning environments is to enhance a real- } \\
\text { world environment through which } \\
\text { students/learners can learn within a safe } \\
\text { environment, while the parents/guardians } \\
\text { offer more real-world reality through which } \\
\text { the students/learners will be able to interact. } \\
\text { The teacher/facilitator will support and } \\
\text { enhance the learning environment, as well as } \\
\text { ensure that all end-users are focused upon the } \\
\text { co-learning environment learning objectives } \\
\text { and professional standards, while ensuring } \\
\text { that all entities work together appropriately } \\
\text { and successfully. }\end{array}$ \\
\hline & Virtual Facilitators/Guides & Virtual Reality & $\begin{array}{l}\text { Virtual reality-style } \\
\text { facilitators/teachers/guides who will } \\
\text { continuously be available to support, enhance } \\
\text { and help the students/learners understand the } \\
\text { knowledge/processes/information/ etc. that is } \\
\text { the focus of the learning objectives and } \\
\text { professional standards. The virtual } \\
\text { facilitators/guides may be real people who are } \\
\text { virtually references in bodily appearance, or } \\
\text { computer-based virtual references (something } \\
\text { like an interactive body whose sole function is } \\
\text { to act as a more highly interactive "help" } \\
\text { function in softwares). }\end{array}$ \\
\hline 5 & Streaming Video & Desktop Video & $\begin{array}{l}\text { The use of streaming video might ease the } \\
\text { pressure on having lots of students in } \\
\text { schools...like "windows into the classroom...or } \\
\text { perhaps creating video ethnographies for } \\
\text { student use. }\end{array}$ \\
\hline 6 & $\begin{array}{l}\text { Online course management } \\
\text { systems }\end{array}$ & Web Based Multi-Mode & $\begin{array}{l}\text { A course Management Systems such as } \\
\text { Blackboard. }\end{array}$ \\
\hline 7 & Weblog & $\begin{array}{l}\text { Computer Conferencing } \\
\text { (Text Only) }\end{array}$ & $\begin{array}{l}\text { A weblog is an often updated site that point to } \\
\text { articles elsewhere on the web, often with } \\
\text { comments, and to on-site articles. New entries } \\
\text { are added at the top of the page, readers can } \\
\text { "catch-up" by scrolling down the page. }\end{array}$ \\
\hline
\end{tabular}




\begin{tabular}{|c|c|c|c|}
\hline $\begin{array}{l}\text { Par. } \\
\text { ID }\end{array}$ & Name of Delivery Mode & Coding Scheme & Description \\
\hline \multirow[t]{3}{*}{8} & Streaming Video sites & Desktop Video & $\begin{array}{l}\text { Online collections of thousands of video clips } \\
\text { that can be incorporated into a lesson }\end{array}$ \\
\hline & Video Conferencing & Desktop Video & Just in time instruction to the desktop \\
\hline & $\begin{array}{l}\text { Team-Taught Distance } \\
\text { Education }\end{array}$ & $\begin{array}{l}\text { Web-Based Team-Taught } \\
\text { Distance Education }\end{array}$ & $\begin{array}{l}\text { Faculty on different universities offer a joint } \\
\text { course for their students }\end{array}$ \\
\hline \multirow[t]{4}{*}{9} & Video Streaming via the Web & Desktop Video & $\begin{array}{l}\text { This mode allows for displays of video via the } \\
\text { Internet such that students can participate in a } \\
\text { variety learning experiences created and } \\
\text { available in video libraries. }\end{array}$ \\
\hline & $\begin{array}{l}\text { Instructional Video Games and } \\
\text { Simulations }\end{array}$ & Virtual Reality & $\begin{array}{l}\text { This mode allows for highly interactive and } \\
\text { challenging instructional strategies that } \\
\text { encourage students' creative and critical } \\
\text { thinking as well as the development of social } \\
\text { skills. }\end{array}$ \\
\hline & Instructional Blogs & $\begin{array}{l}\text { Computer Conferencing } \\
\text { (Text Only) }\end{array}$ & $\begin{array}{l}\text { This mode allows for highly personalized } \\
\text { instructional strategies that encourage } \\
\text { students' creative and critical thinking as well } \\
\text { as the development of literacy and } \\
\text { communication skills. }\end{array}$ \\
\hline & Multi-modal course delivery & Web Based Multi-Mode & $\begin{array}{l}\text { Classrooms of the future will be networked } \\
\text { environments with multiple technologies } \\
\text { available that represent all known current } \\
\text { modes of delivery and additional unforeseen } \\
\text { modes }\end{array}$ \\
\hline \multirow[t]{2}{*}{10} & $\begin{array}{l}\text { Synchronous } \\
\text { asynchronous } \\
\text { telecommuni }\end{array}$ & $\begin{array}{l}\text { Computer Conferencing } \\
\text { (Text \& Video) }\end{array}$ & $\begin{array}{l}\text { Communicating course components via } \\
\text { Internet-based communications that occur in } \\
\text { real-time or with time delays between } \\
\text { participant interactions (may be text-based } \\
\text { communications or video conferencing) }\end{array}$ \\
\hline & $\begin{array}{l}\text { Multi-modal curriculum } \\
\text { resources }\end{array}$ & Web Based Multi-Mode & $\begin{array}{l}\text { Communicating course information via } \\
\text { Internet-based curriculum resources accessible } \\
\text { in synchronously or asynchronously (may be } \\
\text { hypertext-based, video, audio, kinetic, multi- } \\
\text { media presentations) }\end{array}$ \\
\hline 11 & Oral lectures & Traditional & $\begin{array}{l}\text { Communicating course information via oral } \\
\text { lectures that provide direct instruction or } \\
\text { stimulating creative and critical thinking about } \\
\text { course content (may occur in face-to-face } \\
\text { settings and/or through teleconference or } \\
\text { audio-video taping) }\end{array}$ \\
\hline \multirow[t]{3}{*}{12} & $\begin{array}{l}\text { Online synchronous audio } \\
\text { communication }\end{array}$ & Audio Conferencing & $\begin{array}{l}\text { Students and faculty interact in real time using } \\
\text { two-way audio. }\end{array}$ \\
\hline & $\begin{array}{l}\text { Online synchronous video } \\
\text { communication }\end{array}$ & $\begin{array}{l}\text { Digital Video Interactive } \\
\text { (DVI) }\end{array}$ & $\begin{array}{l}\text { Students and faculty interact in real time using } \\
\text { two-way video. }\end{array}$ \\
\hline & $\begin{array}{l}\text { Asynchronous online content } \\
\text { delivery }\end{array}$ & Web-Based Multi-Mode & $\begin{array}{l}\text { Learners download materials for learning } \\
\text { from a common site (be it a document } \\
\text { repository, like Blackboard, or a streaming } \\
\text { server) }\end{array}$ \\
\hline
\end{tabular}




\begin{tabular}{|c|c|c|c|}
\hline $\begin{array}{l}\text { Par. } \\
\text { ID }\end{array}$ & Name of Delivery Mode & Coding Scheme & Description \\
\hline 12 & Online learning assessment & Web-Based Evaluation & $\begin{array}{l}\text { Faculty create instruments and activities, } \\
\text { students demonstrate learning, and faculty } \\
\text { assess student learning. }\end{array}$ \\
\hline \multirow[t]{3}{*}{13} & Asynchronous Discussion & $\begin{array}{l}\text { Computer Conferencing } \\
\text { (text) }\end{array}$ & $\begin{array}{l}\text { This mode employs threaded, online } \\
\text { discussions as a means for students and } \\
\text { instructors to process course material and } \\
\text { share ideas. }\end{array}$ \\
\hline & Course Management System & Web Based Multi-Mode & $\begin{array}{l}\text { A course Management Systems, such as } \\
\text { WebCT or Blackboard, helps facilitate the } \\
\text { construction and delivery of an online course. }\end{array}$ \\
\hline & $\begin{array}{l}\text { Blended Online and Face to } \\
\text { Face Systems }\end{array}$ & Blended & $\begin{array}{l}\text { Blended courses include both face to face and } \\
\text { online experiences for students. }\end{array}$ \\
\hline \multirow[t]{2}{*}{14} & Interactive Simulation & Virtual Reality & $\begin{array}{l}\text { Technology-based interactive scenario } \\
\text { configured much like current game software, } \\
\text { in which the user inputs various moves and } \\
\text { the software reacts accordingly (medicine and } \\
\text { the Army both have these now)...could be } \\
\text { used to model teaching interventions. }\end{array}$ \\
\hline & Web-Based Research & & $\begin{array}{l}\text { Most student assignments may involve a web } \\
\text { research component in which complex } \\
\text { information must be assembled from a variety } \\
\text { of sources. }\end{array}$ \\
\hline \multirow[t]{4}{*}{15} & $\begin{array}{l}\text { N-way Interaction with } \\
\text { Holography }\end{array}$ & Virtual Reality & $\begin{array}{l}\text { This is the decade-from-now equivalent of a } \\
\text { "chat room" that involves synchronous } \\
\text { interaction among multiple parties who are all } \\
\text { "represented" for one another as though they } \\
\text { were sitting around a room. }\end{array}$ \\
\hline & Tablet Wireless PCs & Tablet Wireless PCs & $\begin{array}{l}\text { Book-sized tablet PCs with personalized } \\
\text { writing and drawing capabilities and wireless } \\
\text { connectivity }\end{array}$ \\
\hline & Virtual Texts & hypertext & $\begin{array}{l}\text { Non-print textbooks or other sources with } \\
\text { hyperlinks to examples or applications and/or } \\
\text { embedded exercises and assignments. }\end{array}$ \\
\hline & Face-to-face - No technology & Traditional & $\begin{array}{l}\text { This will still be the primary means of } \\
\text { teaching methods courses in traditional } \\
\text { colleges in } 2015 \text {. }\end{array}$ \\
\hline 16 & $\begin{array}{l}\text { Use of Elmo type projection } \\
\text { devices }\end{array}$ & Traditional & $\begin{array}{l}\text { The delivery mode using a projector not only } \\
\text { for showing students, but for students to show } \\
\text { each other. It can facilitate the sharing of } \\
\text { students' work because they can show their } \\
\text { work on ELMO and not have to transcribe it } \\
\text { onto a transparency. }\end{array}$ \\
\hline \multirow[t]{2}{*}{17} & $\begin{array}{l}\text { Blackboard or related web- } \\
\text { based course }\end{array}$ & Web Based Multi-Mode & $\begin{array}{l}\text { For both graduate and undergraduate courses, } \\
\text { teachers need to be familiar with using a } \\
\text { system like Blackboard. }\end{array}$ \\
\hline & $\begin{array}{l}\text { Teleconferencing/telenet } \\
\text { courses }\end{array}$ & Teleconferencing & $\begin{array}{l}\text { This is where everyone is in different settings, } \\
\text { but video is available. These will be necessary } \\
\text { (as they are now) to reach people in remote } \\
\text { areas. }\end{array}$ \\
\hline
\end{tabular}




\begin{tabular}{|c|c|l|l|}
\hline $\begin{array}{c}\text { Par. } \\
\text { ID }\end{array}$ & \multicolumn{1}{|c|}{ Name of Delivery Mode } & \multicolumn{1}{|c|}{ Coding Scheme } & \multicolumn{1}{c|}{ Description } \\
\hline 17 & Live classroom video access & $\begin{array}{l}\text { Digital Video Interactive } \\
\text { (DVI) }\end{array}$ & $\begin{array}{l}\text { I believe that we will begin to have access to } \\
\text { live classrooms (we can do this now) and that } \\
\text { this can provide somewhat of a field } \\
\text { experience for future teachers. They can } \\
\text { watch a piece of a classroom and discuss it in } \\
\text { their college course. }\end{array}$ \\
\hline
\end{tabular}


Appendix G

Round II Invitation Letter and Questionnaire 


\section{Round II Invitation Letter}

Dear panel members,

Thank you for participating in my Delphi study and for your responses to the Round I questionnaire. You will recall that the purpose of this research is to identify teaching competencies teacher education faculty will need to have a decade from now. Responses from the 17 experts on the panel indicated 42 delivery modes and 167 competencies. The raw data collected from the Round I survey were coded and analyzed, resulting in seven delivery modes and five competency categories.

Each delivery mode, except Mode \#1 and \#2, has sub-modes to differentiate instructional options. A brief explanation has been added for each mode/sub-mode unless a mode is self-descriptive, as in the case of Mode \#3. The five competency categories group capabilities according to the type of instructional activity involved.

The Round II Questionnaire has been posted on the following Web site. Please click the following link to complete the Questionnaire by November 23, 2005. The login information is not required. http://simpleforms.scripts.wvu.edu/delphi/competencies

Approximately two weeks after this due date, you should expect to receive the Round III questionnaire.

Let me again thank you for your interest and continued participation in my study. All respondents in this Delphi study will remain anonymous to other panel members, and your name is required by the researcher only for logistics in administering a multi-part questionnaire. If you have any questions or comments please contact me at sna@solidworks.com or (978) 318-5274.

Sincerely, Sonhwa $\mathrm{Na}$

Doctoral Candidate

Technology Education, West Virginia University 


\section{Round II Questionnaire}

This Round II Questionnaire is divided into two parts, presenting Delivery Modes first, followed by Competencies. Using a 7-point scale, with 1 being strongly disagree and 7 being strongly agree, you will rate your level of agreement on delivery modes/sub-modes and competencies. Simply click the radio button for the level that best describes your opinion concerning the necessity of a specific delivery mode/sub-mode that will be needed by faculty ten years from now.

Space has also been provided for you to offer a justification for your rating. You are encouraged to read through the entire questionnaire before beginning as some delivery modes/sub-modes may have very similar descriptions, though they address subtle differences.

\section{PART I: DELIVERY MODES}

How strongly do you agree that each delivery mode/sub-mode would be used by teacher education faculty in the next ten years?

\section{Mode 1: Face-to-Face (F2F)}

Description: Traditional Face-to-Face Instruction (everyone in the same room)

Comment: Provide a brief reason/justification of your rating

\section{Mode 2: F2F + Satellite Combo} Description: Combination of Face-to-Face and Satellite Instruction (one group of students physically presents in the same room, while other groups participate via satellite)

Comment: Provide a brief reason/justification of your rating
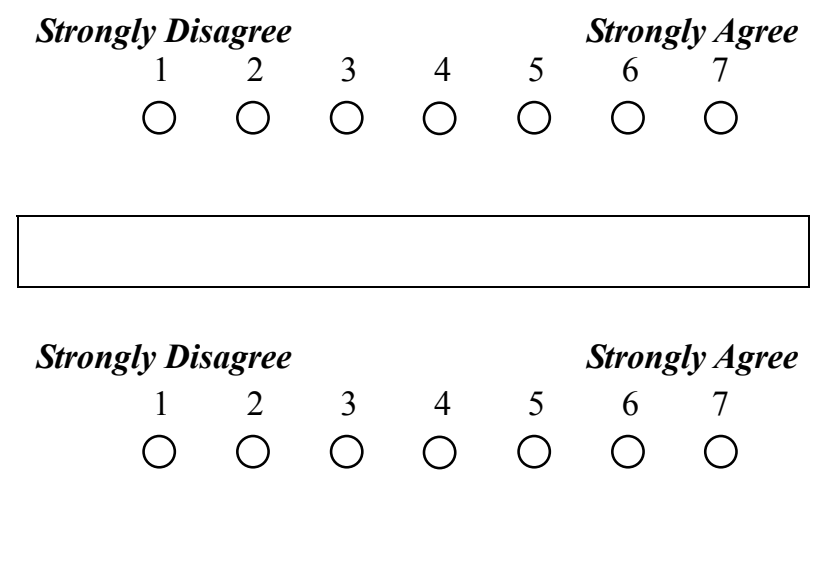

Strongly Agree 


\section{Mode 3: F2F + Web Supplement}

Description: Blended instruction which includes a combination of Face-to-Face (F2F) and various WebSupplemented modes of instruction (asynchronous and synchronous). Course information and activities on the web but the course itself is delivered in a traditional face-to-face manner.

3a. F2F + Web-Asynchronous Text

3b. F2F + Web- Asynchronous Audio

3c. F2F + Web-Asynchronous Video

3d. F2F + Web-Async Text/Audio/Video Comb

3e. F2F + Web-Synchronous Text Combo

3f. F2F + Web-Synchronous Audio Combo

3g. F2F + Web-Synchronous Video Combo

3h. F2F + Web-Sync Text/Audio/Video Combo

3i. F2F + Web-Async/Sync Text Combo

3j. F2F + Web-Async/Sync Audio Combo

3k. F2F + Web-Async/SyncVideo Combo

31. F2F + Web- Async/Sync Text/Audio/Video

Comment: Provide a brief reason/justification of your rating
Strongly Disagree

12

00

00

O 0

00

000

○

Strongly Disagree

0000

0000

0000

$\begin{array}{llll}0 & 0 & 0 & 0\end{array}$

0000

$\circ 000$

Strongly Agree

Strongly Agree

$\begin{array}{lll}5 & 6 & 7 \\ \bigcirc & \bigcirc & \bigcirc \\ \bigcirc & \bigcirc & \bigcirc \\ \bigcirc & \bigcirc & \bigcirc \\ \bigcirc & \bigcirc & \bigcirc \\ \bigcirc & \bigcirc & \bigcirc \\ 0 & \bigcirc & \bigcirc\end{array}$




\section{Mode 4: Web-Asynchronous}

\section{4a. Web-Asynchronous Text}

Description: Web-based instruction delivered only through asynchronous text based communications, such as hypertext documents, discussion boards, email, listserv, Weblogs, etc. Students progress at their own pace and may access the course materials independent of other students and at different times.

\section{4b. Web-Asynchronous Audio}

Description: Web-based instruction which is delivered only through pre-recorded audio based communications, such as recordings, audio clips, voice email, sounds, etc.

\section{4c. Web-Asynchronous Video}

Description: Web-based instruction which is delivered only through pre-recorded video lectures and uses still images, video clips, video resources, etc.

\section{4d. Web-Asynchronous Text/Audio/Video} Description: Web-based instruction which is delivered through a combination of text, audio, and video based asynchronous communications, such as audio/video clips, audio/video libraries, still images, hypertext documents, discussion boards, listserv, email, Weblogs, etc. One example could be online course management tools, such as WebCT or Blackboard.

Comment: Provide a brief reason/justification of your rating

\section{Strongly Disagree}

Strongly Agree

$\begin{array}{rrrrrrr}1 & 2 & 3 & 4 & 5 & 6 & 7 \\ & \bigcirc & \bigcirc & \bigcirc & \bigcirc & \bigcirc & \bigcirc\end{array}$

$\begin{array}{rrrrrrr}1 & 2 & 3 & 4 & 5 & 6 & 7 \\ & \bigcirc & \bigcirc & \bigcirc & \bigcirc & \bigcirc & \bigcirc\end{array}$

$\begin{array}{rrrrrrr}1 & 2 & 3 & 4 & 5 & 6 & 7 \\ & \bigcirc & \bigcirc & \bigcirc & \bigcirc & \bigcirc & \bigcirc\end{array}$

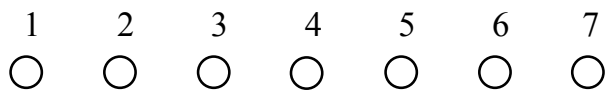




\section{Mode 5: Web-Synchronous}

\section{5a. Web-Synchronous Text}

Description: Web-based instruction which is delivered only through synchronous text based communications, such as whiteboard, instant messaging, etc.

\section{5b. Web-Synchronous Audio}

Description: Web-based instruction delivered only through synchronous audio based communications, such as web phone, audio chat, etc.

\section{5c. Web-Synchronous Video}

Description: Web-based instruction which is delivered only through synchronous video based communications, such as Web conferencing, desktop streaming, video chat, etc. Synchronous text chat is excluded.

\section{5d. Web-Synchronous Text/Audio/Video}

Description: Web-based instruction which is delivered through the combination of text, audio, and video based synchronous communications in real time, such as streaming audio/video, audio/video chat, audio/video conferencing, whiteboard, instant messaging, etc.

Comment: Provide a brief reason/justification of your rating

\begin{tabular}{rrrrrrr}
\multicolumn{3}{c}{ Strongly Disagree } & & & \multicolumn{3}{c}{ Strongly Agree } \\
1 & 2 & 3 & 4 & 5 & 6 & 7 \\
$\bigcirc$ & $\bigcirc$ & $\bigcirc$ & $\bigcirc$ & $\bigcirc$ & $\bigcirc$ & $\bigcirc$
\end{tabular}

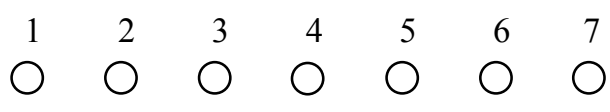

$\begin{array}{rrrrrrr}1 & 2 & 3 & 4 & 5 & 6 & 7 \\ \bigcirc & \bigcirc & \bigcirc & \bigcirc & \bigcirc & \bigcirc & \bigcirc\end{array}$

$\begin{array}{rrrrrrr}1 & 2 & 3 & 4 & 5 & 6 & 7 \\ 0 & 0 & \bigcirc & 0 & \bigcirc & \bigcirc & \bigcirc\end{array}$




\section{Mode 6: Web-Asynchronous/Synchronous Combo}

\section{6a. Web-Async/Sync Text}

Description: Web-based instruction (no F2F contact) which is delivered through a combination of asynchronous and synchronous text based communications, such as hypertext documents, email, listserv, weblogs, whiteboard, and instant messaging.

\section{6b. Web- Async/Sync Audio}

Description: Web-based instruction which is delivered through a combination of

asynchronous and synchronous audio based communications, such as recordings, audio clips, voice mails, web phone, audio chat, etc.

\section{6c. Web- Async/Sync Video}

Description: Web-based instruction which is delivered through a combination of asynchronous and synchronous video based communications only, such as video clips, video resources, Web video conference, video chat, etc.

\section{6d. Web- Async/Sync Text/Audio/Video}

Description: Web-based multi-mode instruction which is delivered through all possible combinations of text, audio, and video based synchronous and asynchronous

communications, such as audio/video clips, streaming audio/video, teleconferencing, audio/video chat, hypertext documents, email, Weblogs, whiteboard, instant messaging, etc.

Comment: Provide a brief reason/justification of your rating

\section{Strongly Disagree}

Strongly Agree

12

$\bigcirc \bigcirc \bigcirc \bigcirc$

6

7

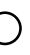

$\begin{array}{lllllll}1 & 2 & 3 & 4 & 5 & 6 & 7 \\ 0 & \bigcirc & \bigcirc & \bigcirc & \bigcirc & \bigcirc & \bigcirc\end{array}$

$\begin{array}{lllllll}1 & 2 & 3 & 4 & 5 & 6 & 7 \\ \bigcirc & \bigcirc & \bigcirc & \bigcirc & \bigcirc & \bigcirc & \bigcirc\end{array}$

$\begin{array}{lllllll}1 & 2 & 3 & 4 & 5 & 6 & 7 \\ \bigcirc & \bigcirc & \bigcirc & \bigcirc & \bigcirc & \bigcirc & \bigcirc\end{array}$ 


\section{Mode 7: Virtual Reality}

7a. Self-Guided Virtual Reality

Description: Self-guided web-based interactive game-like environments used for

teaching/learning purposes (e.g. Avatar) in which individual learners have control over learning processes.

\section{7b. Instructor-Led Virtual Reality}

Description: Instructor-led web delivered simulations and gaming where Avatar-style facilitators/teachers/guides are regularly available to guide, support, enhance and help learners understand the

knowledge/processes/information/ etc. that is foundational to stated learning objectives.

\section{7c. Community-Led Virtual Reality}

Description: Community-led, avatar-style synchronous interaction ("classroom room" of the future) that involves multiple parties who are all "represented" as though they were sitting together in a room. Multi-player, online roleplaying game designed to facilitate collaborative learning.

Comment: Provide a brief reason/justification of your rating

Please list any other delivery modes not listed here.

\section{Strongly Disagree}

Strongly Agree

12

$\bigcirc \bigcirc \bigcirc \bigcirc \bigcirc \bigcirc \bigcirc$

$\begin{array}{lllllll}1 & 2 & 3 & 4 & 5 & 6 & 7 \\ \bigcirc & \bigcirc & \bigcirc & \bigcirc & \bigcirc & \bigcirc & \bigcirc\end{array}$

$\begin{array}{lllllll}1 & 2 & 3 & 4 & 5 & 6 & 7 \\ \bigcirc & \bigcirc & \bigcirc & \bigcirc & \bigcirc & \bigcirc & \bigcirc\end{array}$ 


\section{PART II INSTRUCTIONS}

Using a 7-point scale, with 1 being Not Necessary and 7 being Essential, you will rate your level of agreement on competencies. Simply click the radio button for the level that best describes your opinion concerning the necessity of a specific faculty competency that will be needed ten years from now. If you feel any key competencies have been left out, please list them in the space provided following each category.

\section{PART II: COMPETENCIES}

How strongly do you agree that each competency listed under the five categories would be required for teacher education faculty in order to deliver the course in ten years from now on?

\section{CATEGORY 1: PLANNING AND DESIGNING LEARNING ENVIRONMENT}

\section{Competencies}

1.1. Basic instructional design skills for planning, teaching and learning materials/activities

1.2. Compiling appropriate curriculum resources in online formats

1.3. Conducting research on the web

1.4. Creating an effective online syllabus

1.5. Creating hypertext web pages to supplement teaching

1.6. Design of appropriate learning activities and instructional materials based on students' ability

1.7. Determining when face-to-face instruction is optimum mode of delivery within a course scope and sequence

1.8. Developing lessons that incorporate audio and video in meaningful ways

1.9. Evaluation of computer software for educational purposes

1.10. Selecting lessons and content matched to a delivery method

1.11. Converting existing course materials into appropriate Web formats

1.12. Using web based course management tools such as WebCT and Blackboard

\section{Additional Competencies:}

Do you feel a competency was left out? Please add any other competencies you believe would be required of teacher education faculty in 10 years.
Not Necessary

12

$\bigcirc \bigcirc \bigcirc$

○ $\bigcirc \bigcirc$

$\mathrm{O}$

$\bigcirc 0$

$\bigcirc \bigcirc \bigcirc$

$\bigcirc \bigcirc \bigcirc \bigcirc$

$\bigcirc \bigcirc \bigcirc \bigcirc \bigcirc \bigcirc \bigcirc$

$\bigcirc \bigcirc \bigcirc \bigcirc \bigcirc \bigcirc \bigcirc$

$\bigcirc 00 \bigcirc 00 \bigcirc$
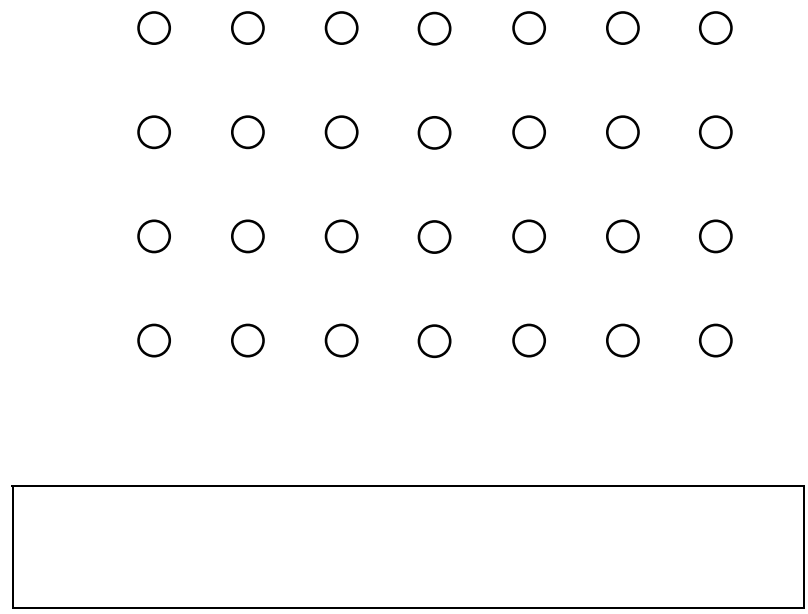

Essential

7

$\bigcirc$
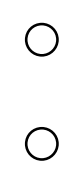

$\bigcirc$
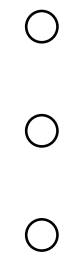

O 


\section{CATEGORY 2: TEACHING AND LEARNING}

\section{Competencies}

2.1. Building online learning communities

2.2. Clear delivery and presentation of content reflecting important ideas, principles and concepts

2.3. Coordinating student access to online curriculum resources

2.4. Developing reciprocity and cooperation among students

2.5. Effective communication using both verbal and non-verbal skills

2.6. Encouraging interaction between receiving sites, among students and with the teacher

2.7. Encouraging students to bring real-life examples into the online classroom

2.8. Facilitating discussions in the two way audio/video environment

2.9. Facilitating face-to-face classroom discussion

2.10. Facilitating individual and group discussions via video streaming

2.11. Incorporating visuals and interaction in meaningful ways, given the constraints of audio chat technology

2.12. Leading online discussions between learners and guests

2.13. Managing group work online

2.14. Managing non-verbal exchange in virtual environment

2.15. Moderating audio discussions over the Web phone using established procedures and policies

2.16. Moderating online discussions to achieve effective levels of student-student interaction

2.17. Monitoring and structuring student learning in virtual environment

2.18. Monitoring each individual's participation 2.19. Personalizing the course based on students' learning style

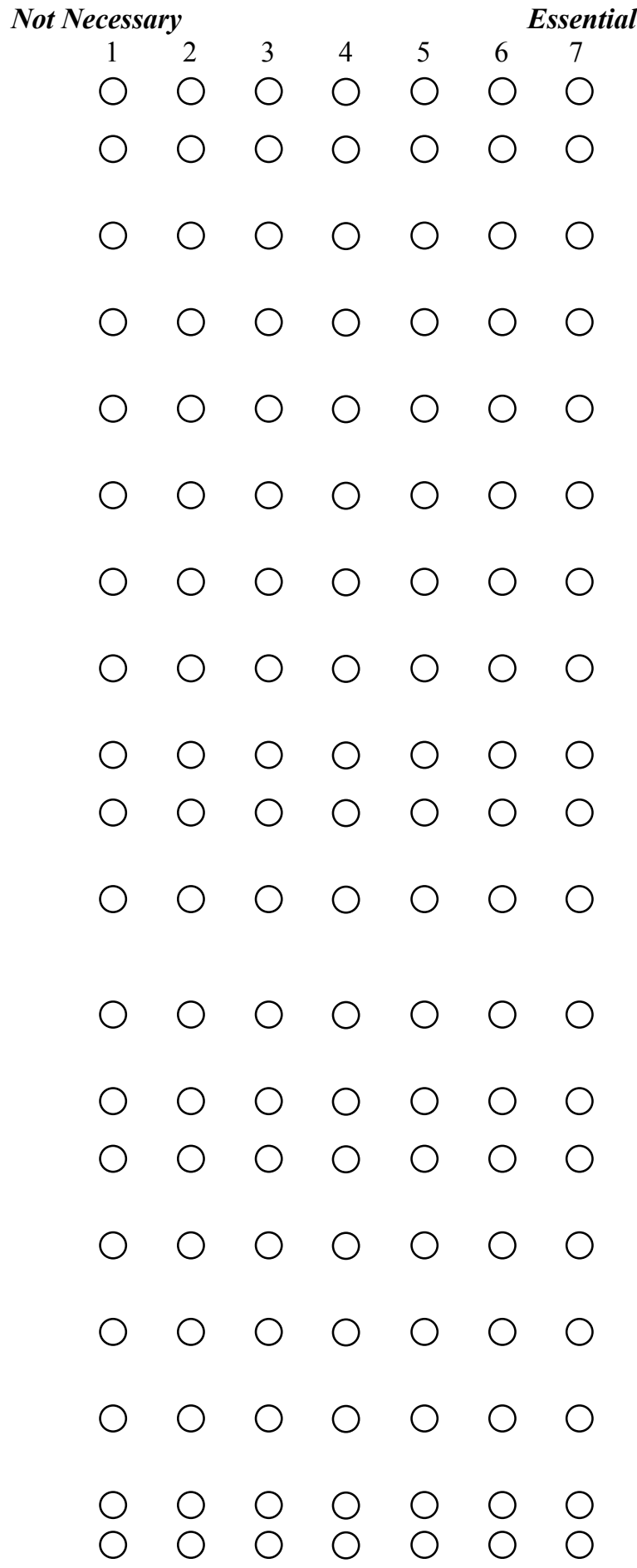

Not Necessary 


\section{Competencies}

2.20. Posting customized assignments in online environment

2. 21. Promoting collaborative learning online

2.22. Promoting student participation in $F 2 F$ instruction

2.23. Providing a different context to ensure that the learners apply the newly gained knowledge in Virtual Reality

2.24. Providing clear objectives, expectations, and policies

2.25. Providing examples of model interactions with other students without betraying confidence

2.26. Providing motivation to distance learners to keep up with their peers moves for assessment purposes

2.27. Providing structure for learners, but allowing for flexibility and negotiation in online course

2.28. Providing students with prompts, and constant, constructive feedback

2.29. Questioning technique to elicit learner participation and growth

2.30. Realistic expectations for workload

2.31. Stimulating appropriate individual and group discussion with the use of instructional video games and simulations

2.32. Stimulating individual/peer/group interaction at each of the Satellite sites

2.33. Tracking students' activities online

2.34. Using appropriate vocal inflections and modulation to maintain learners' attention and interest

2.35. Using the web as a resource

2.36. Using video and audio files in effective ways
Not Necessary

12

34

5

Essential

O

$\mathrm{O} \bigcirc$

$\circ \mathrm{O}$

$\bigcirc \bigcirc$

$\bigcirc 0 \bigcirc \bigcirc 0 \bigcirc \bigcirc$

$\bigcirc \bigcirc \bigcirc \bigcirc 000$

0000000

$\bigcirc \bigcirc \bigcirc \bigcirc \bigcirc \bigcirc \bigcirc$

$\bigcirc 00 \bigcirc 0 \bigcirc \bigcirc$

$\bigcirc 00 \bigcirc 0 \bigcirc \bigcirc$

$\bigcirc \bigcirc \bigcirc \bigcirc \bigcirc \bigcirc \bigcirc$

$\bigcirc \bigcirc \bigcirc \bigcirc \bigcirc \bigcirc \bigcirc$

$\bigcirc \bigcirc \bigcirc \bigcirc \bigcirc \bigcirc \bigcirc$

$\bigcirc 00 \bigcirc 000$

0000000

0000000

$\bigcirc \bigcirc \bigcirc \bigcirc \bigcirc \bigcirc \bigcirc$

\section{Additional Competencies:}

Do you feel a competency was left out? Please add any other competencies you believe would be required of teacher education faculty in 10 years. 


\section{CATEGORY 3: TECHNOLOGY}

\section{Competencies}

3.1. Ability to follow developments in online teaching techniques

3.2. Adopting new technologies into courses

3.3. Advising students on multi-media and notetaking using mobile technologies in classroom

3.4. Archiving and organizing audio/video clips based on content areas

3.5. Archiving course sessions

3.6. Detailed functional knowledge of how to use Telnet through the Web browser

3.7. Identifying and analyzing technical issues resulted from equipment malfunction or operator errors

3.8. Knowledge of a variety of interactive techniques (small group work, projection devices, handhelds) appropriate for the course

environment

3.9. Knowledge of how online text messages may appear to the learners

3.10. Online file management

3.11. Online navigation and search technique

3.12. Preparation of graphics and art work

3.13. Preparation of lecture presentation using presentation software

3.14. Proficiency with all technical systems used in the course

3.15. Publishing multimedia such as audio, video and/or still images online

3.16. Selecting and evaluating technology based on learning materials

3.17. Sending and receiving email

3.18. Streaming audio/video

3.19. Troubleshooting technical problems

3.20. Using asynchronous communications, such as Listserv, Discussion Bards and Weblogs to enhance teaching effectiveness

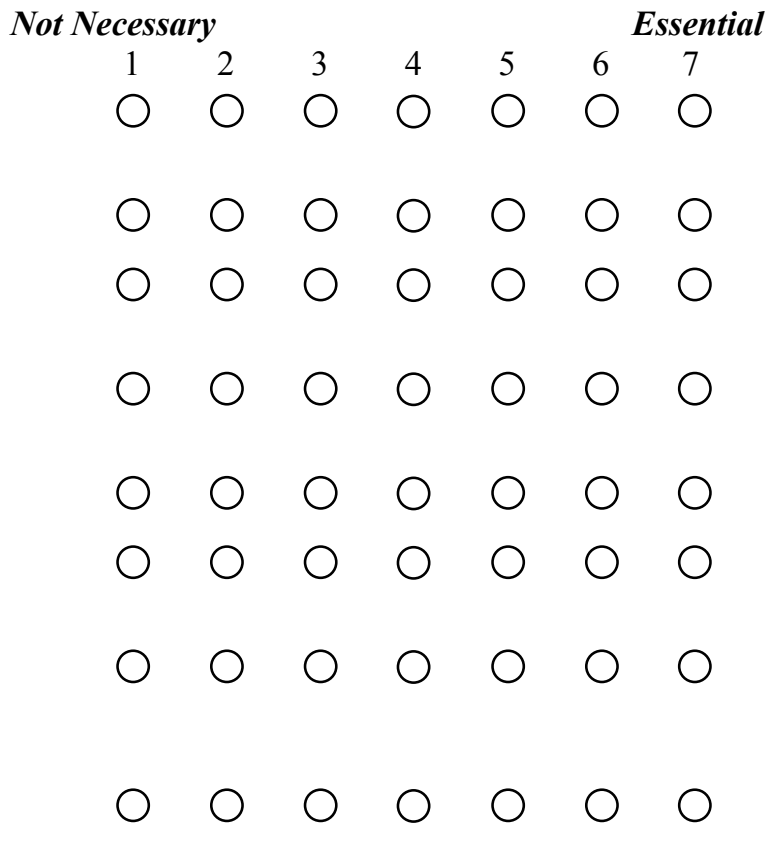

$\bigcirc \bigcirc \bigcirc \bigcirc \bigcirc \bigcirc \bigcirc$

$\bigcirc \bigcirc \bigcirc \bigcirc \bigcirc \bigcirc \bigcirc$

$\bigcirc \bigcirc \bigcirc \bigcirc \bigcirc \bigcirc \bigcirc$

$\bigcirc \bigcirc \bigcirc \bigcirc \bigcirc \bigcirc \bigcirc$

$\circ \bigcirc \bigcirc \bigcirc 000$

$\bigcirc \bigcirc \bigcirc \bigcirc \bigcirc \bigcirc \bigcirc$

$\bigcirc \bigcirc \bigcirc \bigcirc \bigcirc \bigcirc \bigcirc$

$\bigcirc \bigcirc \bigcirc \bigcirc \bigcirc \bigcirc \bigcirc$

0000000

$\bigcirc \bigcirc \bigcirc \bigcirc \bigcirc \bigcirc$

$\bigcirc \bigcirc \bigcirc \bigcirc \bigcirc \bigcirc \bigcirc$

$\bigcirc \bigcirc \bigcirc \bigcirc \bigcirc \bigcirc \bigcirc$ 


\section{Competencies}

3.21. Using FTP to share and retrieve course resources

3.22. Using hypertext to navigate materials in a manner suited to the learner's own learning style

3.23. Using instructional video games and simulations in effective ways

3.24. Using interactive presentations on web

3.25. Using local network to transfer, retrieve, and save teaching and learning materials and to share them among teachers and/or students

3.26. Using multiple technology devices in faceto-face instruction

3.27. Using synchronized communications including chat room, ICQ, NetMeeting, etc.

3.28. Using the Internet effectively

3.29. Visual presentation skills in face-to-face instruction
Not Necessary

$\begin{array}{lllllll}1 & 2 & 3 & 4 & 5 & 6 & 7 \\ \bigcirc & \bigcirc & \bigcirc & \bigcirc & \bigcirc & \bigcirc & \bigcirc\end{array}$

0000000

$\bigcirc \bigcirc \bigcirc \bigcirc \bigcirc \bigcirc \bigcirc$

0000000

$\circ \circ \bigcirc \bigcirc 000$

$\bigcirc \bigcirc \bigcirc \bigcirc \bigcirc \bigcirc \bigcirc$

$\bigcirc \bigcirc \bigcirc \bigcirc \bigcirc \bigcirc \bigcirc$

0000000

$\circ \circ \bigcirc \circ 000$

Additional Competencies:

Do you feel a competency was left out? Please add any other competencies you believe would be required of teacher education faculty in 10 years. 


\section{CATEGORY 4: ASSESSMENT AND EVALUATION}

\section{Competencies}

4.1. Administering appropriate assessments based on a delivery mode

4.2. Assessment and evaluations strategies for data collection

4.3. Assessment of student learning of core course knowledge as well as exemplary learning that reach beyond established course knowledge

4.4. Defining participation and grading criteria

4.5. Designing and developing assessment strategies appropriate for learning objectives and the online environment

4.6. Performing Needs Assessment and selecting instructional goals

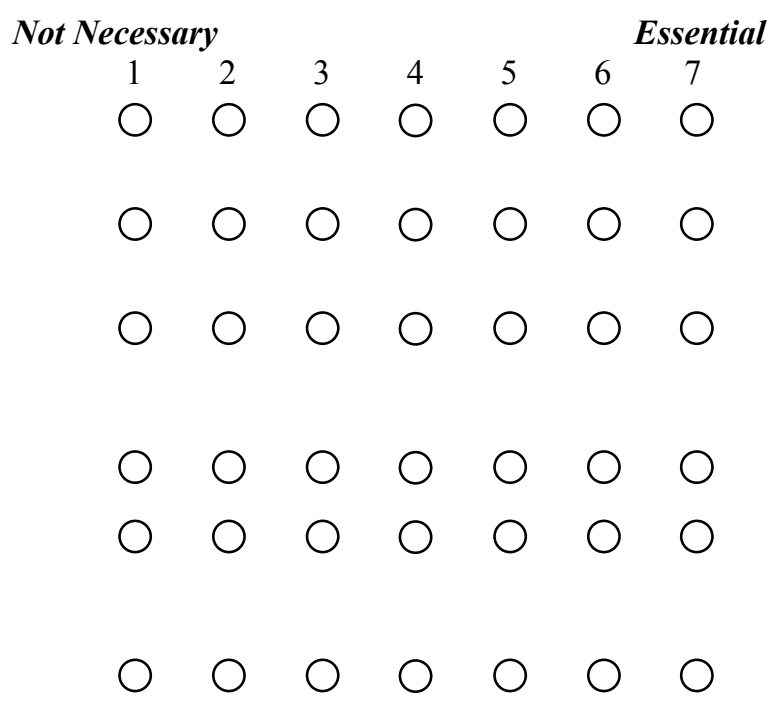

Not Necessary

$\bigcirc \bigcirc$

O

$\bigcirc$

$\bigcirc \bigcirc$

0

$\mathrm{O}$

\section{Additional Competencies:}

Do you feel a competency was left out? Please add any other competencies you believe would be required of teacher education faculty in 10 years.

\section{CATEGORY 5: CULTURAL AND ETHICAL ISSUES}

\section{Competencies}

5.1. Advising students on how to determine relevant online sources

5.2. Awareness of cultural differences

5.3. Referring problems to appropriate Web resources and follow up to assure resolution

5.4. Respecting privacy issues online

5.5. Reviewing demographic data on student

5.6. Setting up model searches online

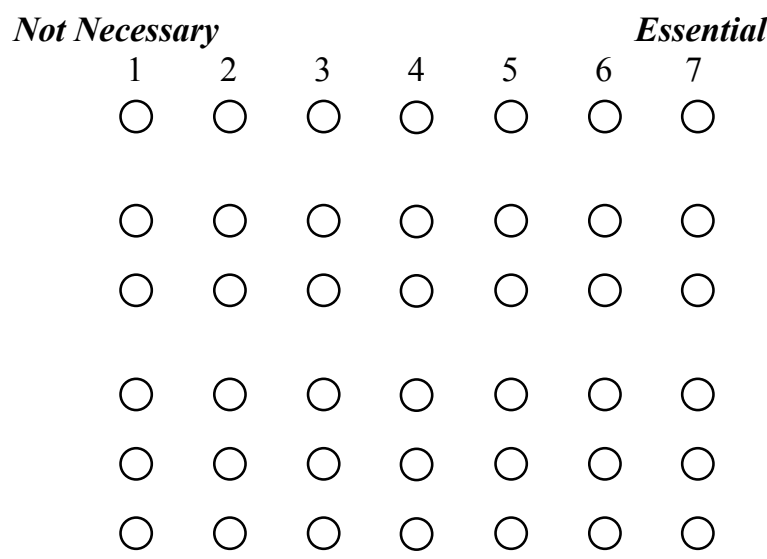

Additional Competencies:

Do you feel a competency was left out? Please add any other competencies you believe would be required of teacher education faculty in 10 years. 
Appendix $\mathrm{H}$

Round III Invitation Letter and Questionnaire 


\section{Delphi Round III Invitation Letter}

Dear Panel Members,

Thank you for participating in my Delphi study and for your responses to the Round II questionnaire. You will recall that the purpose of this research is to identify teaching competencies teacher education faculty will need to have a decade from now. The response from the second round questionnaire was excellent. I have received 17 completed questionnaires. The second round of Delphi has achieved a significant group consensus on both delivery modes $(48.1 \%)$ and competencies $(70.8 \%)$. In the Round III questionnaire, only the delivery modes and competencies that did not reach consensus from Round II were included. Statistical analysis of Round II was also provided:

- Median, mode and the frequency of response

- Comments received from Round II

- Your rating for each item from Round II

Based on Round II results I anticipate this third round to be the final one, and as such your rerating and comments are very important for completing this study. I have used the PDF format in order to provide a questionnaire that could allow the panel electronic commenting and could present the result of Round II in the fewest number of pages. The PDF format was the easiest method for your responding electronically directly on the instrument. You will need Adobe Reader 7 in order to complete the questionnaire. If you do not have it installed on your computer, please download it from the following link.

http://www.adobe.com/products/acrobat/readstep2.html

Please complete the attached PDF, Round III Questionnaire and return it to me via email by February 28, 2006. The estimated time to complete it is about 15-20 min.

Instructions for completing the attached questionnaire are provided on the first page of that document. Should you have any difficulty receiving, reading or responding to the PDF questionnaire, please contact me sna@solidworks.com or (978) 318-5274 and I will work to find a suitable solution.

Let me again thank you for your interest and continued participation in my study.

Sincerely,

Sonhwa $\mathrm{Na}$

Doctoral Candidate

Technology Education, West Virginia University 


\section{Round III Questionnaire}

Panel ID

A11

- Delivery modes and competencies that did not reach consensus from Round II are listed below, followed by the MEDIAN (MODE in parenthesis) and FREQUENCY OF RESPONSE (number of people choosing a given rating).

- Under the "Results of Delphi II" column your rating for each item is circled in red, indicating your position relative to the other respondents.

- Under the "Delivery Mode" and "Competencies" column comments received from Round II are provided in the form of PDF Comment Balloons. These comments provide insight into ratings by other respondents.

- For each item consider all comments and ratings from other panel members and then highlight your new rating in the column entitled "New Response." How to highlight: from the Tools menu, select Commenting and then click Highlight Text Tool.

- If your new response is more than two points away from the MODE, please indicate the reason for your position by adding a Note in the column entitled "Reason." If your new rating is within a two point spread, no reason is necessary. How to add a Note: from the Tools menu, select Commenting and then click the Note Tool to give your reason.

\section{PART I: DELIVERY MODES}

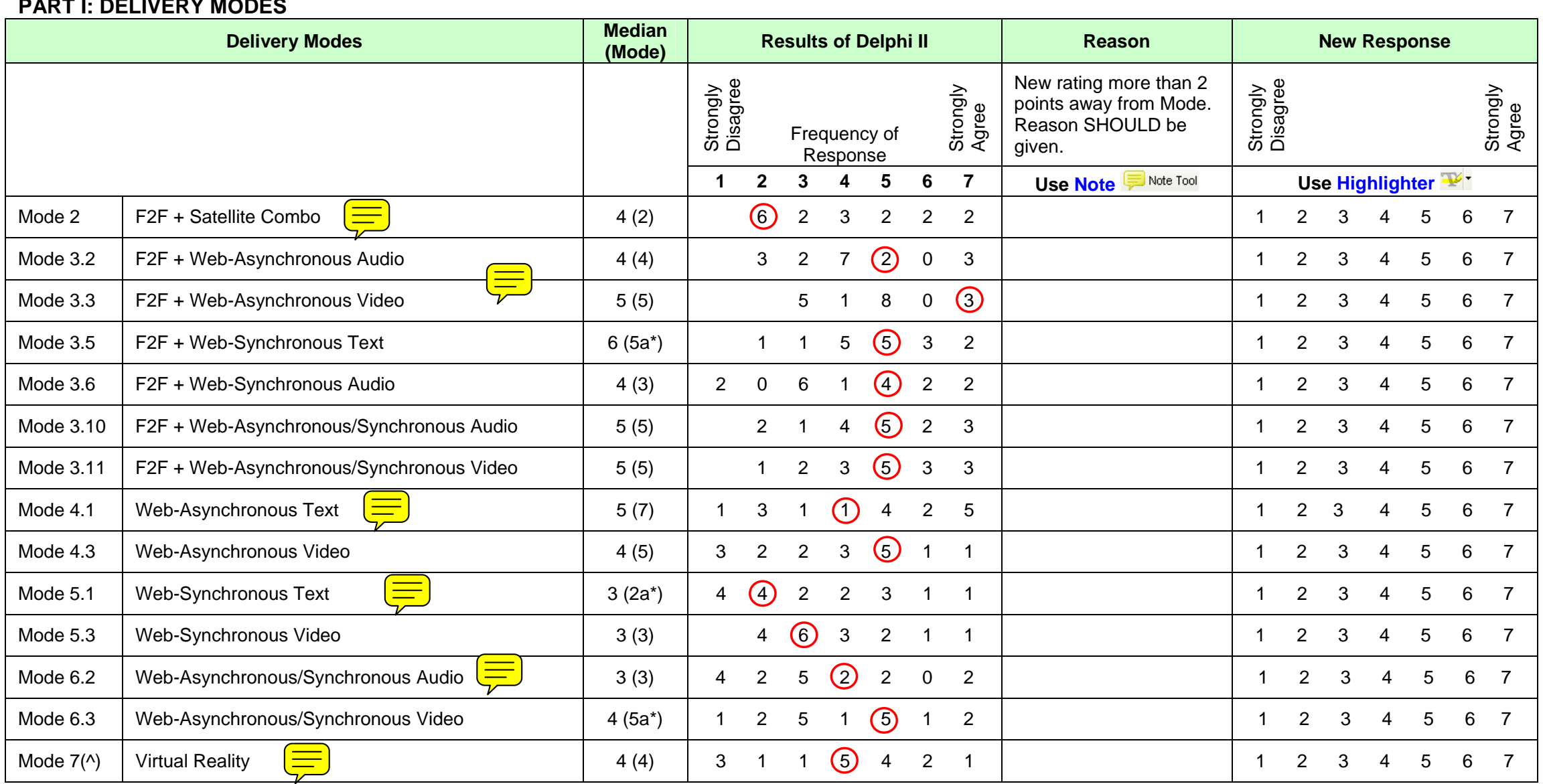

$\left(a^{\star}\right)$ Multiple modes exist. The greatest value is shown. $\left({ }^{\wedge}\right)$ indicates combined mode 
PART II: COMPETENCIES

Category 1: Planning and Designing Learning Environment

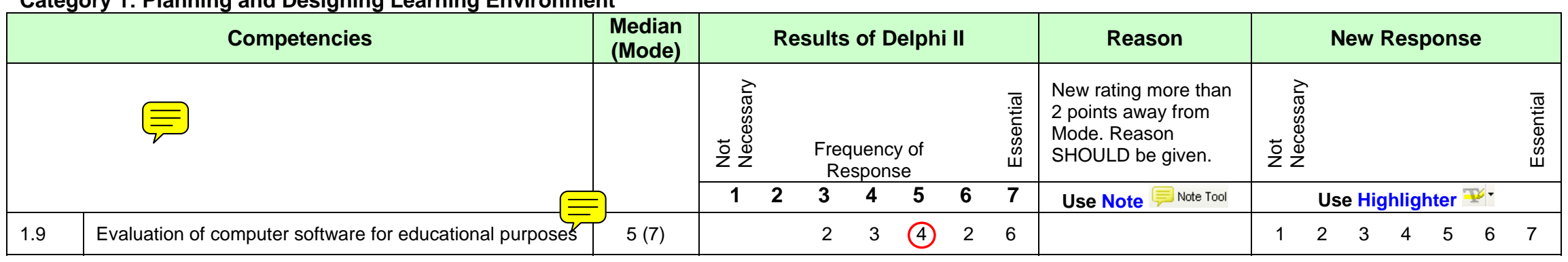

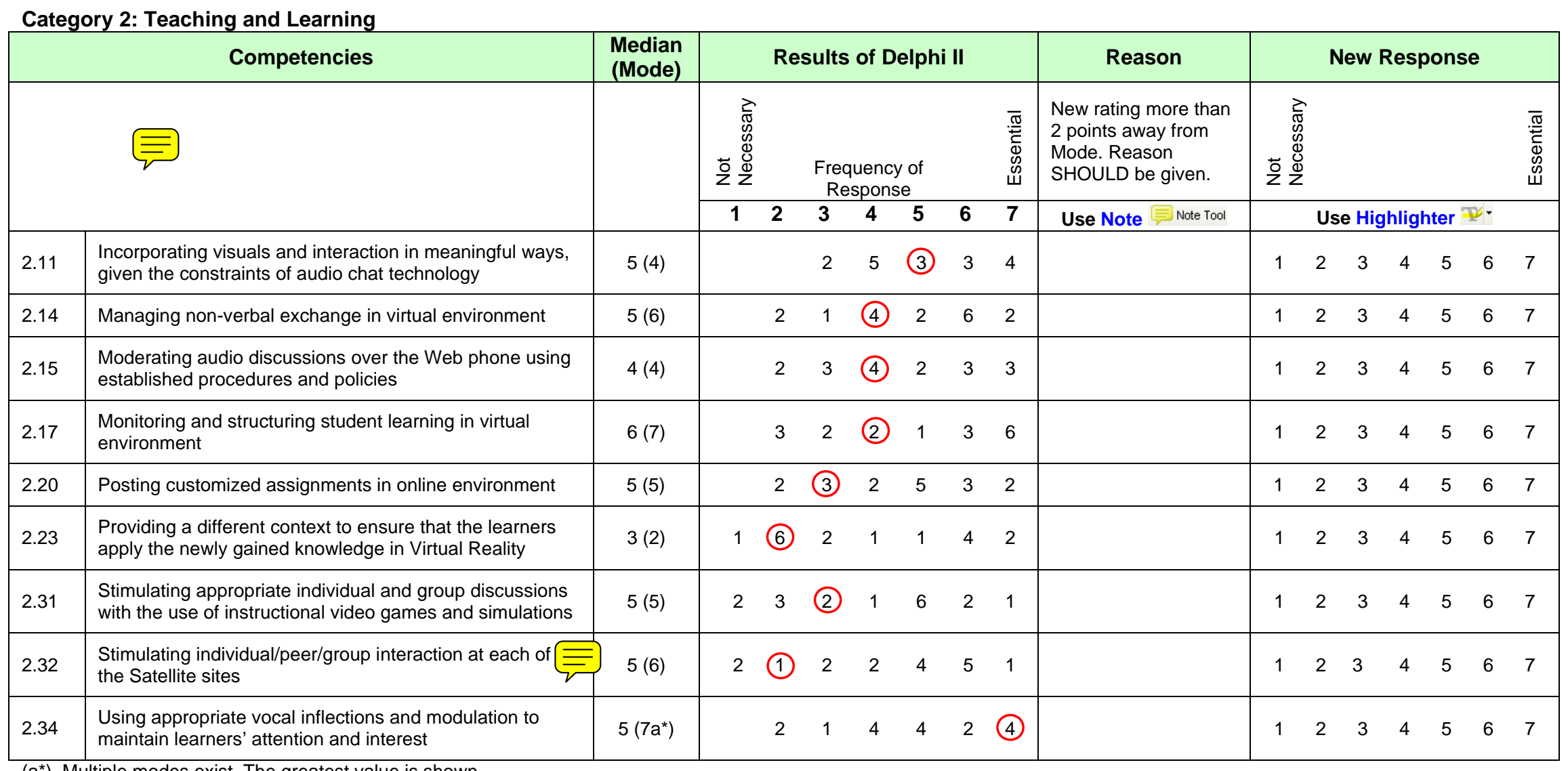

$\left(a^{\star}\right)$ Multiple modes exist. The greatest value is shown. 


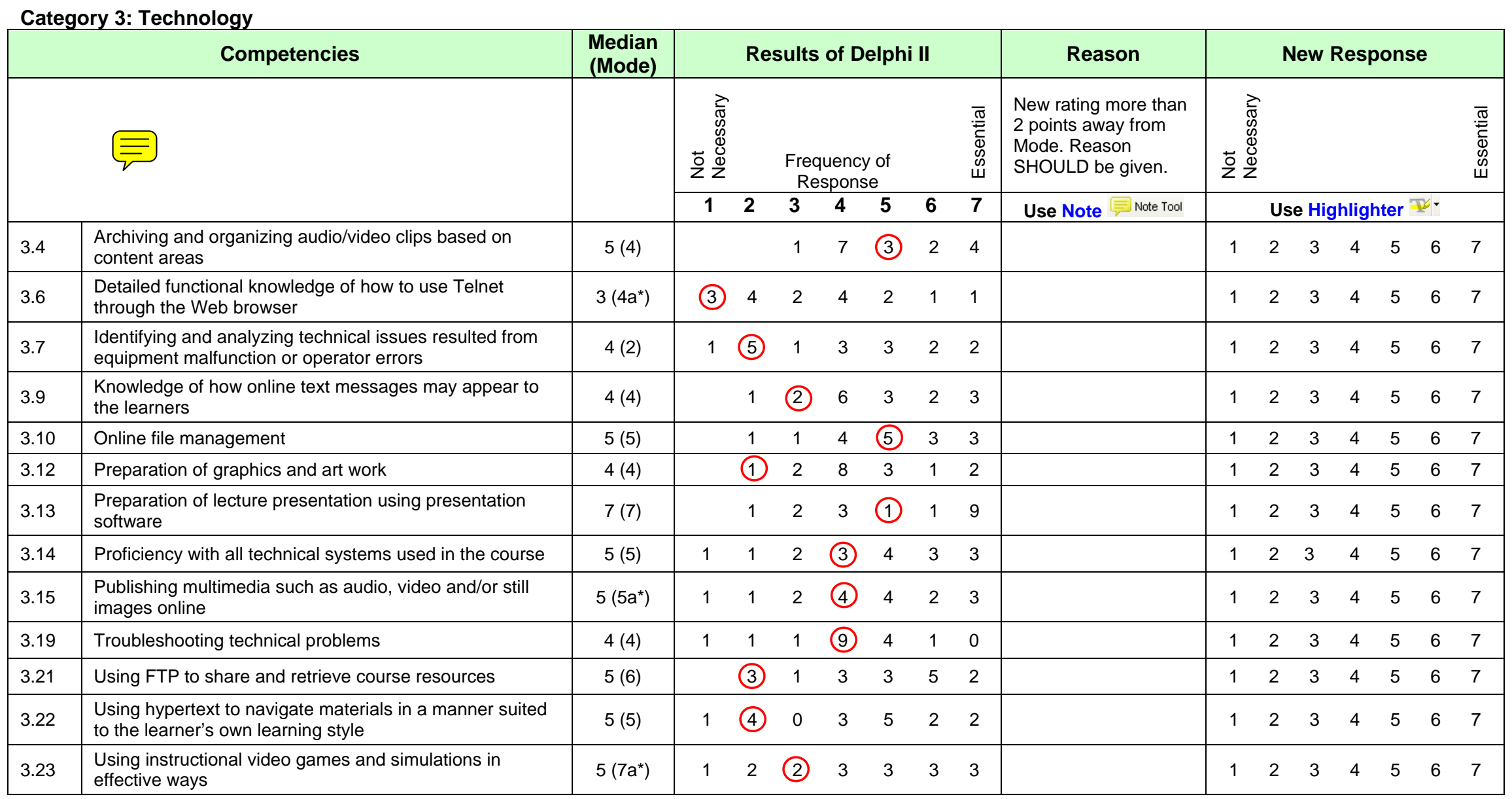

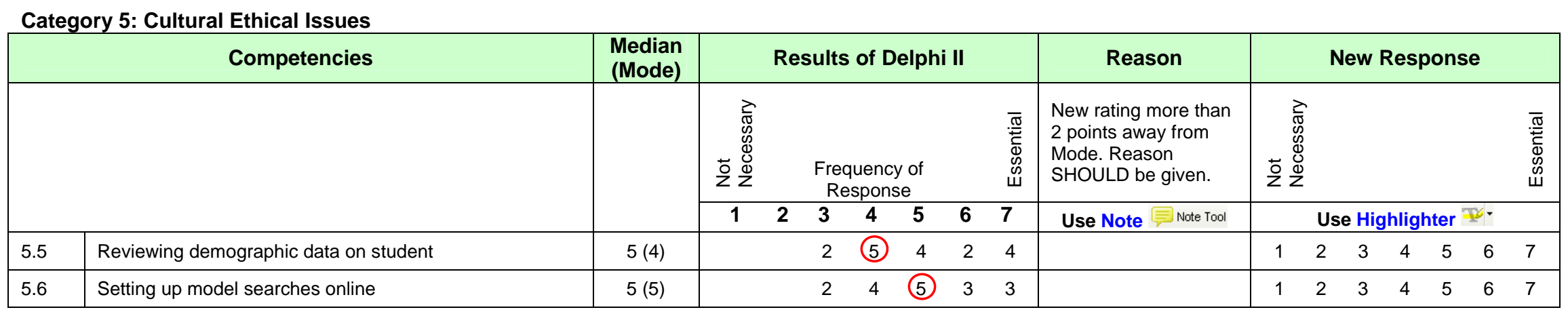

